Universidade de Brasília - UnB

Instituto de Geociências - IGD

Programa de Pós-Graduação Stricto Sensu em

Geociências Aplicadas

POTENCIALIDADE DO SENSOR WORLDVIEW II NA DETECÇÃO DE HEMATITA E GOETHITA EM SOLOS TROPICAIS

Débora Teobaldo

BRASÍLIA - DF

2016

Universidade de Brasília - UnB 


$$
\text { Instituto de Geociências - IGD }
$$

Programa de Pós-Graduação Stricto Sensu em Geociências Aplicadas

\title{
POTENCIALIDADE DO SENSOR WORLDVIEW II NA DETECÇÃO DE HEMATITA E GOETHITA EM SOLOS TROPICAIS
}

\author{
Débora Teobaldo \\ Orientador: Prof. Dr. Gustavo Macedo de Mello Baptista \\ Dissertação de Mestrado apresentada à \\ Banca Examinadora do Instituto de \\ Geociências Aplicadas (Geoprocessamento \\ e Análise Ambiental) da Universidade de \\ Brasília, como exigência para obtenção do \\ Título de Mestre em Geociências Aplicadas.
}

BRASÍLIA - DF 
Instituto de Geociências - IGD

Programa de Pós-Graduação Stricto Sensu em Geociências Aplicadas

\section{POTENCIALIDADE DO SENSOR WORLDVIEW II NA DETECÇÃO DE HEMATITA E GOETHITA EM SOLOS TROPICAIS}

Débora Teobaldo

BANCA EXAMINADORA

Orientador

Dr. Gustavo Macedo de Mello Baptista

Avaliador Interno

Dra. Adriana Reatto dos Santos Braga - Embrapa

Avaliador Externo

Dra. Joselisa Maria Chaves - UEFS

Brasília, 30 de ABRIL de 2016. 


\section{AGRADECIMENTOS}

Aos meus pais, Teobaldo e Beth, pelo apoio desde a pré-escola até o futuro acadêmico, pela compreensão e paciência durante esse processo.

Ao meu Irmão, Caio, que sempre me apoiou até mesmo durante a escolha do curso de graduação, e que sempre está preocupado com meu futuro.

A minha irmã, Isabela, pelo apoio e amizade.

Aos meus amigos pela compreensão da ausência e força durante esse processo.

Ao meu Orientador, Gustavo, pelo incentivo a continuar na carreira acadêmica, pelas conversas e conselhos, pelos trabalhos que realizamos juntos e pela amizade.

Aos queridos amigos do Mestrado na área de Geoprocessamento do Instituto de Geociências, principalmente Ilanna, Marceli e Khalil, pelo conhecimento, ajuda, apoio e força durante esse processo. 
"Obstáculos e dificuldades fazem parte da vida. E a vida é a arte de superá-los"

Mestre DeRose 
TEOBALDO, D. Potencialidade do Sensor WorldView II para Detecção de Hematita e Goethita em Solos Tropicais. № 97. Dissertação (Mestrado em Geociências Aplicadas) - Instituto de Geociências, Universidade de Brasília, Brasília, 2016.

\section{RESUMO}

Comportamento espectral dos solos é um termo utilizado para definir as interações da radiação eletromagnética com os diferentes tipos de solos e fatores intrínsecos a eles, como as propriedades físico-químicas. Com o avanço de técnicas e tecnologias, o sensoriamento remoto vem-se destacando como ferramenta auxiliar para o mapeamento de solos por meio da espectroscopia de reflectância. Com o advento de novos sistemas sensores tem-se a necessidade de investigar suas potencialidades para discriminação espacial dos alvos, como, por exemplo, os constituintes minerais de uma mancha de solo exposto. O objetivo desse trabalho foi estudar a potencialidade do WorldView II na detecção dos óxidos de ferro, devido à presença de bandas novas, quando comparadas ao sensor Landsat TM5, especialmente na faixa da luz visível, na qual estão as principais feições espectrais desses minerais. Os índices desenvolvidos por Madeira Netto (1993), IFe e o IHm foram reescritos com a banda do amarelo e com a do vermelho do WorldView II e, com o resultado, percebeu-se que a melhor discretização da identificação dos óxidos de ferro estão ligados a feição de absorção e não a reflexão e com isso a banda do amarelo favorece somente a visualização da matiz do solo. Foi proposto o índice RHGtpF que é baseado no contínuo removido e na sua profundidade de feição e foi comparado estatisticamente com a relação química $\mathrm{Hm} / \mathrm{Hm}+\mathrm{Gt}$ feita por Madeira Netto (1993) e a RHGtmunsell por meio dos parâmetros da cor do solo. Observou que a relação Hm/Hm+Gt e novo índice são similares entre si, mas a RHGtmunsell e o novo índice não são similares. Algoritmos, como Spectral Angle Mapper (SAM) e Linear Spectral Unmixing (LSU), também foram estudados para classificar os óxidos de ferro com os dados do WorldView II. O resultado do SAM foi satisfatório porque ele classificou corretamente os dois minerais. O resultado do LSU mostra que a correlação entre os dois minerais é inversa devido a diferença química e geomorfológica do meio ambiente. $\mathrm{O}$ índice RHGtPF foi comparado com a relação $\mathrm{Hm} / \mathrm{Hm}+\mathrm{Gt}$ calculada a partir dos dados percentuais do LSU. O coeficiente de correlação foi forte e positivo e verificou a possibilidade de quantificação e identificação dos óxidos de ferro por meio do novo índice espectral.

Palavras chaves: hematita, goethita, sensoriamento remoto, índices espectrais 


\begin{abstract}
Spectral behavior of the soil it's a term used to define the interactions of the electromagnetic radiation with the different types of soil and intrinsicfactors between them, likethephysico-chemicalproperties. With the advance of techniques and technology, the remote sensing has been a very helpful tool for mapping the soils through the spectroscopy of reflectance. With the advance of new sensors systems, there's a need to investigate their potentials for spatial discrimination of the objects, for example, the mineral constituentsof a soil spot. The goal of this study was to investigate the potentials of WorlView 2 in detecting iron oxides, due to the presence of new bands, when compared to the Landsat TM5 sensor, especially in the range of visible light, which are the main spectral features of this minerals. The rates developed by Madeira Netto (1993), IFeand the IHm were rewritten with the yellow band and red band of the WorlView 2and, with the results, it was proved that the better discretization of iron's oxides identification are linked to the feature of absorption and not to the reflection, and with that the yellow band helps only the preview of the soil's hue. It was proposed the RHGtPF's rates that it's based in outgoing removal and in it depth of feature and it was statically compared with the chemistry relation $\mathrm{Hm} / \mathrm{Hm}+\mathrm{Gt}$ made by Madeira Netto (1993) and the RHGt munsell by parameters of the soil's colors. It was noticed that the relation $\mathrm{Hm} / \mathrm{Hm}+\mathrm{Gt}$ and the new indication are similar to each other, but the RHGt munsell and the new indication are different to each other. Algorithms, like Spectral AngleMapper (SAM) and Linear Spectral Unmixing (LSU), were studied as well to classify the iron oxides with the data of WorldView 2. The SAM'sresults was satisfactory because it named correctly both minerals. The LSU's results shows that the correlation between both minerals it's reverse because of the chemical and geomorphological diference in the environment. The RHGtPF's rate was compared with the $\mathrm{Hm} / \mathrm{Hm}+\mathrm{Gt}$ relation estimated from the LSU's percentage data. The correlation coefficient was strong and positive and found the possibility of iron's oxides quantification and identification by the new spectral indication.
\end{abstract}

Index terms: Hematite, goethite, remote sensing, spectral indices 


\section{ÍNDICE}

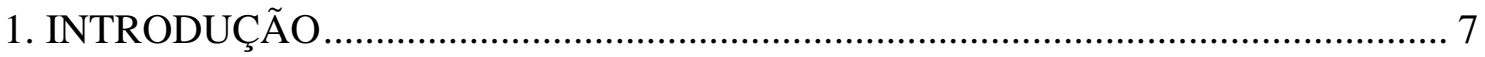

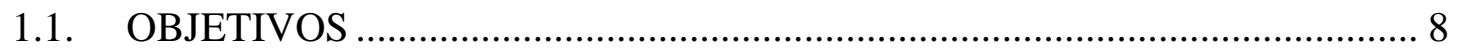

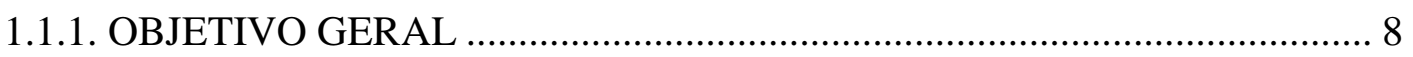

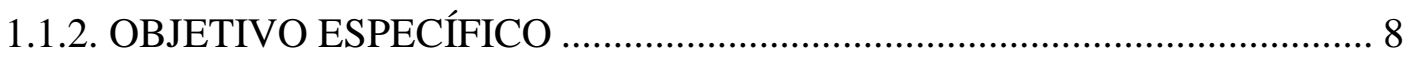

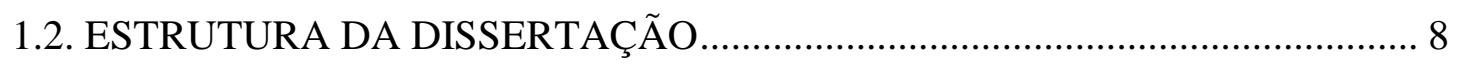

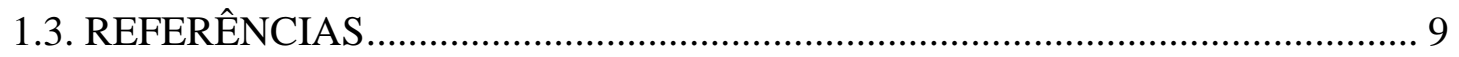

CAPÍTULO 1: ESPECTRORRADIOMETRIA DE SOLOS .......................................... 12

1. INTRODUÇÃ

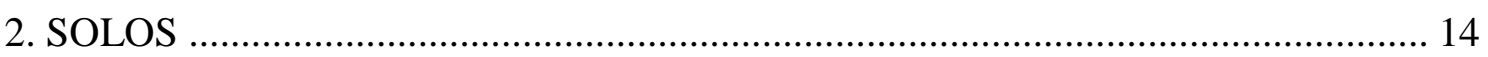

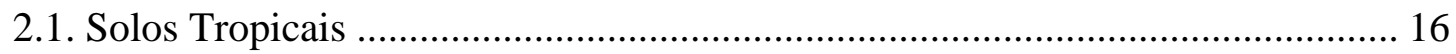

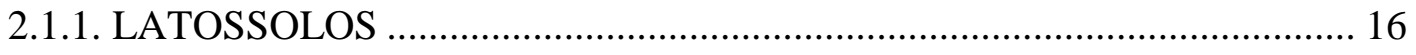

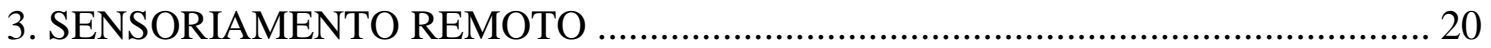

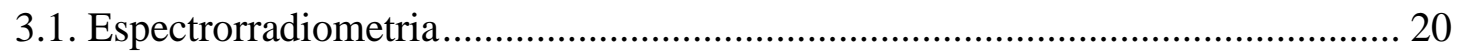

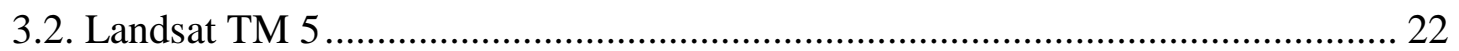

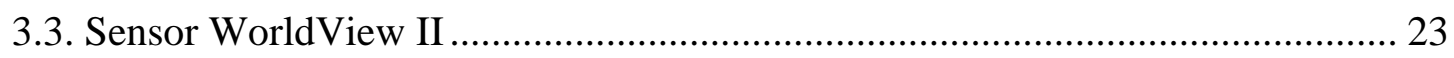

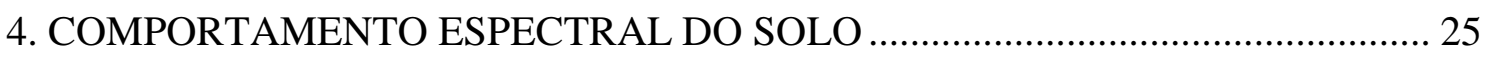

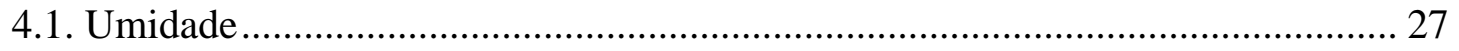

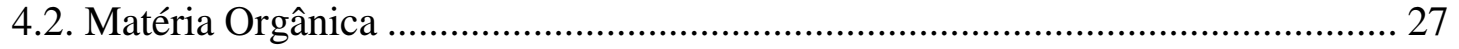

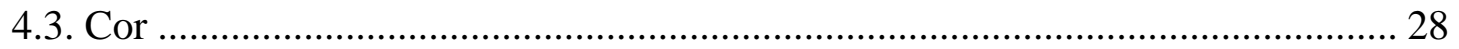

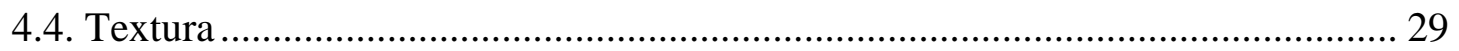

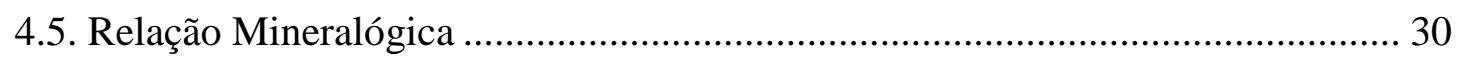

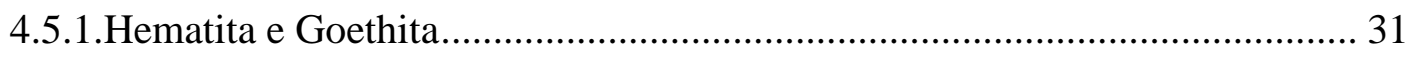

4.5.2. Índices simulados pelo Thematic Mapper (TM) ........................................ 32

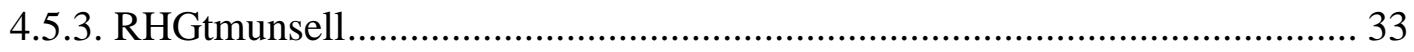

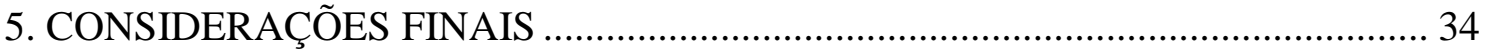

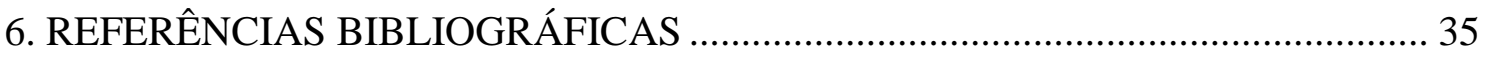

Capítulo 2: POTENCIALIDADE DO SENSOR WORLDVIEW II PARA DETECÇÃO DE HEMATITA E GOETHITA EM SOLOS TROPICAIS.......................................... 42

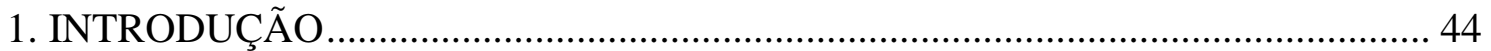

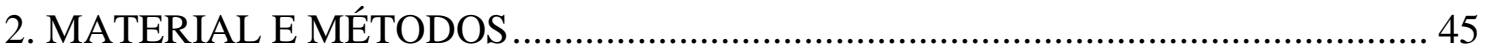

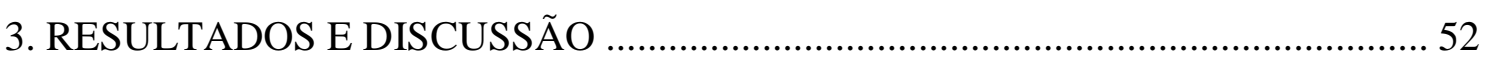

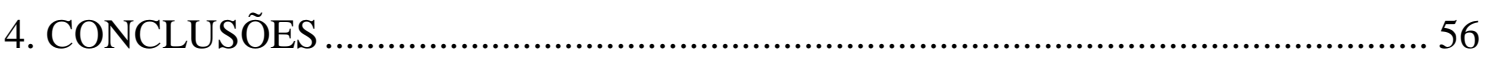


5. REFERÊNCIAS BIBLIOGRÁFICAS

CAPÍTULO 3: DISCRETIZAÇÃO ESPACIAL DOS ÓXIDOS DE FERRO, POR MEIO DE ALGORITMOS E ÍNDICE ESPECTRAL EM DADOS DO SENSOR

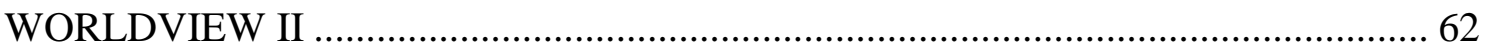

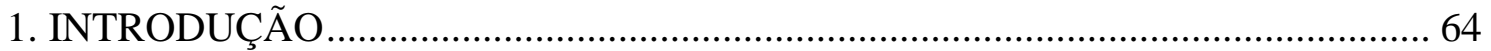

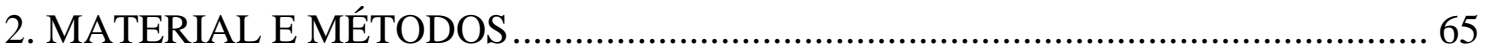

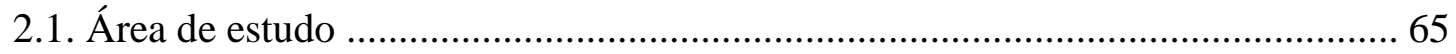

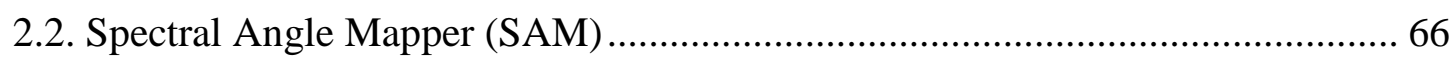

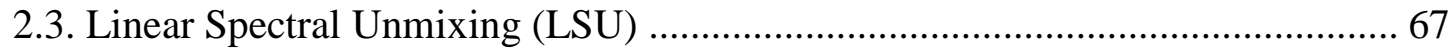

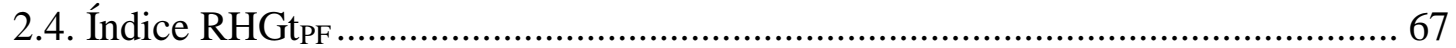

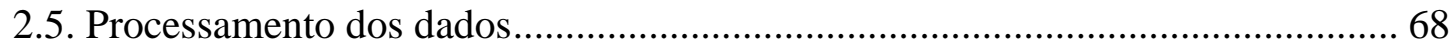

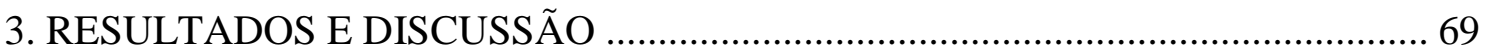

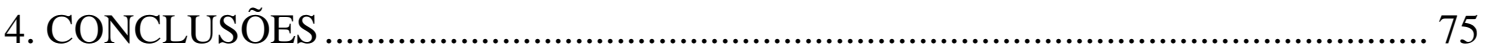

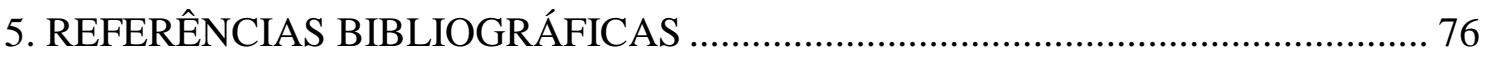

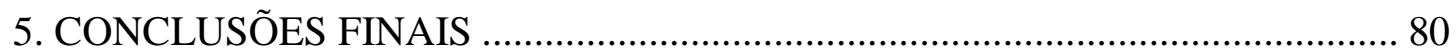




\section{INTRODUÇÃO}

As regiões tropicais apresentam, como características principais, a alta temperatura e as oscilações de umidade que influenciam diretamente o meio ambiente. Cada compartimento ambiental busca atingir um equilíbrio com as condições ambientais vigentes. Dessa forma as propriedades físicas, químicas e mineralógicas do solo, por exemplo, se alteram visando a harmonização do sistema (GUERRA \& CUNHA, 1996).

A degradação química é mais acelerada nesses ambientes, devido à presença de água, podendo resultar em solos altamente intemperizados e em minerais secundários (GUERRA \& CUNHA, 1996). Essas características de regiões tropicais interferem diretamente nas características do solo, como espessura, cor e mineralogia (DALMOLIN et al.,2005; GALVÃO et al., 2008).

A cor do solo é uma propriedade considerada principal na classificação de solos que podem identificar visualmente de forma simples e rápida a presença de elementos, como a matéria orgânica e os óxidos de ferros e, consequentemente, o processo que atua na formação do solo, como a oxidação do ferro (MADEIRA NETTO, 1993; FERNANDES et al., 2004; BAPTISTA e MENESES, 2009). A determinação da escala de cores normalmente é feita por meio de padrões contidos na carta de Munsell (CAMPOS et al., 2003).

Com isso, os solos brasileiros mais intemperizados são os Latossolos e sua característica é a presença de óxidos de ferro na sua composição, ou seja, o mineral hematita $\left(\mathrm{Fe}_{2} \mathrm{O}_{3}\right)$ e goethita $(\mathrm{FeOOH})$, que pode ser identificado e diferenciado por meio das cores (MADEIRA NETTO et al., 1997; FERNANDES et al., 2004; BARBOSA et al., 2009). Muitos autores (CAMARGO et al., 2008; BAPTISTA e MENESES, 2009; CAMPOS et al., 2010; SILVA JUNIOR et al., 2012) afirmam que a presença de óxidos de ferro está intimamente relacionada à característica pedohídrica com grande influência nos atributos físicos e químicos do solo.

A identificação e a diferenciação desses óxidos de ferro podem ser observadas por meio da cor dos solos que são expressas mediante a reflectância espectral dos solos que é obtida via sensoriamento remoto (CAMPOS et al., 2003). Portanto, esses óxidos de ferro devem se diferenciar por suas assinaturas ou feições espectrais em comprimentos de ondas específicos de acordo com suas transições eletrônicas (BAPTISTA e MENESES, 2009). No caso a transição eletrônica chamada de efeito cristalino da hematita e goethita, ocorrem em 0,53 $\mu \mathrm{m}$ e 0,48 $\mu \mathrm{m}$, respectivamente, ou seja, na faixa do visível que é responsável pelas cores desses minerais (SHERMAN e WAITE, 1985). 
Para uma melhor visualização e diferenciação da cor dos óxidos de ferro, há a necessidade de uma imagem de satélite de um sistema sensor que discrimine particularmente cada comprimento de onda de forma separada, ou seja, de forma multiespectral.

Com o lançamento do WorldView II, um sistema sensor de alta resolução espacial, contendo novas bandas na região do VNIR, sendo uma no azul costal $(0,4-0,45 \mu \mathrm{m})$, uma no amarelo $(0,585-0,625 \mu \mathrm{m})$, na borda do vermelho $(0,705-0,745 \mu \mathrm{m})$, além de duas bandas no NIR $(0,770-0,895 \mu \mathrm{m}$ e $0,86-1,04 \mu \mathrm{m})$ proporcionou novos estudos devido à suas características espectrais.

Com isso, os espectros de reflectância apresentam melhor as bandas de absorção que denotam as transições de campo cristalino da hematita e da goethita e, portanto, devem permitir uma discretização espacial mais acurada dessa relação mineralógica, bem como a possibilidade de sua quantificação.

Estudar a relação hematita/(hematita+goethita) é importante, porque permite inferir o caráter pedohídrico da região, ou seja, analisar o estado físico químico do ambiente e consequentemente os minerais que estão inseridos de acordo com a topossequência; classificar, de acordo com a cor, o tipo de solo; qual estágio de oxidação ou redução o material se encontra; e estudar e analisar a flutuação do nível freático por meio das concreções ferruginosas, localizadas em ambientes goethíticos.

\subsection{OBJETIVOS}

\subsubsection{OBJETIVO GERAL}

Testar a potencialidade do sistema sensor WorldView II na detecção dos minerais hematita e goethita por meio de índice de pronfundidade de feição em solos tropicais.

\subsubsection{OBJETIVO ESPECÍFICO}

- Avaliar a potencialidade do WorldView II para discretização e quantificação da relação mineralógica hematita/(hematita+goethita);

- Proposição de um índice com a profundidade da feição do sensor WorldView II.

\subsection{ESTRUTURA DA DISSERTAÇÃO}

A dissertação de mestrado segue a estrutura de artigos científicos, composta em três capítulos: 
Capítulo 1 - Artigo de revisão: ESPECTRORRADIOMETRIA DE SOLOS. Este artigo aborda uma revisão teórica acerca dos solos, do sensoriamento remoto e do comportamento espectral dos solos. Trata das propriedades do solo e como elas podem influenciar no seu espectro eletromagnético.

Capítulo 2 - Artigo 2: POTENCIALIDADE DO SENSOR WORLDVIEW II PARA DETECÇÃO DE HEMATITA E GOETHITA EM SOLOS TROPICAIS. Testa o índice proposto por Madeira Netto (1993) para sensor TM5 do Landsat com dados espectrais reamostrados para o WorldView II e propõe um índice baseado na profundidade das feições espectrais dos dois minerais, hematita e goethita. O capítulo submetido na Revista Pesquisa Agropecuária Brasileira.

Capítulo 3 - Artigo 3: DISCRETIZAÇÃO ESPACIAL DOS ÓXIDOS DE FERRO DA UNIVERSIDADE DE BRASÍLIA (DF) POR MEIO DOS ALGORITMOS LINEAR SPECTRAL UNMIXING E SPECTRAL ANGLE MAPPER DOS DADOS DO SENSOR WorldView II. Apresenta a aplicação de dois algoritmos desenvolvidos como classificadores espectrais para identificação dos minerais hematita e goethita com dados da biblioteca espectrais Jet Propulsion Laboratory (JPL) convolucionados para o sensor WorldView II. Parte foi apresentado no XVII Simpósio Brasileiro de Sensoriamento Remoto no ano de 2015 na cidade de João Pessoa, PB. O capítulo submetido na Revista Brasileira de Cartografia.

\subsection{REFERÊNCIAS}

BAPTISTA, G.M.M; MENESES, P.R. Identificação de sesquióxidos de ferro da fração argila de solos tropicais por meio de decomposição espectral linear dos dados do sensor AVNIR-2 do sistema ALOS. Anais XIV Simpósio Brasileiro de Sensoriamento Remoto, Natal, Brasil, INPE, p. 7655-7662. 2009.

BARBOSA, I.O.; LACERDA, M.P.C; BILICH, M.R. Relações pedomorfogeológicas nas chapadas elevadas do Distrito Federal. Revista Brasileira de Ciência do Solo, 33:1373-1383, 2009.

CAMARGO, L.A.; MARQUES JÚNIOR, M.; PEREIRA, G.T.; HORVAT, R.A. Variabilidade espacial de atributos mineralógicos de um latossolo sob diferentes formas do relevo. I mineralogia da fração argila. Revista Brasileira de Ciência do Solo, 32:2269-2277, 2008. 
CAMPOS, P.M; LACERDA, M.P.C; LOPES DA SILVA, C.; CAROLINO DE SÁ, M.A; GOMES DE SOUSA, D.M. Drenagem interna como fator de diferenciação de Latossolos do Distrito Federal. Pesquisa Agropecuária Brasileira, Brasília, v.45, n.3, p.306-314, mar. 2010.

CAMPOS, R.C; DEMATTÊ, J.A.M.; QUARTAROLI, C.F. Determinaçao indireta do teor de hematita no solo a partir de dados de colorimetria e radiometria. Pesquisa Agropecuária Brasileira, Brasilia, v. 38, n. 4, p. 521-528, abr. 2003.

DALMOLIN, R.S.D.; KLAMT, C.N.G.E.; DICK, D.P. Relação entre os constituintes do solo e seu comportamento espectral. Ciência Rural, Santa Maria, v.35, n.2, p.481-489, mar-abr, 2005.

FERNANDES, R.B.A.; BARRÓN, V. TORRENT, J.; FONTES, M.P.F. Quantificação de óxidos de ferro de latossolos brasileiros por espectroscopia de refletância difusa.Revista Brasileira de Ciência do Solo, 28:245-257, 2004.

GALVÃO, L.S.; FORMAGGIO, A.R.; COUTO, E.G.; ROBERTS, D.A. Relationships between the mineralogical and chemical composition of tropical soils and topography fioni hyperspectral remote sensing data. Journal of Photogrammetry \& Remote Sensing 63 (2008) 259271. 2008.

GUERRA, A.J.T.; CUNHA, S.B. Geomorfologia e Meio Ambiente. ED. BERTRAND BRASIL, 1996, 372 PÁGS.

MADEIRA NETTO, J.S. Étude quantitative des relations constituants minéralogiques réflectance diffuse des latosols brésiliens: Aplication à I'utilisation pédologique des donné es satellitaires TM (région de Brasilia). Paris: Éd. I'ORSTOM, 236p. (ORSTOM. Collection Etudes et Theses). 1993.

MADEIRA NETTO, J.S.; BEDIDI, A.; CERVELLE, B.; POUGET, M.; FLAY, N. Visible spectrometric indices of hematite $(\mathrm{Hm})$ and goethite $(\mathrm{Gt})$ content in lateritic soils: the application of Thematic Mapper (TM) image for soil-mapping in Brasília, Brazil. International Journal of Remote Sensing. London, v.18, p.2835-2852, 1997.

SHERMAN, D.M.; WAITE, T.D. Electronic spectra of Fe3+ oxides and oxide hydroxides in the near IR to near UV. American Mineralogist. V.70, p.1262-1269, 1985. 
SILVA JUNIOR, J.F.; MARQUES JÚNIOR, M.; CAMARGO, L.A.; TEIXEIRA, D.B.; PANOSSO, A.R.; PEREIRA, G.T. Simulação geoestatística na caracterização espacial de óxidos de ferro em diferentes pedoformas. Revista Brasileira de Ciência do Solo, 36:1690-1703. 2012. 
CAPÍTULO 1: ESPECTRORRADIOMETRIA DE SOLOS 
Resumo. Com o avanço de técnicas e tecnologias, o sensoriamento remoto vem-se destacando como ferramenta auxiliar para o mapeamento de solos por meio da espectroscopia de reflectância de solos. Comportamento espectral dos solos é um termo utilizado para definir as interações da radiação eletromagnética com os diferentes tipos de solos e fatores intrínsecos a eles, como as propriedades físico-químicas. Essas características do solo controlam a sua curva espectral e as propriedades mais estudadas são matéria orgânica, a textura do solo, a cor, a umidade e os óxidos de ferro. Esse estudo tem crescido desde a década de 80 e necessita de um suporte de pesquisa para obter melhor entendimento acerca do comportamento espectral do solo. O objetivo desse artigo é destacar o comportamento espectral de solos em função dos vários constituintes do solo. Palavras chaves: Solo, espectroscopia, comportamento espectral de solos, propriedades do solo

\begin{abstract}
With the advance of techniques and technology, the remote sensing has been a very helpful tool for mapping the soils through the spectroscopy of reflectance. Spectral behavior of the soil it is a term used to define the interactions of the electro-magnetic radiation with the different types of soil and intrinsic factors to them, like the physical-chemical properties. This soil's specifications control the spectral curves and the properties most studied are organic material, soil texture, color, moisture e iron oxides. This study has been growing since the 80 's and it needs research support to achieve better understanding about the spectral behavior soil. The purpose of this article it has to emphasize the spectral behavior soil according to the many constituents of soil.
\end{abstract}

Key words: Soil, spectroscopy, spectral behavior soil, soil properties.

\title{
1. INTRODUÇÃO
}

Os solos são corpos tridimensionais constituídos por três estados físicos, o gasoso, o líquido e o sólido e formados por matéria mineral e orgânica. Ele compõe a paisagem e acompanha a transformação dos seus cinco principais fatores que são: o clima, o relevo, o material de origem, os organismos e o tempo (JACOMINE, 2009).

Um dos solos mais comum no Brasil é o latossolo (REATTO et al., 2004; REATTO et al., 2008). Suas características são solo homogêneo e de ambiente tropical com alta temperatura e umidade (REGITANO et al., 2001). Ele predomina em relevos mais estáveis e o segundo nível categórico de classificação está relacionado a cor e, consequentemente, ao caráter pedohídrico, ou seja, a topossequência que está ligada ao nível freático e a diferentes estados de oxirredução (CAMARGO et al., 2008; REATTO et al., 2008; BAPTISTA e MENESES, 2009; BARBOSA et al., 2009; CAMPOS et al., 2010; SILVA JUNIOR et al., 2012). 
O sensoriamento remoto é uma ferramenta relativamente nova e que estuda a interação da radiação eletromagnética com os diferentes alvos, como vegetação, área urbana e solo (JENSEN, 2011; NOVO, 2010). Cada alvo apresenta um comportamento espectral que é decorrente da sua caraterística física, química ou mineralógica que descreve o alvo (ALVARENGA et al., 2003). Em relação aos solos, o sensoriamento remoto vem se destacando como uma ferramenta auxiliar para o mapeamento de solos (DEMATTÊ et al., 2004; DALMOLIN et al.,2005). O estudo de Demattê et al. (2004) demostrou que com padrões previamente descritos se classifica o solo até o segundo nível categórico.

O comportamento espectral do solo estuda a associação do sensoriamento remoto com cada propriedade do solo, isto é, a interação eletromagnética com cada característica do solo, seja física, química e mineralógica (ALVARENGA et al., 2003). As propriedades do solo mais conhecidas e estudadas e que influenciam a curva espectral do solo são: a umidade, matéria orgânica, cor, textura e a mineralogia (MADEIRA NETTO e BAPTISTA, 2000; ALVARENGA et al., 2003; DALMOLIN et al.,2005; JENSEN, 2011; VIVALDI et al., 2013; CEZAR et al., 2013).

O presente trabalho contribui com uma revisão bibliográfica dos conceitos de solos e latossolos, de sensoriamento remoto, suas ferramentas e sensores e do comportamento espectral de cada propriedade do solo, bem como ela influencia na sua curva espectral. Também trata de forma mais detalhadas os minerais hematita e goethita, responsáveis pelas cores avermelhadas e amareladas, respectivamente dos solos tropicais e, assim como, sua quantificação.

\section{SOLOS}

O solo é um material tridimensional, inconsolidado e dinâmico. Ele é constituído por partes líquidas, gasosas e sólidas que são a água, ar, matéria orgânica e matéria mineral que ocupam a maior parte da crosta terrestre (JACOMINE, 2009; EMBRAPA, 2013). A sua formação é gerada por meio das transformações das rochas que é resultante da ação integrada do clima e organismos sobre o material de origem.

Essa transformação é devido a cinco principais fatores de formação do solo, conhecidos como o clima, os organismos, o material originário, o relevo e o tempo (BRADY e WEIL, 2013). As características e diferenças de cada solo deriva desses cinco fatores. Esses fatores podem influenciar na sua espessura, na cor, na textura, nos tipos de minerais existentes e na quantidade de matéria orgânica. Essas diferenças ocorrem devido as várias condições naturais que determinam as características individuais de cada solo (GUERRA e CUNHA, 1996). 
O intemperismo por meio de processos biológicos, químicos e físicos transformam as rochas e geram um processo de síntese do solo (GUERRA e CUNHA, 1996). O resultado dessa síntese é a formação de camadas chamadas de horizontes do solo (BRADY e WEIL, 2013). O estudo do solo é a análise de cada horizonte e é feito por meio de uma corte vertical chamado de perfil do solo. Segundo Jacomine (2009), o perfil do solo expõe os diferentes horizontes as quais são aproximadamente paralelas à superfície do terreno e são estudadas as características físicas ou morfológicas, como a cerosidade, espessura, textura, estrutura e outras características.

De acordo com Brady e Weil (2013), os horizontes são nomeados e diferenciados por letras maiúsculas. Os seis horizontes principais são os $\mathrm{O}, \mathrm{A}, \mathrm{E}, \mathrm{B}, \mathrm{C}$ e R, os quais possuem caraterísticas particulares:

Horizonte O: É comum em solos orgânicos; possui matéria orgânica que é resultado de plantas mortas e resíduos animal.

Horizonte A: Camada mais superficial que predominam partículas minerais que foram escurecidas devido a lixiviação e o acúmulo de matéria orgânica.

Horizonte E: É um horizonte de cor clara devido a lixiviação ou eluviação de argilas, ou óxidos de ferro e de alumínio, e que predominam a concentração de mineral mais resistentes na forma de areia e silte.

Horizonte B: É o horizonte diagnóstico, o qual nomeia os solos; possui menos matéria orgânica que os horizontes mais próximos a superfície; Acúmulo de argilas silicatadas, óxidos de ferro e de alumínio.

Horizonte C: Material inconsolidado; Saprolito, ou seja, rocha alterada que se intemperizou.

Horizonte R: Material consolidado; Rocha matriz ou rocha mãe.

Os horizontes secundários são identificados com letras minúsculas, seguidos da nomeação do horizonte principal, obtendo mais detalhes dos horizontes.

As camadas do solo se distinguem não somente pelos cinco fatores de formação do solo, mas também pelos processos de formação que é diferente em cada região. Os quatro processos são conhecidos como adição, remoção, translocação e transformação, os quais são eventos que afetam 
e expressam seus efeitos em cada horizonte (GUERRA e CUNHA, 1996). Esses dois conceitos de formação dos solos estão relacionados entre si (GHIDIN et al., 2006).

\subsection{Solos Tropicais}

A região tropical tem como característica a alta temperatura e umidade (REGITANO et al., 2001). O processo químico mais predominante nessa região é o químico devido a maior presença de água. Isso influencia também na espessura do solo pois quanto maior a penetração da água, mais intemperizado e espesso será o solo (GUERRA e CUNHA, 1996). A água e a temperatura elevada facilitam as reações de intemperismo e a diferenciação dos horizontes, consequentemente há um aumento dos teores de argila e de matéria orgânica e diminuição do seu pH e da relação entre Si/Al (BRADY e WEIL, 2013).

Além dos quatro processos de formação dos solos, existem os processos pedogenéticos ou específicos de formação do solo que expressam essas peculiaridades de cada região devido ao clima. O processo pedogenético comum e predominante nas regiões tropicais é chamado de latolização que se caracteriza pela perda de sílica e de bases do solo e pelo enriquecimento de oxihidróxidos de ferro e de alumínio, ou seja, é a remoção de sílica de minerais primários e transformando-os em minerais secundários da fração argila (DALMOLIN et al., 2005).

Esse processo caracteriza o desenvolvimento de solos profundos, na sua grande maioria latossolos devido à evolução pedogenética que é muito acentuada na região tropical (BARBOSA et al., 2009).

\subsubsection{LATOSSOLOS}

Os solos profundos e evoluídos mais comuns na região tropical são os Latossolos, de acordo com o Sistema Brasileiro de Classificação de Solos (SiBCS). Esses solos altamente intemperizados são predominantes no Brasil e eles ocupam extensas áreas cultivadas e são de extrema importância na proteção ao meio ambiente e na resolução de problemas relacionados a agricultura como produção de alimentos (FONTES et al., 2001).

Os latossolos são solos constituídos por material mineral, com horizonte B latossólico (horizonte subsuperficial) imediatamente abaixo de qualquer um dos tipos de horizonte superficial, exceto hístico (EMBRAPA, 2013). São solos com estágio avançado de intemperização, isto é, muito profundo e evoluídos resultado de transformações do material constitutivo. A presença de minerais primários é quase inexistente e também de minerais secundários menos resistentes ao 
intemperismo (JACOMINE, 2009). Esse processo de lixiviação de minerais primários ou bases do solo e o enriquecimento de óxidos de ferro e alumínio, é chamado de laterização ou latolização.

Algumas das características que devem ser observadas no horizonte subsuperficial do Latossolo são espessura mínima de cinquenta centímetros, agregados granulares muito pequenos (microagregados) (GOMES et al., 2004), a relação molecular $\mathrm{SiO}_{2} / \mathrm{Al}_{2} \mathrm{O}_{3}$, chamada de $\mathrm{Ki}$, deve ser igual ou menor que 2,2 e possui capacidade de troca catiônica inferior a $17 \mathrm{cmol} / \mathrm{kg}$, sem correção para carbono (EMBRAPA, 2013). Uma das características mais peculiares nos Latossolos é a cor que pode variar desde amarelo ou mesmo bruno-acinzentadas até vermelhoescuro-acinzentadas, nos matizes de 2.5 YR a 10YR da carta de Munsell (EMBRAPA, 2013).

Os latossolos compreendem quatro subsordens ou classes do segundo nível categórico são elas: Latossolo Bruno, Latossolo Amarelo, Latossolo Vermelho e Latossolos Vermelho-Amarelo (JACOMINE, 2009; EMBRAPA, 2013). O nome dado no segundo nível categórico dos Latossolos reflete a cor devido à presença de minerais óxidos de ferro, hematita e goethita, a cor avermelhada e amarelada, respectivamente.

Segundo Embrapa (2013), os Latossolos Brunos abrangem solos de cores brunadas com matiz de 4YR. Os Latossolos amarelo compreendem os solos com matiz 7,5 YR ou mais amarelos nos primeiros centímetros do horizonte B. Já os Latossolos Vermelhos com matiz de 2,5YR ou mais vermelhos nos primeiros centímetros do horizonte B. E por fim, os Latossolos Vermelho-Amarelos que são solos de cores vermelho-amareladas ou amarelo-avermelhadas que não se enquadram nas classes anteriores.

\subsubsection{Mineralogia da fração argila}

Primeiramente, as partículas de textura do solo são divididas em areia, silte e argila. As argilas são consideradas as mais menores, ou seja, são pequenas partículas dos solos, porém as que mais apresentam cargas elétricas que atraem íons de minerais dissolvidos. Por meio desse mecanismo de forte ligação dos íons de minerais, eles não são lixiviados pela água da chuva (JENSEN, 2011).

Essas partículas de solo são encontradas em solos tropicais que são altamente intemperizados com altas temperaturas e precipitação. Como já foi dito, nessas regiões as bases do solo são lixiviadas e o solo é enriquecido por óxidos de ferro ou alumínio. Por isso a mineralogia da fração argila é caracterizada por poucos minerais presente (MADEIRA NETTO e BAPTISTA, 2000), 
como minerais de argila do tipo 1:1 e óxidos de ferro e alumínio (BAPTISTA et al., 1998; REGITANO et al., 2001).

Um desses minerais presentes é o alumínio (Al), terceiro elemento mais abundante na crosta terrestre e está presente em minerais de argila, como a caulinita e a gibbsita. Outro elemento também muito presente na fração argila dos solos é o ferro $(\mathrm{Fe})$ na forma de óxidos de ferro, como hematita e goethita (PEDROTTI et al., 2003). O ferro é transformado da forma divalente $\left(\mathrm{Fe}^{2+}\right)$ para a forma trivalente $\left(\mathrm{Fe}^{3+}\right)$ (SAMBATTI et al., 2002).

De acordo com inúmeros autores, como Baptista et al. (1998), Inda Junior e Kämpf (2005), Alves et al. (2008), Barbosa et al. (2009), Vendrame et al. (2011), os minerais mais comumente presentes na fração argila dos latossolos são a caulinita, gibbsita, goethita e hematita. Para Fontes (2001), a gibbsita é praticamente o único óxido de alumínio presente nesse solo devido ao intemperismo.

Esses minerais são utilizados para avaliar o grau de alteração do solo. Os minerais de alumínio, caulinita e gibbsita, são utilizados para calcular o índice Ki e os minerais de ferro, goethita e hematita, são utilizados para calcular o índice Kr. Esses índices são relações moleculares sílica/alumínio $\left(\mathrm{SiO}_{2} / \mathrm{Al}_{2} \mathrm{O}_{3}=\mathrm{Ki}\right)$ e sílica/óxidos de ferro e alumínio $\left(\mathrm{SiO}_{2} / \mathrm{Al}_{2} \mathrm{O}_{3}+\mathrm{Fe}_{2} \mathrm{O}_{3}=\mathrm{Kr}\right)$ (KER, 1997).

Esses minerais estão presentes no latossolo, de forma variada dependendo também do seu tipo (ALVES et al., 2008; VENDRAME et al., 2011). Barbosa et al. (2009) e Campos et al. (2010), perceberam que os óxidos de ferro estavam ligados intimamente à morfologia e também a cor do solo e que nos latossolos com cor mais amarela percebia-se o mineral goethita e nos latossolos avermelhados a hematita.

\subsubsection{1. Óxidos de ferro}

O termo óxidos de ferro é utilizado genericamente para óxidos, hidróxidos e oxidróxidos de ferro (KER, 1997). Esses minerais são encontrados na fração argila dos solos tropicais, como o Latossolo e em ambientes com diferentes estágios de oxidação. Eles são resultado da oxidação do ferro ferroso $\left(\mathrm{Fe}^{2+}\right)$ presente em minerais primários que se transforma em ferro férrico $\left(\mathrm{Fe}^{3+}\right)$ (BAPTISTA e MENESES, 2009). A forma mais frequente de ocorrência desses minerais secundários de ferro são a hematita $\left(\mathrm{Fe}_{2} \mathrm{O}_{3}\right)$ e goethita $(\mathrm{FeOOH})$ e que normalmente ocorrem associados (CAMARGO et al., 2008). 
Goethita é um oxidróxido de ferro que possui uma estrutura ortorrômbica com cada íon $\mathrm{Fe}^{3+}$ coordenado com três íons $\mathrm{O}^{2-}$ e três íons $\mathrm{OH}^{-}$(OLIVEIRA et al., 2013). Nos locais nos quais predominam esse mineral, ambientes oxi-redutores, imprimem aos solos a coloração amarela ou bruna encontradas nos solos (FONTES et al., 2001). Ela é formada em condições de baixo pH, alta umidade e altas concentrações de carbono (VENDRAME et al., 2011). Quando é aquecida a temperaturas superiores a $200^{\circ} \mathrm{C}$, sofre desidroxilação para formar hematita (OLIVEIRA et al., 2013).

Hematita é um óxido de ferro que precipita em microambientes de baixa porosidade, preferencialmente ricos em argilas, e a atividade da água é menor (GUERRA e CUNHA, 1996), ou seja, ambientes oxidados. Ela ocorre em ambientes com altas temperaturas e é responsável pela cor avermelhadas dos solos (FONTES et al., 2001).

Segundo Vendrame et al. (2011), os óxidos de ferro influenciam as propriedades físicas e químicas dos solos devido aos seus graus de cristalinidade e por apresentarem cargas variáveis dependentes do $\mathrm{pH}$ do solo. A goethita e a hematita são, normalmente, identificadas e diferenciadas pela cor nos solos (MADEIRA NETTO et al., 1997; MELO et al., 2001; FERNANDES et al., 2004; BARBOSA et al., 2009).

Os óxidos de ferro determinam a cor dos solos (CORREA et al., 2008). A presença de goethita torna o solo mais amarelado e a hematita mais avermelhado. A hematita mascara o efeito da goethita, quanto maior o teor de hematita mais vermelho é o solo (KER, 1997). Essa diferença entre as cores e a presença desses minerais no solo é que nomeiam e caracterizam o Latossolo, como por exemplo Latossolo vermelho, Latossolo amarelo e Latossolo vermelho amarelo (BARBOSA et al., 2009).

Muitos autores (MELO et al., 2001; MOTTA et al., 2002; INDA JUNIOR e KÄMPF, 2005; GHIDIN et al., 2006; CAMARGO et al., 2008; BAPTISTA e MENESES, 2009; CAMPOS et al., 2010; SILVA JUNIOR et al., 2012) afirmam que a presença de óxidos de ferro está intimamente relacionada à característica pedohídrica. Motta et al., (2002), Ghidin et al.(2006), Barbosa et al. (2009) e Campos et al. (2010) estudando uma topossequência de latossolos e a variação do regime hídrico, observaram que a ocorrência do Latossolo Vermelho, solo mais vermelho, estava associada a locais mais elevados e de melhor drenagem interna e em contrapartida os Latossolos mais amarelados estava em pedoambientes mais úmidos nas bordas do relevo. 
Para Motta et al. (2002), os solos hidromórficos, mais redutores, estão associados às áreas deprimidas, onde se localizam as nascentes ou rede de drenagem, próximas de cursos d'água. Além de indicadores pedogenéticos também está vinculado a ambientes de diferentes estágios de oxidação (INDA JUNIOR e KÄMPF, 2005). Reatto et al. (2008) observou que os minerais intemperizados combinam com o componente regional que está associado a idade da superfície geomorfológica e a exigência hidráulica ao longo de uma topossequência.

\section{SENSORIAMENTO REMOTO}

Sensoriamento remoto é uma ciência que tem por objetivo obter informações sobre um objeto sem estar em contato físico, ou seja, remotamente. Essa ferramenta é bastante utilizada para monitorar e estudar a Terra, bem como suas características biofísicas e de uso e ocupação (JENSEN, 2011).

As informações adquiridas por sensoriamento remoto são obtidas por meio do instrumento denominado sensor, cujo papel é registrar a radiação eletromagnética diretamente ou indiretamente, por reflexão, substituindo suas propriedades reais, ou seja, a energia eletromagnética é o grande elo entre o objeto na superfície terrestre e os sistemas sensores (JENSEN, 2011). Novos sistemas sensores surgem e há uma necessidade de investigação das suas potencialidades (BAPTISTA e MENESES, 2009).

Tendo o conhecimento de como funciona as interações entre a radiação eletromagnética e os diferentes materiais é um requisito bastante importante para interpretação de dados. (ALVARENGA et al., 2003). Essas interações podem prover informações sobre composição química de rochas e de minerais que não estejam completamente recobertos por vegetação densa. O sensoriamento remoto é uma ferramenta muito importante para identificação e mapeamento dos materiais da superfície terrestre (JENSEN, 2011).

\subsection{Espectrorradiometria}

A espectroscopia é o estudo da interação da radiação eletromagnética com o objeto analisado (DALMOLIN et al.,2005; ALBA et al., 2008). A forma dessa radiação é em função do comprimento de onda, no intervalo de 1 nanômetro a 1000 micrômetros $\left(10^{-9}-10^{-3} \mathrm{~m}\right.$ ) (ALBA, 2007), que está sendo refletida, emitida ou espalhada por um meio gasoso, líquido ou sólido (MADEIRA NETTO e BAPTISTA, 2000; ALVARENGA et al., 2003; DALMOLIN et al.,2005; ALBA, 2007). Essa extração de informação é feita por meio da absorção, transmissão e reflexão da energia incidente no objeto estudado (DALMOLIN et al., 2005). Espectrorradiometria de 
reflectância é uma técnica que mede em diferentes comprimentos de onda a energia eletromagnética refletida da superfície dos materiais e é representada na forma de um gráfico cujo nome é curva de reflectância (PEDROZA et al., 2010).

De acordo com Madeira Netto e Baptista (2000), a espectroscopia de reflectância permiti a exploração dos dados de reflectância espectral de maneira mais completa e complexa pois depende da compreensão das propriedades de reflectância e de suas relações com seus constituintes. O espectro da faixa óptica normalmente utilizado em sistemas sensores abrange a região de 0,4 a 2,5 $\mu \mathrm{m}$ e apresentam feições ou bandas de absorção devido à interação dos átomos constituintes no objeto (DALMOLIN et al.,2005). Essas feições são assinaturas espectrais que o objeto possui quando determinado comprimento de onda incide sobre ele, e elas são sensíveis a ligações químicas específicas dos materiais como por exemplo, aos minerais (MIURA et al., 2009). Os minerais possuem assinatura espectral própria e no comprimento de onda específico (JENSEN, 2011). Essas feições de absorção são devido aos processos eletrônicos e vibracionais.

Para entender melhor o processo eletrônico, deve-se compreender os eventos quânticos dos átomos presentes no objeto que ocorrem em comprimentos de ondas específicos que são a absorção e a emissão. A absorção de fótons causa uma mudança de um estado de energia mais baixo para um mais alto e a emissão é o contrário, de um estado de mais alta para um de mais baixa energia (MADEIRA NETTO e BAPTISTA, 2000). Essas transições de níveis de energia são que causa as feições nos espectros eletromagnéticos e ocorrem principalmente na faixa espectral do visível ao infravermelho próximo (DALMOLIN et al.,2005).

O efeito do campo cristalino é um processo eletrônico que se encontra nos espectros minerais e ocorre em virtudes do número de elétrons vagos nos orbitais externos dos elementos de transição. Um exemplo é o ferro, elemento mais comum na composição de minerais e solos, que com a incidência da radiação em determinado comprimento de onda absorvida pelo íon, os elétrons desemparelhados são excitados para um de maior energia e essa absorção define uma feição espectral tornando a identificação do mineral possível (MADEIRA NETTO e BAPTISTA, 2000). Sherman e Waite em 1985, diferenciaram dois minerais na região do visível, a goethita e a hematita, pela cor que é determinada pela transição de efeito cristalino que ocorre em $0,48 \mu \mathrm{m}$ e $0,53 \mu \mathrm{m}$, respectivamente.

O processo vibracional sucede devido às vibrações das ligações inter e intra moleculares decorrentes da absorção de energia e por demandar menos energia se comparando com o processo 
eletrônico, está ligado a comprimento de onda maiores localizados no infravermelho de ondas curtas, entre 1,2 e $3 \mu \mathrm{m}$ (MADEIRA NETTO E BAPTISTA, 2000). Esse processe está presente nos minerais caulinita e gibbsita (DALMOLIN et al.,2005).

Os sistemas sensores de alta resolução espectral (hiperespectrais) e os espectrorradiômetros de laboratório ou de campo conseguem obter essas informações detalhadas sobre os objetos analisados (BAPTISTA et al., 2007). Para Alba (2007), Alba et al. (2008) e Cezar et al. (2013), a espectroscopia de reflectância difusa é uma técnica promissora e versátil que pode ser aplicada em campo ou em laboratório se comparando com outras técnicas destrutivas e onerosas, como as analíticas convencionais.

Segundo Alvarenga (2003), a ligação entre os objetos da superfície e os sensores remotos é a radiação eletromagnética (REM) e a espectrorradiometria é fundamental para compreender o entendimento das interações entre a REM e os diferentes materiais. Um exemplo muito estudado são os solos e seus constituintes (MADEIRA NETTO e BAPTISTA, 2000; DEMATTÊ et al., 2004; DALMOLIN et al.,2005).

\subsection{Landsat TM 5}

Em 1967, a NASA iniciou o programa ERTS que objetiva, o lançamento de sete satélites para adquirir informações dos recursos da Terra (JENSEN, 2011). Posteriormente, o programa passou a denominar Landsat e é um dos mais antigos sistemas de satélites dos Estados Unidos adquirindo dados desde 1972 (JENSEN, 2011). Seus sensores são de varredura multiespectral (MSS) e os mapeados temáticos (TM) (JENSEN, 2011).

O Landsat 5 foi desenvolvido pela NASA, lançado em março de 1984 (CHANDER e MARKHAM, 2003) e possui o sistema sensor Thematic Mapper (TM) que é um sensor ópticomecânico whiskbroom que registra a energia na faixa de todos os espectros eletromagnético (visível, infravermelho próximo, de ondas curtas e termal) (JENSEN, 2011). Suas características orbitais são: repetitiva, circular, Sol-síncrona e quase polar e sua altura é de $705 \mathrm{Km}$ em relação à superfície terrestre (NOVO, 2010). Sua resolução temporal é de 16 dias, isto significa a frequência que o satélite gira em torno da terra para registrar uma mesma área.

O Landsat 5 possui 7 regiões de intervalos de comprimentos de ondas, mas conhecido como bandas espectrais, as quais são ótimas para obter informações sobre parâmetros biofísicos (JENSEN, 2011). Isso caracteriza-o como um sistema multiespectral que possui dezenas de 
bandas. As bandas 1 a 5 e 7 possuem resolução espacial de $30 \mathrm{~m}$, entretanto a banda 6 é de $120 \mathrm{~m}$, ou seja, isso significa a menor unidade entre dois objetos, mais conhecido como dimensão do pixel (JENSEN, 2011). Essas e outras características sobre o Landsat 5 estão na tabela 1.

Tabela 1: Características do Landsat TM 5

\begin{tabular}{|c|c|c|}
\hline Espectral & Bandas & Faixa espectral \\
\hline & Azul & $0,45-0,52 \mu \mathrm{m}$ \\
\hline & Verde & $0,52-0,60 \mu \mathrm{m}$ \\
\hline & Vermelho & $0,63-0,69 \mu \mathrm{m}$ \\
\hline & Infravermelho Próximo & $0,76-0,90 \mu \mathrm{m}$ \\
\hline & Infravermelho de Ondas Curtas & $1,55-1,75 \mu \mathrm{m}$ \\
\hline & Infravermelho Termal & $10,4-12,5 \mu \mathrm{m}$ \\
\hline & Infravermelho de Ondas Curtas & $2,08-2,35 \mu \mathrm{m}$ \\
\hline \multirow{2}{*}{ Espacial } & Visível e infravermelho & $30 \mathrm{~m}$ \\
\hline & Termal & $120 \mathrm{~m}$ \\
\hline Radiométria & 8 bits & \\
\hline Temporal & 16 dias & \\
\hline Altitude do sensor & $705 \mathrm{Km}$ & \\
\hline
\end{tabular}

Fonte: Adaptado de Jensen, 2011

\subsection{Sensor WorldView II}

O sistema sensor multiespectral WorldView II foi lançado em 8 de outubro de 2009 (DIGITAL GLOBE, 2010; KUMAR e ROY, 2013). Ele possui oito bandas espectrais estreitas entre a faixa do azul, do visível e do infravermelho próximo e uma banda pancromática. Essas oito bandas estão divididas em: azul costal (coastal), azul, verde, amarelo, vermelho, borda do vermelho (red-edge), infravermelho próximo 1(NIR-1) e infravermelho próximo 2 (NIR-2) (DIGITAL GLOBE, 2010; 


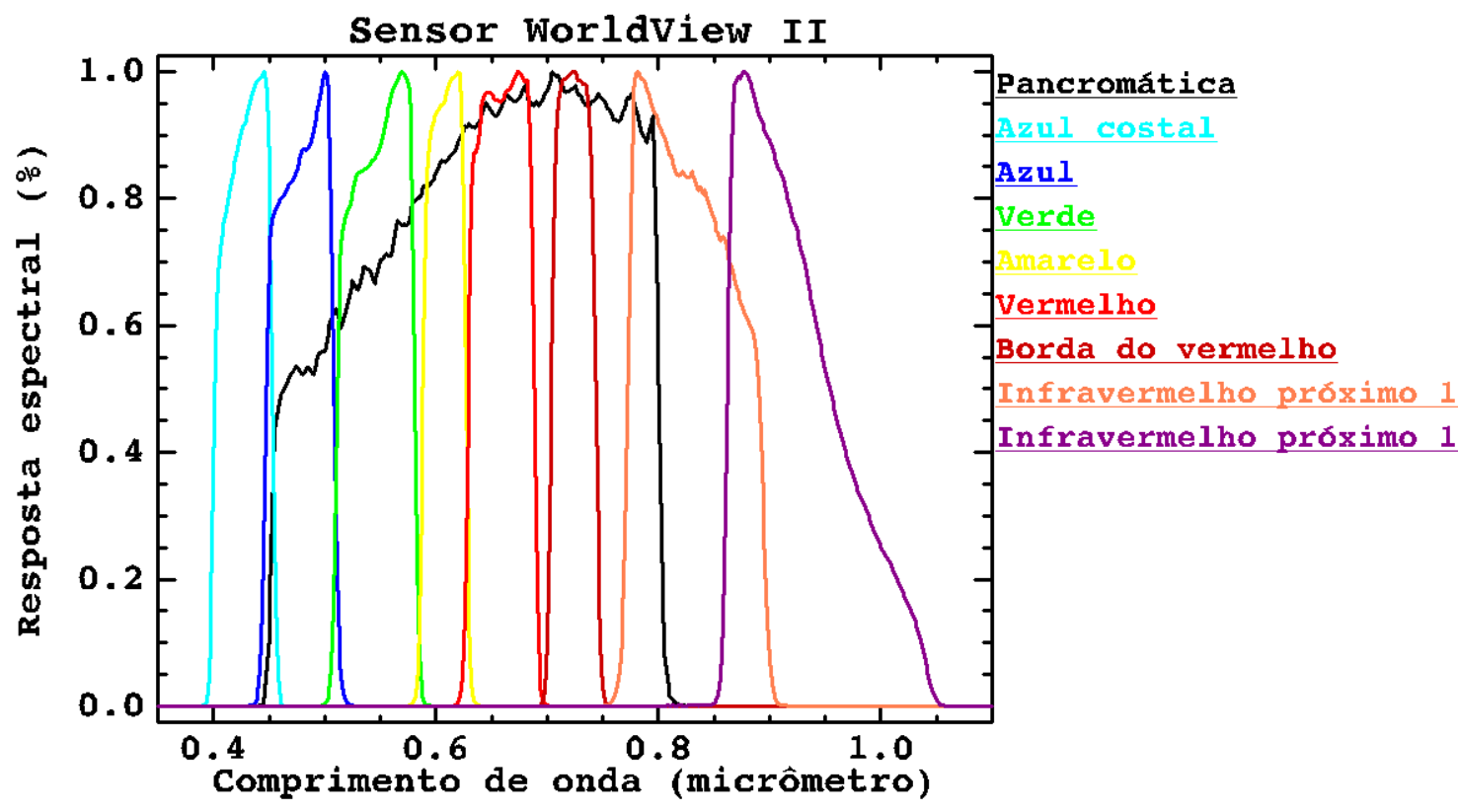

Figura 1: Funções de resposta espectral das bandas do sensor WorldView II.

É um sensor de alta resolução espacial, espectral e radiométrica. Ele possui $2 \mathrm{~m}$ de resolução espacial na faixa óptica e uma resolução mais elevada de $0,5 \mathrm{~m}$ na banda pancromática. Possui banda bem estreitas na faixa do visível e do infravermelho próximo tendo como objetivo melhor resolução espectral. E obtém imagens com 11 bits de resolução radiométrica (KUMAR e ROY, 2013), excelente para o estudo de batimetria (LEE et al., 2013). Essas especializações e outras foram compiladas na tabela 2 :

Tabela 2: Características do WorldView II

\begin{tabular}{l|l|l} 
Espectral & Bandas & Faixa espectral \\
\hline & Azul costal & $0,4-0,450 \mu \mathrm{m}$ \\
\hline & Azul & $0,45-0,51 \mu \mathrm{m}$ \\
\hline & Verde & $0,51-0,58 \mu \mathrm{m}$ \\
\hline & Amarelo & $0,585-0,625 \mu \mathrm{m}$ \\
\hline & Vermelho & $0,63-0,69 \mu \mathrm{m}$ \\
\hline & Borda do Vermelho & $0,705-0,745 \mu \mathrm{m}$ \\
\hline & NIR 1 & $0,770-0,895 \mu \mathrm{m}$ \\
\hline & NIR 2 & $0,860-1,040 \mu \mathrm{m}$ \\
\hline Espacial & Pancromática & $0,450-0,800 \mu \mathrm{m}$ \\
\hline & Multiespectral & $2 \mathrm{~m}$ \\
\hline Radiométria & Pancromática & $0,5 \mathrm{~m}$ \\
\hline Temporal & 11 bits & \\
\hline & 1,1 dia & \\
\hline
\end{tabular}




\section{\begin{tabular}{l|l} 
Altitude do sensor & $770 \mathrm{Km}$ \\
\hline
\end{tabular}}

Fonte: Adaptado de Digital Globe, 2010

Segundo Novack et al. (2011), o WorldView II foi o primeiro satélite de alta resolução dispondo de 8 bandas espectrais estreitas, abrangendo da faixa do azul até o infravermelho. A alta resolução fornece informações detalhadas que permite discriminação de detalhes finos (KUMAR \& ROY, 2013), desde estudo sobre planejamento urbano (NOVACK et al., 2011; CAVALCANTE et al., 2013), processamento de algoritmos (PADWICK et al., 2010), ecossistemas costeiros (LEE et al., 2013), classificação (KUMAR e ROY, 2013), vegetação (VIEIRA SOUZA et al., 2011) e uso e cobertura (ALMEIDA e MOREIRA DE SOUZA, 2011).

\section{COMPORTAMENTO ESPECTRAL DO SOLO}

Comportamento espectral dos solos é um termo utilizado para definir as interações da radiação eletromagnética com os diferentes tipos de solos e fatores intrínsecos a eles (ALVARENGA et al., 2003), como as propriedades físico-químicas (DEMATTÊ et al., 2005). Com o avanço de técnicas e tecnologias, o sensoriamento remoto vem-se destacando como ferramenta auxiliar para o mapeamento e levantamento pedológicos por meio da espectroscopia de reflectância de solos (DEMATTÊ et al., 1998; DEMATTÊ et al., 2004; DALMOLIN et al.,2005; FIORIO et al., 2010). E para Jensen (2011), felizmente, algumas características de solos podem ser medidas remotamente sobre determinadas condições como, não tiverem recobertos por vegetação ou dosséis densos.

A espectroscopia de reflectância de solos estuda o registro do fluxo de radiação eletromagnética refletida pelo solo em determinado comprimento de onda (DALMOLIN et al.,2005; FIORIO et al., 2010). Existem vários tipos de solos e com diferentes constituintes (SOUSA JUNIOR et al., 2008), eles podem ser identificados e até quantificados, em certos casos, pela análise de sua resposta espectral (DALMOLIN et al.,2005), com a possibilidade de atingir o terceiro nível categórico na classificação de solo juntamente com análise química (DEMATTÊ et al., 2004). E o estudo de Demattê et al. (2004) demostrou que com padrões previamente descritos por outros pesquisadores (EPIPHANIO et al., 1992; FORMAGGIO et al.,1996; DEMATTÊ et al., 2001) se classifica o solo até o segundo nível categórico apenas com o espectro do solo.

O maior desafio de estudar o comportamento espectral do solo é separar a radiância de interesse com as dos demais componentes heterogêneos presentes no solo (JENSEN, 2011; GENÚ e DEMATTÊ, 2012). Os constituintes mineralógicos influenciam as curvas espectrais dos solos 
na forma de feições de absorção, chamadas de assinatura espectral (ALVARENGA et al., 2003; NANI e DEMATTÊ, 2006). Não só os minerais, mas também as características físicas e químicas interferem no espectro eletromagnético do solo (DEMATTÊ et al., 1998; DALMOLIN et al.,2005).

De acordo com muitos autores (DEMATTÊ et al., 1998; MADEIRA NETTO e BAPTISTA, 2000; ALVARENGA et al., 2003; DALMOLIN et al.,2005; SOUSA JUNIOR et al., 2008; JENSEN, 2011; VIVALDI et al., 2013; CEZAR et al., 2013), essas propriedades físicas e químicas que controlam a curva espectral do solo são a matéria orgânica, a textura do solo, arenosa ou argilosa, a cor, a umidade e os óxidos de ferro.

Vários estudos sobre o comportamento espectral de solos e seus componentes foram compilados e sintetizados na tabela 3 .

Tabela 3: Estudos sobre comportamento espectral de solos e seus componentes.

\begin{tabular}{c|c|c}
\hline Autores & Ano & Assunto \\
\hline Sousa Júnior et al. & 2011 & Componentes do solo com o sensor Aster \\
\hline Demattê et al. & 2004 & Componentes do solo com o sensor Landsar TM \\
5
\end{tabular}




\begin{tabular}{|c|c|c|}
\hline Botelho et al. & 2006 & $\begin{array}{c}\text { Cor dos solos estudando a carta de Munsell e } \\
\text { colorimetria }\end{array}$ \\
\hline Campos et al. & 2003 & $\begin{array}{l}\text { Comparação de Índice de avermelhamento com } \\
\text { o teor de hematita }\end{array}$ \\
\hline Barbosa et al. & 2009 & Evolução geomorfológica e pedológica \\
\hline Nani e Demattê & 2006 & Espectrorradiometria laboratorial de solos \\
\hline Baptista et al. & 1998 & $\begin{array}{c}\text { Discretização do grau de intemperismo } \\
\text { utilizando o sensor AVIRIS }\end{array}$ \\
\hline Baptista e Meneses & 2009 & $\begin{array}{c}\text { Estudo de algoritmos na discretização de óxidos } \\
\text { de ferro. }\end{array}$ \\
\hline
\end{tabular}

\subsection{Umidade}

A umidade é uma propriedade físico-química do solo que influencia seu comportamento espectral. Quando um solo está úmido, ele se torna mais escuro porque a água absorve grande parte da energia radiante incidente. Dessa forma, quanto maior a umidade do solo, maior será a absorção de energia e, portanto, menor será a reflectância ao longo do espectro óptico (JENSEN, 2011).

Para Dalmolin (2005), não ocorre alterações significativas na forma das curvas espectrais em função da umidade, há apenas uma redução de albedo, entretanto as bandas de absorção de água nos comprimentos de onda de 1,4 e 1,9 $\mu \mathrm{m}$ ficam mais acentuadas.

Segundo Alvarenga (2003) e Demattê (1998), as moléculas de água podem estar presentes nas estruturas de alguns minerais, particularmente em relação à presença de minerais 1:1 e 2:1. Por exemplo, o aumento do teor de umidade em uma amostra com o argilo-mineral caulinita fez com que aumentasse a largura e a profundidade da feição de absorção centrada em 1,4 $\mu$ m, e na região de 1,9 $\mu \mathrm{m}$ isso também ocorreu, mas de forma mais modesta. Esses comprimentos de onda são devidos às vibrações de moléculas de água adsorvidas nos minerais (DEMATTÊ et al., 1998).

\subsection{Matéria Orgânica}

A matéria orgânica é um dos principais constituintes que afetam a curva espectral dos solos (DALMOLIN et al.,2005). Sua presença causa um mascaramento nas demais propriedades do solo, diminuindo as feições de absorção de outros constituintes, como o ferro total (DALMOLIN et 
al.,2005). Percebe-se essa influência na região do visível e do infravermelho próximo (ALVARENGA et al., 2003).

Para Demattê et al. (2004), Sousa Junior et al. (2008), Jensen (2011), quanto maior a quantidade de matéria orgânica, maior será a absorção de energia incidente e, consequentemente, menor a intensidade da reflectância espectral. Portanto, a matéria orgânica afeta a resposta espectral dos solos diminuindo a reflectância na faixa do espectro óptico, de 400 a $2500 \mathrm{~nm}$ (GENÚ e DEMATTÊ, 2012). Sousa Junior et al. (2011) observou correlações negativas no estudo da matéria orgânica com as leituras espectrais das oito bandas do sensor ASTER com coeficiente médio de $-0,45$.

\subsection{Cor}

A cor é o atributo mais utilizado para diferenciar os solos principalmente por sua fácil visualização e por ser referência obrigatória em qualquer descrição de solo e diferenciação dos seus horizontes (FERNANDES et al., 2004; BOTELHO et al., 2006; SOUSA JUNIOR et al., 2008). Pode-se fornecer indícios sobre composição, propriedades e origem dos solos e tendo relações com as condições ambientais que atuam na formação do solo (FERNANDES et al., 2004).

Normalmente, a cor é avaliada por meio da comparação visual de torrões de solo com padrões de cores da caderneta de Munsell e está relacionada com a presença de óxidos de ferro e matéria orgânica no solo (DALMOLIN et al.,2005; BOTELHO et al., 2006). O sistema de Munsell é definido por três parâmetros: a matiz, valor (brilho) e croma (saturação) (BOTELHO et al., 2006). A determinação da cor é feita de forma visual comparando a amostra com os padrões contidos na caderneta (CAMPOS et al., 2003). É um sistema utilizado mundialmente pelos pedólogos devido a sua fácil e rápida aplicação em trabalhos de campo. Porém, é um método de percepção visual que depende de cada observador no qual apresenta subjetividade (BOTELHO et al., 2006). Segundo Campos et al. (2003) e Botelho et al. (2006), a obtenção da cor com instrumentos de medida via sensoriamento remoto, como os espectrorradiômetros, resultam em maior precisão devido as condições serem controladas e não há a subjetividade do observador.

As informações sobre as cores estão intimamente relacionadas a outros atributos do solo que podem influenciar no resultado da cor especificamente. Esses outros atributos são a matéria orgânica e a umidade, que pode escurecer a cor verdadeira, e a presença de óxidos de ferro (GUERRA e CUNHA, 1996; CAMPOS et al., 2003; FERNANDES et al., 2004; DALMOLIN et al.,2005; BARBOSA et al., 2009). 
Para Botelho et al. (2006), a matéria orgânica confere cores escuras aos horizontes superficiais, já as cores vermelhas, amarelas e brunadas à presença de óxidos de ferro. As cores acinzentadas estão relacionadas aos ambientes de redução e remoção dos óxidos de ferro. Cores avermelhadas são atribuídas à presença do mineral hematita, cores amareladas são devido à presença do mineral goethita e solos ricos em quartzo e pobres de matéria orgânica e óxidos de ferro apresentam cores claras. Conclui-se que os maiores valores de refletância correspondem aos solos mais claros e amarelados, e os menores valores, aos mais escuros e de coloração vermelha mais intensa (FERNANDES et al., 2004).

Nos latossolos brasileiros, a cor tem importância para a classificação no segundo nível categórico. A presença de óxidos de ferro nesses solos intemperizados é quase absoluta e o uso dos dados proporcionados pela cor é garantia adicional para a quantificação desses dois minerais (FERNANDES et al., 2004). As relações funcionais entre os dados referentes a cor e aos teores de óxidos de ferro é uma alternativa simples e rápida para a semiquantificação dos teores de óxidos de ferro, hematita e goethita (CAMPOS et al., 2003).

\subsection{Textura}

A textura do solo também é uma propriedade física que interfere no comportamento espectral do solo. A granulometria e a forma das partículas determinam a quantidade de espaços porosos para serem ocupados por água e por ar.

Para Alvarenga (2003), solos de textura argilosa tendem a ter maior reflectância em virtude dos menores espaços e por ser mais densamente compactos e solos arenosos as partículas são maiores e com espaços também maiores na região do visível entre a 0,4 a $1 \mu \mathrm{m}$. Segundo Baptista e Madeira Netto (2001), a explicação para esse comportamento é que há uma relação inversa entre o tamanho das partículas e a reflectância. Quanto menor for o tamanho das partículas (argila), maior será o albedo dos solos, isto é, os materiais com partículas menores apresentam superfície mais uniforme, com menor número de poros para reter a luz incidente, enquanto a maior granulometria (areia) cria superfícies mais irregulares, com sombreamentos e maior retroespalhamento interno da luz e com isso maior reflectância (Sousa Junior et al., 2008)

Porém, não se deve esquecer que as propriedades dos solos são conjuntas e uma controla a outra e vice e versa. Jensen (2011), lembra que quanto mais fina a textura, maior a capacidade do solo em manter um alto conteúdo de umidade quando ocorrem precipitações e diminuindo a reflectância na curva espectral. Outros constituintes dos solos que conjugados com a granulometria 
podem gerar resultados diferentes é a matéria orgânica e os óxidos de ferro. Nani e Demattê (2006) observaram que s solos com textura argilosa e maiores teores de ferro têm os pontos concentrados em reflectâncias mais baixas. Solos com alto teor de matéria orgânica, argila e óxidos de ferro resultam na diminuição da intensidade de reflectância, em oposição aos solos arenosos e com alto teor de quartzo que resultam no aumento da reflectância (SOUSA JUNIOR et al., 2008; GENÚ e DEMATTÊ, 2012). Isso ocorre em virtude dos solos arenosos serem ricos em quartzo e geralmente apresentarem baixos teores de matéria orgânica e óxidos de ferro (DALMOLIN et al.,2005).

\subsection{Relação Mineralógica}

Para Madeira Netto e Baptista (2000), as relações definidas entre alguns componentes físicoquímicos e espectrais dos solos são normalmente válidas para condições e que devem ser definidas experimentalmente.

Para a análise quantitativa e qualitativa, o estabelecimento de relações entre os dados referentes a cor e aos teores minerais é uma alternativa simples e prática para a sem quantificação ou quantificação dos teores mineralógicos (CAMPOS et al., 2003). Existem vários métodos para identificação e quantificação mineralógica de solos intemperizados (MARTINS, 2000). Por exemplo, alguns minerais são utilizados para avaliar o grau de alteração do solo, como os minerais de alumínio, caulinita e gibbsita, são utilizados para calcular o índice Ki e os minerais de ferro, goethita e hematita, são utilizados para calcular o índice Kr. Esses índices são relações moleculares sílica/alumínio $\left(\mathrm{SiO}_{2} / \mathrm{Al}_{2} \mathrm{O}_{3}=\mathrm{Ki}\right)$ e sílica/óxidos de ferro e alumínio $\left(\mathrm{SiO}_{2} / \mathrm{Al}_{2} \mathrm{O}_{3}+\mathrm{Fe}_{2} \mathrm{O}_{3}=\mathrm{Kr}\right)$ (KER, 1997).

O estudo de certas feições ou bandas de absorção de energia em determinados comprimentos de onda ou em regiões espectrais bem específicas, chamadas de assinaturas ou feições espectrais, é um modo de extrair informações sobre os solos por meio do sensoriamento remoto (DEMATTÊ et al., 2003). Essas bandas de absorção ocorrem ao longo do espectro óptico e que podem ser usadas para identificar diferentes minerais do solo como os óxidos de ferro e os argilominerais (DALMOLIN et al.,2005). Os minerais possuem bandas específicas de absorção em determinado comprimento de onda e que está relacionada a sua presença no material estudado.

As relações mineralógicas são desenvolvidas entre o ponto de inflexão, ou seja, ponto de mínima reflectância, no qual ocorre a feição de absorção em um determinado comprimento de onda e os pontos de máxima situado entre a feição. Esses pontos são necessários para a medição da intensidade de absorção (BAPTISTA et al., 1998). 
Um exemplo de relação mineralógica é a da caulinita e gibbsita desenvolvida por Baptista et al. (1998). Ele desenvolveu o índice RCGBscale, por meio das imagens scale do algoritmo Spectral Feature Fitting, que determina a relação entre a caulinita e gibbsita. Logo depois, Baptista (2000) por meio dos dados do sensor hiperespectral AVIRIS desenvolveu o índice espectral RCGb que permite a espacialização e quantificação da relação caulinita / (caulinita + gibbsita).

\subsubsection{Hematita e Goethita}

No espectro eletromagnético do solo, a hematita e a goethita são determinadas e também diferenciadas na região do visível e do infravermelho próximo (DALMOLIN et al.,2005; BAPTISTA e MENESES, 2009; GENÚ e DEMATTÊ, 2012; CEZAR et al., 2013). Sherman e Waite (1985) diferenciaram esses óxidos de ferro na região do visível pela cor que é determinada pela transição de efeito cristalino $2(6 \mathrm{~A} 1) \Rightarrow 2(4 \mathrm{~T} 1)$ que ocorre em $0,48 \mu \mathrm{m}$ e $0,53 \mu \mathrm{m}$, respectivamente (Figura 2).

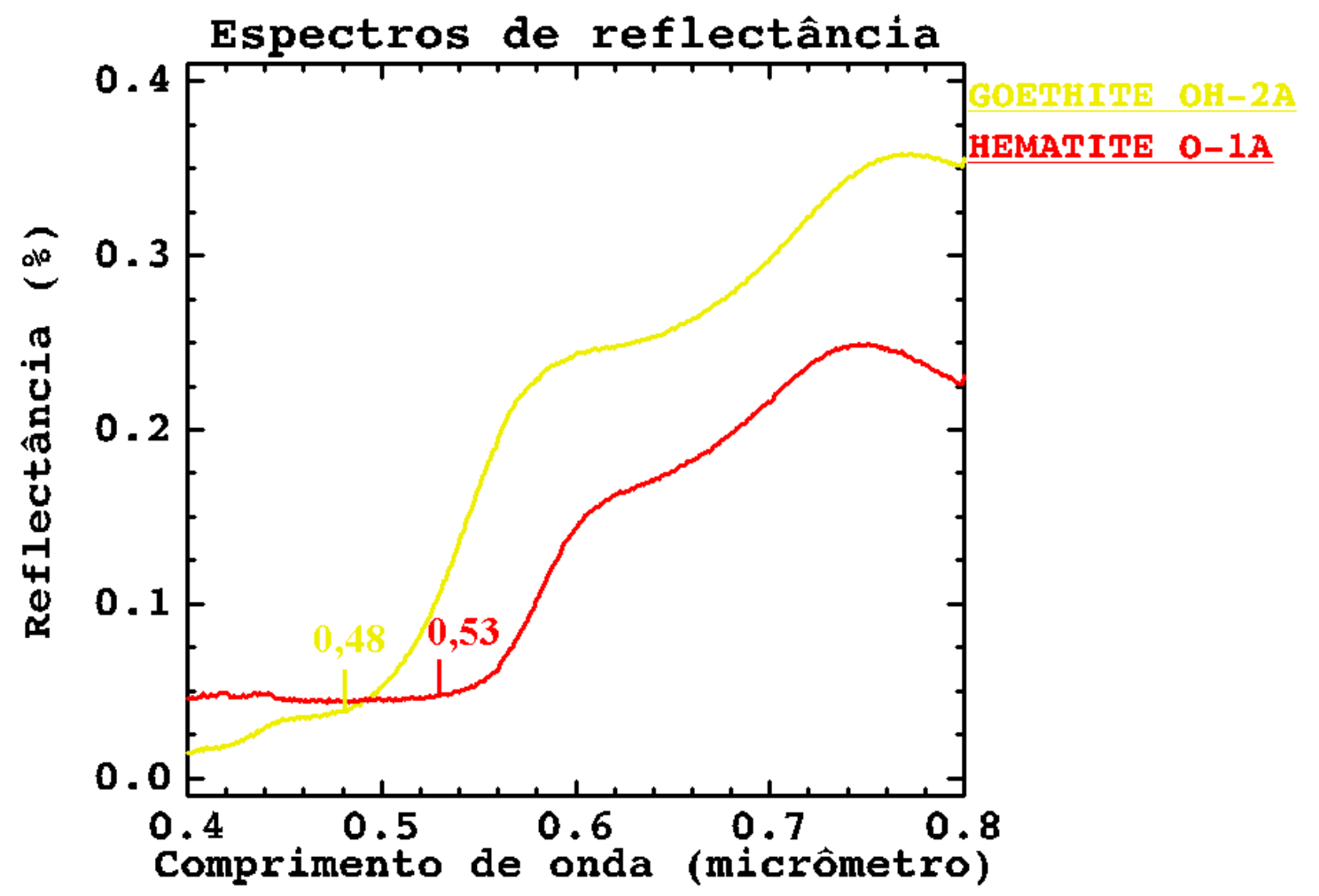

Figura 2: Posicionamento das transições de hematita e goethita da biblioteca espectral do Jet Propulsion Laboratory (JPL)

De acordo com Baptista e Meneses (2009), nota-se que a grande diferença entre esses dois espectros ocorre na banda centrada em $0,56 \mu \mathrm{m}$, na qual ocorre a inflexão da feição da hematita e ocorre um pico de reflectância na goethita. A cor da goethita e da hematita são devido a seu pico 
de reflectância na região do amarelo e do vermelho, respectivamente na região do visível. O espectro da goethita apresenta maior reflectância na região de 0,48 a $0,9 \mu \mathrm{m}$ do que da hematita (DALMOLIN et al.,2005)

Fernandes et al. (2004) comparou os tipos de solos com o percentual de goethita e hematita, bem como com sua relação $\mathrm{Hm} / \mathrm{Hm}+\mathrm{Gt}$ e concluiu que diferentes índices de avermelhamento avaliados por eles, a partir de observações de campo correlacionaram-se significativamente com a relação $\mathrm{Hm} /(\mathrm{Hm}+\mathrm{Gt})$ e com o teor de hematita.

\subsection{2. Índices simulados pelo Thematic Mapper (TM)}

Madeira Netto (1993), estudou a possibilidade de substituir os comprimentos de ondas espectrais do espectro de laboratório, que estão relacionados com os principais constituintes mineralógicos dos latossolos, pelas bandas reamostradas a partir de uma simulação das bandas do Landsat 5 (TM), com o objetivo de mostrar que estes mesmos parâmetros de laboratório são ainda válidos considerando apenas as partes do espectro, correspondente as bandas espectrais.

A equação 1 representa o algoritmo utilizado por Madeira Netto (1993) para reamostrar os espectros de reflectância difusa obtidos em laboratório para as amostras de solo para as respostas espectrais das bandas do Landsat TM 5 (MADEIRA NETTO, 1993).

$$
S T M i=\frac{\sum_{\lambda 1 i}^{\lambda 2 i} R \lambda * S \lambda}{\sum_{\lambda 1 i}^{\lambda 2 i} S \lambda} * 255
$$

Sendo que,

$\mathrm{STMi}=$ bandas espectrais de reflectância TM $(\mathrm{i}=1,2,3,4,5,7)$;

$\mathrm{R} \lambda=$ reflectância difusa no comprimento de onda $\lambda$;

$\mathrm{S} \lambda=$ valor sensibilidade da função do sensor TM no comprimento de onda $\lambda$

$\lambda$ li e $\lambda 2 \mathrm{i}=$ limites inferiores e superiores da banda espectral.

Madeira Netto (1993) desenvolveu um índice espectral com bandas simuladas do sensor Landsat TM 5 para verificar a proporção relativa entre os óxidos de ferro. Esse índice pode ser comparado ao matiz do solo e também a composição mineralógica. Ele utilizou as bandas simuladas do vermelho (STM3) e verde (STM2) para essas amostras de solo que têm matiz que variam do amarelo ao vermelho. $\mathrm{O}$ índice férrico ou índice de matiz proposto por Madeira Netto (1993) é o IFe (STM) detalhado na equação 2: 


$$
I F e(S T M)=\frac{S T M 3-S T M 2}{S T M 3+S T M 2}
$$

Madeira Netto (1993) verificou a existência de uma boa correlação entre o índice IFe(STM) e a relação $H m / G t+H m$, o que foi bastante esperado por ser uma região que reflete a cor dos minerais estudados.

Depois de vários testes, Madeira Netto (1993) também desenvolveu um índice proporcional aos teores de hematita (Hm\%) com as bandas 1, 2 e 3 simuladas do TM5, denominado de apresentado na equação 3:

$$
\operatorname{IHm}(S T M)=\frac{S T M 3^{2}}{S T M 1 * S T M 2^{3}}
$$

Madeira Netto (1993) validou esses índices espectrais com os dados químicos e mineralógicos e deram boas correlações. O coeficiente de correlação (r) de Pearson do índice IFe(STM) com a relação $H m / G t+H m$ foi de 0,934 e a correlação do índice IHm(STM) com a teor de Hm\% foi de 0,954 .

Tabela 4: Coeficiente de correlação de Pearson (r)

\begin{tabular}{lcc}
\hline & $\underline{\mathbf{H m}}$ & Hm \\
\hline IFe(STM) & 0,934 & $\%$ \\
\hline IHm(STM) & 0,849 & 0,727 \\
\hline
\end{tabular}

Adaptado de Madeira Netto (1993)

\subsubsection{RHGtmunsell}

Para quantificação do teor de hematita e goethita, Santana (1984) e seguido por Martins (2000) propuseram uma relação hematita/(hematita+goethita) com base na carta de Munsell. Para relembrar, a carta de Munsell é definida por meio dos valores de matiz, valor (brilho) e croma (saturação). Primeiramente, calcula-se o fator de vermelho que leva em conta o croma (C), o valor (V) e o complementar dos matizes $\left(\mathrm{M}^{*}\right)$, todos obtidos visualmente por meio da tabela de cores de Munsell (Equação 4).

$$
\mathrm{FV}=\frac{\mathrm{M} *+\mathrm{C}}{\mathrm{V}}
$$

Equação 4 
De acordo com Martins (2000), os matizes (M) dos solos com hematita e goethita são amarelo e vermelho (YR) ou somente vermelho $(R)$. Os valores de $M^{*}$ são complementares dos matizes (M) quando são misturas de amarelo e vermelho, isso significa que, por exemplo, para uma cor de 2,5 YR, o valor de $M^{*}$ é igual a 7,5. A referência dessa complementação é o 10R. Em contrapartida, para matiz apenas com vermelho, os valores de $M^{*}$ são os mesmos de $\mathrm{M}$, como por exemplo para 10R, o M* é 10.

Para a determinação do índice de relação hematita e goethita (RHGt) a partir da observação das cores no sistema de Munsell, necessita do fator de vermelho (Equação 5).

$$
\text { RHGtmunsell }=\left(\frac{\mathrm{FV}-3,5}{8,33}\right) \quad \text { Equação } 5
$$

Fernandes et al. (2004) estudou a correlação entre a relação $\mathrm{Hm} / \mathrm{Hm}+\mathrm{Gt}$ com o fator de vermelho descrito por Santana (1984) em que gerou um coeficiente de determinação de 0,86 .

\section{CONSIDERAÇÕES FINAIS}

O solo é um elemento que sempre está em constante evolução, mesmo que seja em um tempo considerado grande e que depende de alguns fatores da natureza. Ele é influenciado pelo clima, pelos organismos, pelo material de origem, pelo tempo e pelo relevo. Quando esses fatores mudam, dependendo da região onde se encontra, muda-se também o tipo de solo, pois sua classificação depende de fatores físicos, químicos e mineralógicos que diferenciam de acordo com a região.

O sensoriamento remoto é uma ferramenta que analisa alvos remotamente, sem a necessidade de tocá-los fisicamente. A interpretação dos dados de sensoriamento remoto pode ser feita física e quimicamente. Nos casos do solo, consegue-se analisar mineralogicamente. Um dos alvos mais complexos de ser compreendido espectralmente é o solo porque ele possui vários constituintes visto em conjunto (JENSEN, 2011).

O comportamento espectral do solo depende das suas propriedades. E cada propriedade tem uma atuação diferente na curva espectral e é o que dificulta a processo de análise. O que muitos pesquisadores (DEMATTÊ et al., 2004; DALMOLIN et al. 2005; SOUSA JÚNIOR et al., 2011) estudam é as propriedades individualmente para saber como cada uma pode influenciar no espectro do solo. E também os principais minerais nele associados. Nos solos tropicais, os minerais responsáveis pela cor dos solos são a hematita e goethita. Muitos estudiosos desenvolveram índices e relações (SANTANA, 1984; MADEIRA NETTO, 1993; MARTINS, 2000) para quantificação 
dos óxidos de ferro nos solos, desde índices espectrais, relações com a carta de Munsell e relações químicas.

De forma geral, o comportamento espectral de solos é uma área que deve ser mais estudada e incentivada já que a análise química é muito cara economicamente, devido aos reagentes, e para o meio ambiente, com o surgimento de muito resíduos ao final de cada processo (CEZAR et al., 2013) e muito onerosa (SOUSA JUNIOR et al., 2011). É importante o conhecimento de como cada componente do solo se comporta na curva espectral e, com isso, tendo um auxílio nas classificações dos solos e no seu mapeamento (DEMATTÊ et al., 2004).

\section{REFERÊNCIAS BIBLIOGRÁFICAS}

ALBA, J. M.F.; FLORES, C. A.; GARRASTAZU, M. C. Espectrorradiometria como instrumento de caracterização de solos de terras baixas. Embrapa Florestas. 2008.

ALBA, J.M.F. O Uso da Espectrorradiometria no Mapeamento de Solos: Estudo de Caso na Estação Experimental Terras Baixas. Embrapa Clima Temperado. 2007

ALMEIDA, W.S.; MOREIRA SOUZA, N. Avaliação das informações espectrais dos dados WorldView 2/Digital Globe para classificação temática de uso e cobertura do solo. 201. Anais XV Simpósio Brasileiro de Sensoriamento Remoto - SBSR, Curitiba, PR, Brasil. 2011.

ALVARENGA, B.S.; D’ARCO, E.; ADAMI, M.; FORMAGGIO, A.R. O ensino de conceitos e práticas de espectrorradiometria laboratorial: estudo de caso com solos do estado de São Paulo. Anais XI SBSR, Belo Horizonte, Brasil, INPE, p. 739-747. 2003.

ALVES, M.E.; MASCARENHAS, Y.P.; VAZ, C.M.P. Comparação de procedimentos de quantificação de caulinita e gibbsita na fração argila desferrificada de latossolos. Revista Brasileira de Ciências do Solo, 32:569-577, 2008.

BAPTISTA, G.M.M.; MENESES, P.M. Identificação de sesquióxidos de ferro da fração argila de solos tropicais por meio de decomposição espectral linear dos dados do sensor AVNIR-2 do sistema ALOS. Anais XIV Simpósio Brasileiro de Sensoriamento Remoto, Natal, Brasil. 2009.

BAPTISTA, G.M.M.; MADEIRA NETTO, J.S. MENESES, P.R. Mapeamento dos teores de argila de solos tropicai, por meio de dados de sensoriamento remoto multiespectral (ASTER) e hiperespectral (AVIRIS). Sociedade \& Natureza, Uberlândia, 12(23): 133-146, jan./jun. 2000. 
BAPTISTA, G.M.M.; MADEIRA NETTO, J.S.; MENESES, P.R. Determinação da Relação Sílica Alumina a partir dos Dados do Sensor AVIRIS (JPL/NASA), para Discretização Espacial do Grau de Intemperismo de Solos Tropicais. Anais IX Simpósio Brasileiro de Sensoriamento Remoto, Santos, Brasil. 1998.

BARBOSA, I.O.; LACERDA, M.P.C.; BILICH, M.R. Relações pedomorfogeológicas nas chapadas elevadas do distrito federal. Revista Brasileira de Ciência do Solo, 33:1373-1383, 2009.

BOTELHO, M.R.; DALMOLIN, R.S.D.; PEDRO, F.A.; AZEVEDO, A.C.; RODRIGUES, R.B.; MIGUEL, P. Medida da cor em solos do Rio Grande do Sul com a carta de Munsell e por colorimetria. Ciência Rural, v.36, n.4, jul-ago, 2006.

BRADY, N.C.; WELL, R.R. Elementos da Natureza e Propriedades dos Solos. Editora Bookman. $3^{\text {a }}$ Edição. 2013.

CAMARGO, L.A.; MARQUES JÚNIOR.J.; PEREIRA, G.T.; HORVAT, R.A. Variabilidade espacial de atributos mineralógicos de um latossolo sob diferentes formas do relevo. I mineralogia da fração argila Revista Brasileira de Ciências do Solo, 32:2269-2277, 2008.

CAMPOS, P.M.; LACERDA, M.P.C.; LOPES SILVA, C.; CAROLINO SÁ, M.A.; GOMES SOUSA, D.M. Drenagem interna como fator de diferenciação de Latossolos do Distrito Federal. Pesquisa agropecuária brasileira, Brasília, v.45, n.3, p.306-314, mar. 2010.

CAMPOS, R.C.; DEMATTÊ, J.A.M.; QUARTAROLI, C.F. Determinação indireta do teor de hematita no solo a partir de dados de colorimetria e radiometria. Pesquisa agropecuária brasileira, Brasília, v. 38, n. 4, p. 521-528, abr. 2003.

CAVALVANTE, L.B.; INÁCIO, A.S.; GOMES, H.B. Utilização de imagens do satélite WorldView-2 e do sensor ASTER para análise de bacias hidrográficas - estudo de caso: bacia do tabuleiro do Martins, Maceió/AL. XX Simpósio Brasileiro de Recursos Hídricos. Bento Gonçalves RS. Novembro de 2013.

CEZAR, E.; NANNI, M.R.; CHICATI, M.L.; SOUZA JÚNIOR, I.G.; COSTA, A.C.S. Uso de dados espectrais para estimar a relação entre óxidos de ferro e minerais 2:1 com suas respectivas reflectâncias. Semina: Ciências Agrárias, Londrina, v. 34, n. 4, p. 1479-1492, jul./ago. 2013. 
CHANDER, G.; MARKHAM, B. Revised Landsat-5 TM Radiometric Calibration Procedures and Post calibration. Dynamic Ranges. IEEE transactions on geoscience and remote sensing, vol. 41, no. 11, November 2003.

CORREA, M.M.; KER, J.C.; BARRÓN, V.; FONTES, M.P.F.; TORRENT, J.; CURI, N. Caracterização de óxidos de ferro de solos do ambiente tabuleiros costeiros. Revista Brasileira de Ciências do Solo, 32:1017-1031, 2008.

DALMOLIN, R.S.D.; KLAMT, C.N.G.E.; DICK, D.P. Relação entre os constituintes do solo e seu comportamento espectral. Ciência Rural, Santa Maria, v.35, n.2, p.481-489, mar-abr, 2005.

DEMATTÊ, J. A. M.; TOLEDO, A. M. A.; SIMÕES, M. S. Metodologia para reconhecimento de três solos por sensores: laboratorial e orbital. Revista Brasileira de Ciência do Solo, 28:877-889, 2004.

DEMATTÊ, J.A.M., DEMATTÊ, José Luiz, CAMARGO, W., FIORIO, Peterson, NANNI, Marcos. Remote sensing in the recognition and mapping of tropical soils developed on topographic sequences. Mapping Sciences and Remote Sensing, v.38, p.79 - 102, 2001.

DEMATTÊ, J.A.M.; EPIPHANIO, J.C.N.; FORMAGGIO, A.R. Influência da matéria orgânica e de formas de ferro. Bragantia, Campinas, v.62, n.3, p.451-464, 2003.

DEMATTÊ, J.A.M.; SOUSA, A.A.; NANNI, M.R. Avaliação espectral de amostras de solos e argilominerais em função de diferentes níveis de hidratação. Anais IX Simpósio Brasileiro de Sensoriamento Remoto, Santos, Brasil, 11-18 setembro 1998, INPE, p. 1295-1298.

DEMATTÊ, J.A.M.; GENÚ, A.M.; FIORIO, P.R.; ORTIZ, J.L.; MAZZA, J.A. LEONARDO, H.C.L. Comparação entre mapas de solos obtidos por sensoriamento remoto espectral e pelo método convencional. Pesquisa agropecuária brasileira, Brasília, v.39, n.12, p.1219-1229, dez. 2004.

DEMATTÊ, J.A.M.; SILVA, M. L. S.; ROCHA, G.C.; CARVALHO, L.A.; FORMAGGIO, A.R.; FIRME, L.P. Variações espectrais em solos submetidos à aplicação de torta de filtro. Revista Brasileira de Ciências do Solo, 29:317-326, 2005.

DIGITAL GLOBE. White Paper: The Benefits of the 8 Spectral Bands of WorldView-2. Corporate (U.S.) 303.684.4561 or 800.496.1225. 2010. 
SANTOS, H. G.; $\quad$ ALMEIDA, J. A.; OLIVEIRA, J. B.; LUMBRERAS, J. F.; ANJOS, L. H. C.; COELHO, M. R.; PAULO KLINGER TITO JACOMINE; CUNHA, T. J. F.; OLIVEIRA, V. A. Sistema Brasileiro de Classificação de Solos. $3^{\text {a }}$ edição. 2013. Embrapa. 353 páginas.

EPIPHANIO, J.C.N.; FORMAGGIO, A.R.; VALERIANO, M.M.; OLIVEIRA, J.B. Comportamento espectral de solos do estado de São Paulo. São José dos Campos-SP, INPE. 1992.

FERNANDES, R. B. A.; BARRÓN, V.; TORRENT, J.; FONTES, M.P.F. Quantificação de óxidos de ferro de latossolos brasileiros por espectroscopia de refletância difusa. Revista Brasileira de Ciência do Solo, 28:245-257, 2004.

FIORIO, P.R.; DEMATTÊ, J.A.M.; NANNI, M.R.; FORMAGGIO, A.R. Diferenciação espectral de solos utilizando dados obtidos em laboratório e por sensor orbital. Bragantia, Campinas, v.69, n.2, p.453-466, 2010.

FONTES, M.P.F.; CAMARGO, O.A.; SPOSITO, G. Eletroquímica das partículas coloidais e sua relação com a mineralogia de solos altamente intemperizados. Scientia Agricola, v.58, n.3, p.627646, jul./set. 2001.

FORMAGGIO, A.R.; EPIPHANIO, J.C.N.; VALERIANO, M.M.; OLIVEIRA, J.B. Comportamento espectral $(450-2450 \mathrm{~nm})$ de 14 classes de solos tropicais brasileiros. Revista Brasileira de Ciência do Solo, 20: 467-474. 1996.

GENÚ, A.M.; DEMATTÊ J.A.M. Espectrorradiometria de solos e comparação com sensores orbitais. Bragantia, Campinas, v. 71, n. 1, p.82-89, 2012.

GHIDIN, A.A; MELO, V.F.; LIMA, V.C.; LIMA, J.M.J.C. Topossequência de latossolos originados de rochas basálticas no paraná. I - mineralogia da fração argila. Revista Brasileira de Ciências do Solo, 30:293-306, 2006.

GOMES, J. B. V.; CURI, N.; SCHULZE, D. G.; MARQUES, J. J. G. S. M.; KER, J. C.; MOTTA, P. E. F. Mineralogia, morfologia e análise microscópica de solos do bioma cerrado. Revista Brasileira de Ciências do Solo, 28:679-694, 2004.

GUERRA, A.J.T.; CUNHA, S.B. Geomorfologia e Meio Ambiente. Editora Bertrand, Brasil, 1996. 
INDA JUNIOR, A.V.; KÄMPF, N. Variabilidade de goethita e hematita via dissolução redutiva em solos de região tropical e subtropical. Revista Brasileira de Ciências do Solo, 29:851-866, 2005

JACOMINE, P.K.T. A Nova Classificação Brasileira De Solos. Anais da Academia Pernambucana de Ciência Agronômica, Recife, vols. 5 e 6, p.161-179. 2009.

JENSEN, J.R. Sensoriamento Remoto do Ambiente: uma perspectiva em recursos terrestres. Editora Parêntese. 2011.

KER, J.C. Latossolos do Brasil: uma revisão. GEONOMOS, 5(1):17-40.1997.

KUMAR, M.; ROY, P.S. Utilizing the potential of World View -2 for discriminating urban and vegetation features using object based classification techniques. Journal of the Indian Society of Remote Sensing 41(3):711-717 DOI 10.1007/s12524-012-0257-9. 2013.

LEE, Z.; WEIDEMANN, A.; ARNONE, R. Combined Effect of Reduced Band Number and Increased Bandwidth on Shallow Water Remote Sensing the Case of WorldView 2. Ieee Transactions On Geoscience And Remote Sensing. 2013.

MADEIRA NETTO, J.S.; BAPTISTA, G.M.M. Reflectância espectral de solos. Planaltina: Embrapa Cerrado. ISSN 1517-5111. N. 25. 2000.

MELO, V. F.; FONTES, M. P. F.; NOVAIS, R. F.; SINGH, B.; SCHAEFER, C. E. G. R. Características dos óxidos de ferro e de alumínio de diferentes classes de solos. Revista Brasileira de Ciências do Solo, 25:19-32, 2001.

MIURA, A. K.; CORAZZA, R.; WIEFELS, A. C.; NOVAES, M. R.; SANTOS, S. B.; FORMAGGIO, A. R. Uso da espectrorradiometria de laboratório como ferramenta didática em apoio ao ensino do comportamento espectral do solo. In: $7^{\text {a }}$ Jornada de Educação em Sensoriamento Remoto no Âmbito do MERCOSUL, 2009, Santa Maria / RS. $7^{\text {a }}$ Jornada de Educação em Sensoriamento Remoto no Âmbito do MERCOSUL, 2009.

MOTTA, P. E. F. Mineralogia, morfologia e análise microscópica de solos do bioma cerrado. Revista Brasileira de Ciências do Solo, 28:679-694, 2004. 
NANNI, M.R.; DEMATTÊ, J.A.M. Comportamento da linha do solo obtida por espectrorradiometria laboratorial para diferentes classes de solo. Revista Brasileira de Ciências do Solo, 30:1031-1038, 2006.

NOVACK, T.; RIBEIRO, B.M.G; KUX, H.J.H. Análise dos dados do satélite WorldView-2 para a discriminação de alvos urbanos semelhantes com base em algoritmos de seleção de atributos. Anais XV Simpósio Brasileiro de Sensoriamento Remoto - SBSR, Curitiba, PR, Brasil, 30 de abril a 05 de maio de 2011, INPE p.7815. 2011.

NOVO, E.M.L.M. Sensoriamento Remoto: princípios e aplicações. $4^{\mathrm{a}}$ edição revista. Editora Edgard Blucher Ltda. São Paulo. 2010.

OLIVEIRA, L.C.A.; FABRIS, J.D.; PEREIRA, M.C.; Óxidos de Ferro e suas Aplicações em Processos Catalíticos: uma revisão. Química Nova, Vol. 36, No. 1, 123-130, 2013.

PADWICK, C.; DESKEVICH, M.; PACIFICI, F.; SMALLWOOD, S. WorldView 2 PanSharpening. Annual Conference, San Diego, Califórnia. ASPRS 2010.

PEDROSA, S.A.; MENESES, P.R.; CARMELO, A.C. Espectrorradiometria de reflectância de rochas carbonáticas na região do infravermelho de ondas curtas. Revista Brasileira de Geociências. 40(4): 593-599. Dezembro de 2010.

PEDROTTI, A.; FERREIRA, M. M.; CURI, N.; SILVA, M. L. N.; LIMA, J. M.; CARVALHO, R. Relação entre atributos físicos, mineralogia da fração argila e formas de alumínio no solo. Revista Brasileira de Ciência do Solo, 27:1-9, 2003.

REATTO, A.; MARTINS, E.S.; FARIAS, M.F.R.; SILVA, A.V.; CARVALHO JÚNIOR, O.A. Mapa Pedológico Digital - SIG Atualizado do Distrito Federal Escala 1:100.000 e uma Síntese do Texto Explicativo. Ministério da Agricultura, Pecuária e Abastecimento \& Embrapa. Documentos 120. ISSN 1517-5111. Junho, 2004.

REATTO, A.; BRUAND, A.; MARTINS, E.S.; MULLER, F.; MEDRADO DA SILVA, E.; CARVALHO JR, O. A.; BROSSARD, M. Variation of the kaolinite and gibbsite content at regional and local scale in Latosols of the Brazilian Central Plateau. Comptes Rendus Geoscience 340 (2008) 741-748. 2008. 
REGITANO, J.B; ALLEONI, L.R.F; TORNISIELO, L.V. Atributos de Solos Tropicais e a Sorção De Imazaquin. Scientia Agricola, v.58, n.4, p.801-807, out./dez. 2001.

SAMBATTI, J. A.; COSTA, A. C. S.; MUNIZ, A. S.; SENGIK, E.; SOUZA JUNIOR, I. G.; BIGHAM, J. M. Relações entre a substituição isomórfica de Fe por Al e as características químicas e mineralógicas de hematitas sintéticas. Revista Brasileira de Ciência do Solo, 26:117-124, 2002.

SHERMAN, D.M.; WAITE, T.D. Electronic spectra of Fe3+ oxides and oxide hydroxides in the near IR to near UV. American Mineralogist. V.70, p.1262-1269, 1985.

SILVA JÚNIOR, J.F.; SIQUEIRA, D.S.; MARQUES JÚNIOR, J.; PEREIRA, G.T. Classificação numérica e modelo digital de elevação na caracterização espacial de atributos dos solos. Revista Brasileira de Engenharia Agrícola e Ambiental, v.16, n.4, p.415-424, 2012.

SOUSA JÚNIOR, J.G.; DEMATTÊ, J.A.M.; ARAÚJO, S.R. Modelos espectrais terrestres e orbitais na determinação de teores de atributos dos solos: potencial e custos. Bragantia, Campinas, v. 70, n. 3, p.610-621, 2011.

SOUSA JUNIOR, J.G.A.; DEMATTÊ, J.A.M.; GENÚ, A.M. Comportamento espectral dos solos na paisagem a partir de dados coletados por sensores terrestre e orbital. Revista Brasileira de Ciências do Solo, 32:727-738, 2008.

VENDRAME, P.R.S.; EBERHARDT, D.N.; BRITO, O.R.; MARCHÃO, R.L.; QUANTIN, C.; BECQUER, T. Formas de ferro e alumínio e suas relações com textura, mineralogia e carbono orgânico em Latossolos do Cerrado. Semina: Ciências Agrárias, Londrina, v. 32, suplemento 1, p. 1657-1666, 2011.

VIEIRA SOUZA, U.D.; ALFAYA, F.A.V.S; KUX, H.J.H. Contribuição das novas bandas espectrais do satélite Worldview-II para a classificação de tipos vegetais em habitats costeiros: resultados iniciais. Anais XV Simpósio Brasileiro de Sensoriamento Remoto - SBSR, Curitiba, PR, Brasil. 2011.

VIVALDI, D.D. BAPTISTA, G.M.M. MENESES, P.R. Avaliação dos processamentos de crosstalk e de correção atmosférica em dados ASTER para identificação da relação mineralógica caulinita/(caulinita + gibbsita) em solos no município de São João d'Aliança (GO). Brazilian Jornal of Geology. 43(3): 571-582. Setembro de 2013. 
Capítulo 2: POTENCIALIDADE DO SENSOR WORLDVIEW II PARA DETECÇÃO DE HEMATITA E GOETHITA EM SOLOS TROPICAIS. 


\section{RESUMO}

Com o advento de novos sistemas sensores no sensoriamento remoto tem-se a necessidade de investigação das suas potencialidades para discriminação dos alvos, como os minerais do solo. $\mathrm{O}$ objetivo desse trabalho foi simular as bandas do sensor WorldView II, a partir dos espectros obtidos em laboratório por Madeira Netto (1993), visando estudar sua potencialidade na detecção dos óxidos de ferro, além de propor um índice espectral baseado na profundidade de feição espectral denominado RHGtPf. Os índices IFe e IHm desenvolvidos por Madeira Netto para as bandas do sensor Landsat TM 5 foram ajustados para o WorldView II visando testar a potencialidade da nova banda do amarelo. Os resultados gerados mostraram que o amarelo degrada em $2 \%$ em relação a banda do vermelho. Isso se deve ao fato da quantificação e identificação do mineral ser localizada na feição de absorção e não na reflectância, isso só é melhorado na visualização da cor. Um novo índice espectral, RHGtPF baseado na profundidade de feição com o contínuo espectral removido, foi proposto visto que as novas bandas do sensor WorldView II do azul costal e do amarelo, permitem individualizar melhor as feições de absorção da goethita e da hematita separadamente. Observou que o novo índice é similar estatisticamente com a relação $\mathrm{Hm} / \mathrm{Hm}+\mathrm{Gt}$, porém não é similar com essa relação mineralógica obtida por meio da cor de Munsell.

Termos para indexação: Relação mineralógica, sensoriamento remoto, índices espectrais

\section{ABSTRACT}

With the advent of new sensors systems, there is a need to investigate their potentials for spatial discrimination of the objects, for example, the mineral constituents of a soil spot. The objective of this study was to simulate the bands of the WorldView II sensor as from of the laboratory specters obtained by Madeira Netto (1993), aiming to study your potentiality in detection of iron oxides, besides to proposing a spectral index based on the depth of spectral feature called RHGtPf. The IFe and IHm indices developed by Madeira Netto for bands of Landsat TM 5 sensor were adjusted for WorldView II to test the potential of the new band of yellow. The results showed that the yellow degrades to $2 \%$ as for the band of red. This is because the quantification and identification of the mineral be located in the feature of absorption and not in reflectance, it is only improved in the visualization of color. A new spectral index, RHGtPF based on depth feature with the continuous spectral removed, was proposed as the new bands of WorldView II sensor costal blue and yellow, allow better individualize the features of absorption of goethite and hematite separately. Observed 
that the new index is statistically similar with to the ratio $\mathrm{Hm} / \mathrm{Gt}+\mathrm{Hm}$, nevertheless is not similar with this mineralogical relation obtained by means of the Munsell color.

Index terms: Mineralogical relation, remote sensing, spectral indices

\section{INTRODUÇÃO}

Os solos tropicais apresentam-se bastante intemperizados devido as altas temperaturas e as oscilações de umidade que influenciam diretamente na região a que estão inseridos (JACOMINE, 2009). Os latossolos, que representam $40 \%$ do planalto central do Brasil (REATTO et al., 2008) e $60 \%$ dos solos brasileiros (SCHAEFER et al.,2008), são os solos mais comuns na região tropical. Eles apresentam minerais intemperizados ou secundários que são: na fração argila, os óxidos de ferro (hematita e goethita), óxidos de alumínio (gibbsita) e minerais de argila (argilominerais) do grupo 1:1 (caulinita) (BAPTISTA et al., 2011; BOTELHO et al., 2006; NANI e DEMATTÊ, 2006; ALVES et al., 2008; CORREA et al., 2008; VENDRAME et al., 2011).

Os óxidos de ferro (hematita e goethita) são encontrados em solos intemperizados. Estudos demonstram que esses minerais estão ligados a cor do solo e o regime pedohídrico da região, ou seja, a relação entre a topossequência com o nível do lençol freático e diferentes estados químicos de oxirredução (INDA JUNIOR e KÄMPF, 2005; CAMARGO et al., 2008; REATTO et al., 2008; BARBOSA et al., 2009; CAMPOS et al., 2010; BAPTIST et al., 2011; SILVA JUNIOR et al., 2012).

A identificação e a quantificação desses minerais são muito estudadas nas diferentes áreas da ciência que estudam os solos (SANTANA, 1984; MADEIRA NETTO, 1993; BAPTISTA et al., 2011). Dentre as diversas áreas que atuam na compreensão da cobertura pedológica encontra-se o Sensoriamento Remo, por meio do estudo de seu comportamento espectral, bem como a compreensão de como os constituintes e propriedades do solo podem influenciar na sua curva espectral (DALMOLIN et al.,2005; SOUSA JUNIOR et al., 2008; GENÚ \& DEMATTÊ et al., 2011; VIVALDI et al., 2013; CEZAR et al., 2013; ALVES et al., 2015)

Com o advento de novos sistemas sensores tem-se a necessidade de investigação das suas potencialidades para discriminação dos alvos. Estudos dos componentes dos solos com a potencialidade de sensores para identifica-los é crescente (DÊMATTÊ et al., 2004; SOUSA JÚNIOR et al.,2011), inclusive estudos de minerais intemperizados (MADEIRA NETTO, 1993; 
BAPTISTA et al., 2011) e óxidos de ferro (LAGACHERIE et al., 2008; BALENA et al., 2011; GERIGHAUSEN et al., 2012; CAMARGO et al., 2014; BAHIA et al., 2015) nos solos tropicais.

Madeira Netto (1993) estudou vários tipos de solos do Brasil, por meio da sua composição química e da técnica de espectrorradiometria de solos. Por meio dos espectros de reflectância difusa por ele obtidos, foi possível a determinação de dois índices espectrais simulados para as bandas do Landsat TM5, denominados por Índice férrico (IFe (STM)) e Índice hematita (IHm (STM)), nos quais é possível verificar alta correlação com a relação $\mathrm{Hm} / \mathrm{Hm}+\mathrm{Gt}$ e o percentual de hematita, respectivamente, validando-os por meio dos dados químicos de laboratório.

Diante do exposto, o objetivo desse trabalho foi simular as bandas do sensor WorldView II a partir dos espectros obtidos em laboratório por Madeira Netto (1993), visando estudar sua potencialidade na detecção dos óxidos de ferro, além de propor um índice espectral baseado na profundidade de feição espectral denominado RHGtpf.

\section{MATERIAL E MÉTODOS}

A área de estudo abrange os Estados de Goiás, Minas Gerais, São Paulo, Paraná e o Distrito Federal. As características da área de estudo como coordenadas, relevo, clima, tipo de solos e vegetação, foram detalhadas na tabela 1.

Tabela 1: Características da área de estudo

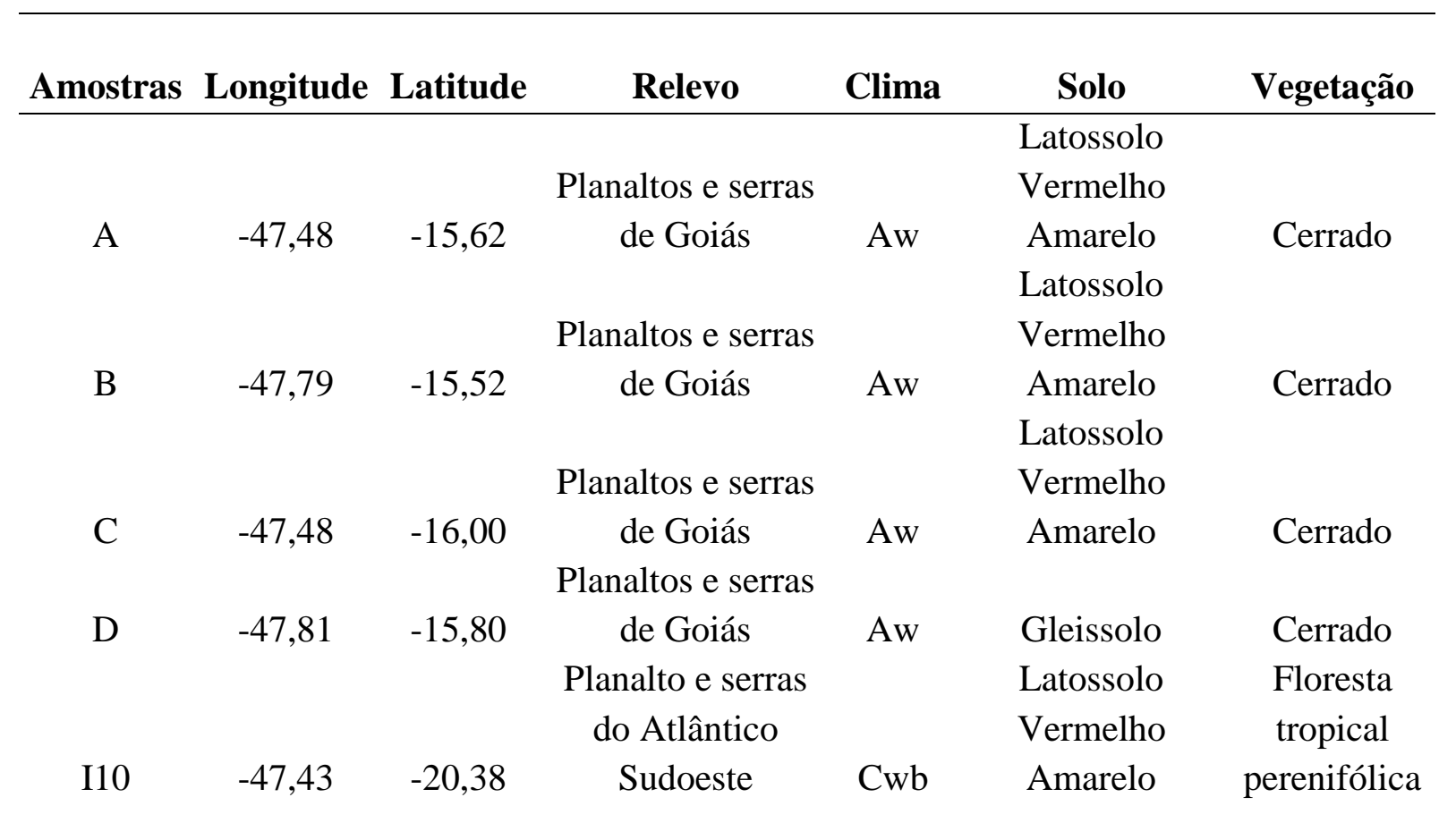




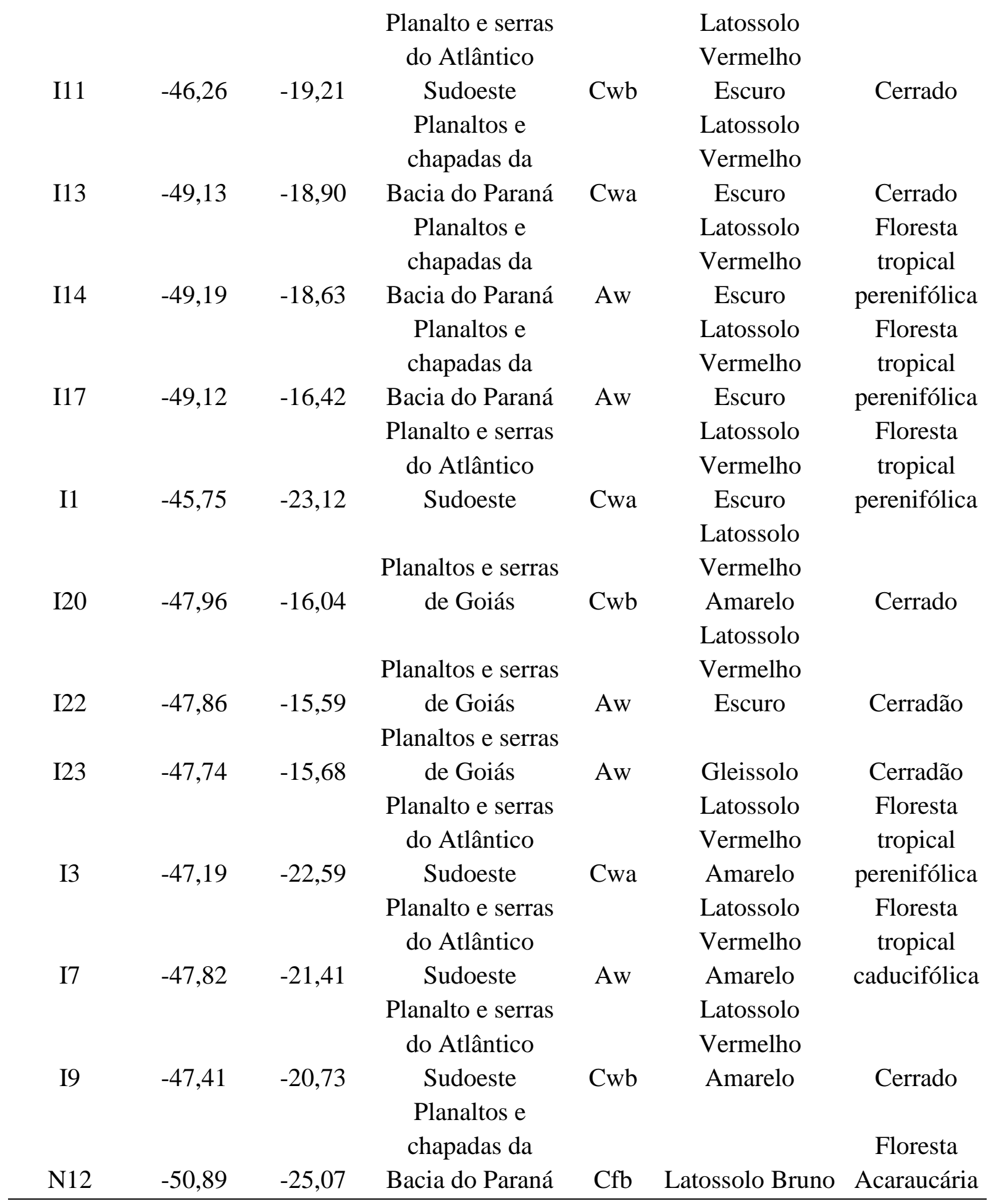

Para analisar os índices espectrais denominados de índice férrico (IFe) e índice hematita (IHm) com o sensor WorldView II, adotou-se os mesmos espectros já validados por Madeira Netto (1993) e também suas análises físico-químicas resumidas na Figura 1. A tabela 2 apresenta os resultados das análises físico-químicas das 56 amostras do Madeira Netto (1993). 


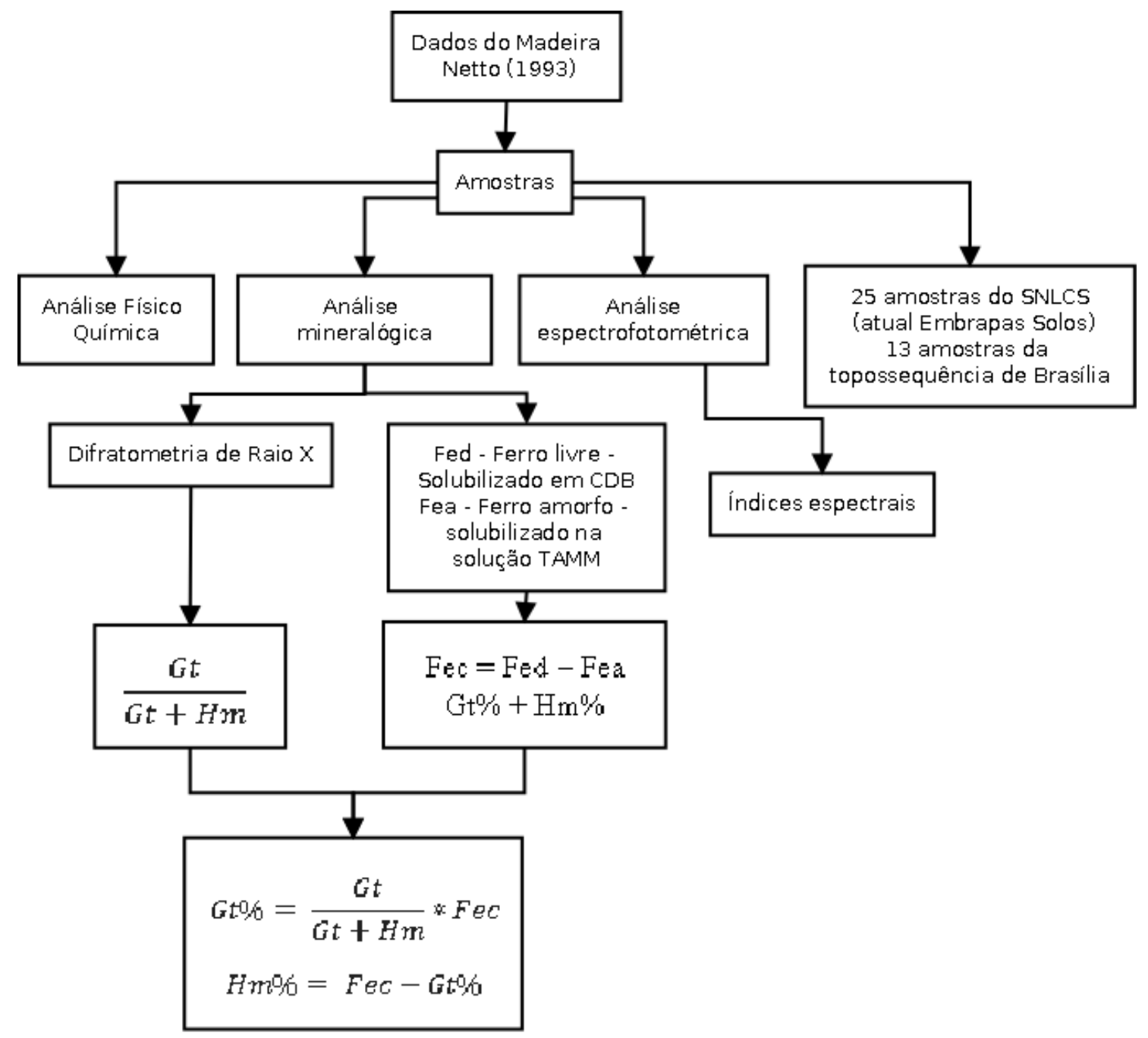

Figura 1: Fluxograma do processo feito com as amostras por Madeira Netto (1993)

Tabela 2: Análises físico-químicas das amostras feita por Madeira Netto (1993)

\begin{tabular}{|c|c|c|c|c|c|c|}
\hline Amostras & Profundidade & Cor - Munsell & $\frac{\mathrm{Hm}}{\mathrm{Hm}+\mathrm{Gt}}$ & $\begin{array}{c}\mathrm{Hm} \\
\%\end{array}$ & $\begin{array}{l}\mathrm{Gt} \\
\%\end{array}$ & RGHtmunsell \\
\hline A1 Ap1 & $0-17$ & 10YR 5/4 & 0,18 & 1,1 & 4,9 & $-0,32$ \\
\hline A1 BA & $40-67$ & 10YR 6/6 & 0,20 & 1,2 & 4,7 & $-0,30$ \\
\hline A1 Bw3 & $123-220$ & 7,5YR 6/8 & 0,00 & 0 & 6,8 & 0,04 \\
\hline A2 Ap2 & $12-27$ & $6,5 Y R 5 / 4$ & 0,36 & 2,7 & 4,7 & 0,10 \\
\hline A2 BA & $43-57$ & 6,5YR 6/8 & 0,40 & 3,1 & 4,6 & 0,16 \\
\hline A2 Bw2 & $115-210$ & $5 Y R 6 / 8$ & 0,34 & 3,2 & 6,2 & 0,34 \\
\hline A3 Ap1 & $0-15$ & 2,5YR 4/6 & 0,74 & 8,6 & 3,1 & 0,66 \\
\hline A3 BA & $45-65$ & $2,5 \mathrm{YR} 4 / 8$ & 0,78 & 9,8 & 2,7 & 0,72 \\
\hline A3 Bw2 & $120-260$ & 2,5YR 5/8 & 0,72 & 8,5 & 3,3 & 0,67 \\
\hline B1 Ap1 & $0-11$ & 10YR 6,5/3 & 0,00 & 0 & 1,3 & $-0,36$ \\
\hline B1 BA & $45-57$ & 10YR 7/4 & 0,00 & 0 & 1 & $-0,35$ \\
\hline
\end{tabular}




\begin{tabular}{|c|c|c|c|c|c|c|c|}
\hline B1 & Bw3 & $150-175$ & 7,5YR 8/6 & 0,33 & 0,4 & 0,8 & $-0,03$ \\
\hline B2 & Ap & $0-12$ & 5YR 5/6 & 0,62 & 3,6 & 2,2 & 0,32 \\
\hline B2 & BA & $26-49$ & 4YR 5,5/7 & 0,60 & 3,6 & 2,4 & 0,45 \\
\hline B2 & Bw2 & $100-154$ & 4YR 5,5/7 & 0,59 & 3 & 2,1 & 0,45 \\
\hline B3 & Ap1 & $0-11$ & $3,5 \mathrm{YR} 4 / 6$ & 0,72 & 7,1 & 2,7 & 0,54 \\
\hline B3 & BA & $48-73$ & $2,5 \mathrm{YR} 4 / 7$ & 0,73 & 7,4 & 2,8 & 0,69 \\
\hline B3 & Bw2 & $105-290$ & $2,5 \mathrm{YR} 5 / 8$ & 0,65 & 7 & 3,8 & 0,67 \\
\hline $\mathrm{C} 1$ & Ap1 & $0-11$ & $5 Y 5 / 2,5$ & 0,00 & 0 & 6,1 & $-0,36$ \\
\hline $\mathrm{C} 1$ & BA & $40-56$ & $10 \mathrm{YR} 7 / 6$ & 0,00 & 0 & 5 & $-0,32$ \\
\hline $\mathrm{C} 1$ & Bw2 & $138-168$ & $10 Y R 7 / 6$ & 0,21 & 1,1 & 4,1 & $-0,32$ \\
\hline $\mathrm{C} 2$ & Ap1 & $0-15$ & 10YR 5,5/3 & 0,23 & 1,2 & 4 & $-0,35$ \\
\hline $\mathrm{C} 2$ & BA & $48-63$ & 7,5YR 6/6 & 0,29 & 1,5 & 3,6 & 0,00 \\
\hline $\mathrm{C} 2$ & Bw2 & $148-255$ & 7,5YR 7/6 & 0,23 & 1,3 & 4,4 & $-0,02$ \\
\hline $\mathrm{C} 3$ & Ap1 & $0-12$ & 7,5YR 5/4 & 0,41 & 2,8 & 4,1 & $-0,02$ \\
\hline $\mathrm{C} 3$ & BA & $34-54$ & 5YR 6/6 & 0,25 & 1,5 & 4,6 & 0,30 \\
\hline $\mathrm{C} 3$ & Bw2 & $81-162$ & 5YR 5,5/8 & 0,40 & 2,4 & 3,6 & 0,35 \\
\hline D1 & Ap & $0-12$ & 5YR 5/8 & 0,66 & 4,96 & 2,6 & 0,37 \\
\hline D2 & Ap & $0-12$ & 7,5YR 4/4 & 0,38 & 1,8 & 2,9 & 0,00 \\
\hline D3 & Ap & $0-12$ & $10 \mathrm{YR} 5 / 3$ & 0,06 & 0,2 & 3,3 & $-0,35$ \\
\hline D4 & Ap & $0-12$ & 10YR 5/1 & 0,00 & 0 & 0,9 & $-0,40$ \\
\hline $\mathrm{I} 10$ & $\mathrm{~A}$ & $12-30$ & 7,5YR 5,5/4 & 0,31 & 2,2 & 5 & $-0,03$ \\
\hline $\mathrm{I} 10$ & BA & $55-90$ & $6,5 Y R 6 / 6$ & 0,25 & 1,9 & 5,8 & 0,12 \\
\hline I11 & $\mathrm{A} 2$ & $10-25$ & $5 \mathrm{YR} 5 / 5$ & 0,37 & 5,6 & 9,4 & 0,30 \\
\hline I11 & Bw4 & $239-280+$ & 2,5YR 5,5/7 & 0,57 & 8,8 & 6,7 & 0,63 \\
\hline $\mathrm{I} 13$ & $\mathrm{BA}$ & $40-70$ & 4YR 4,5/6 & 0,67 & 6,7 & 3,3 & 0,46 \\
\hline I13 & Bw4 & $400-520$ & $3,5 \mathrm{YR} 4,5 / 6$ & 0,80 & 8,6 & 2,2 & 0,52 \\
\hline I14 & Ap & $0-25$ & $3,5 \mathrm{YR} 3 / 3$ & 0,92 & 19,7 & 1,7 & 0,48 \\
\hline $\mathrm{I} 17$ & $\mathrm{AB}$ & $23-40$ & $3,5 \mathrm{YR} 4 / 5$ & 0,72 & 10,2 & 4 & 0,51 \\
\hline $\mathrm{I} 17$ & Bw5 & $275-410$ & $1,5 \mathrm{YR} 5 / 7$ & 0,81 & 11,6 & 2,8 & 0,77 \\
\hline I1 & Ap & $0-23$ & 10YR 5/2,5 & 0,00 & 0 & 6,5 & $-0,36$ \\
\hline I1 & $\mathrm{Bw}$ & $290-390+$ & 4YR 6/6 & 0,37 & 2,3 & 4 & 0,42 \\
\hline & A & $0-10$ & $2,5 \mathrm{YR} 4 / 4$ & 0,56 & 6,8 & 5,4 & 0,60 \\
\hline $\mathrm{I} 20$ & Bw1 & $50-110$ & 2,5YR 5/8 & 0,62 & 7,7 & 4,7 & 0,67 \\
\hline $\mathrm{I} 22$ & Ap & $0-10$ & $5 \mathrm{YR} 4 / 3$ & 0,75 & 6,6 & 2,2 & 0,27 \\
\hline $\mathrm{I} 22$ & Bw1 & $67-150$ & $5 \mathrm{YR} 4 / 7$ & 0,73 & 6,3 & 2,3 & 0,39 \\
\hline $\mathrm{I} 23$ & Ap & $0-18$ & 10YR 4,5/1 & 0,00 & 0 & 0,4 & $-0,39$ \\
\hline $\mathrm{I} 23$ & $\mathrm{Bg} 2$ & $70-110$ & $10 Y R$ 8/1 & 0,00 & 0 & 0,2 & $-0,41$ \\
\hline $\mathrm{I} 3$ & $\mathrm{~A} 2$ & $4-22$ & 4YR 4/4 & 0,54 & 3,3 & 2,8 & 0,42 \\
\hline I4 & Ap & $0-13$ & 4YR 4/4 & 0,62 & 6,1 & 3,7 & 0,42 \\
\hline I4 & Bw1 & $64-155$ & 2,5YR 4,5/7 & 0,63 & 6,6 & 3,9 & 0,67 \\
\hline $\mathrm{I} 7$ & Bw1 & $85-180$ & $1,5 \mathrm{R} 3 / 6$ & 0,94 & 22 & 1,4 & 0,84 \\
\hline I9 & $\mathrm{A} 2$ & $15-30$ & 10YR 4,5/3 & 0,10 & 1 & 8,9 & $-0,34$ \\
\hline I9 & $\mathrm{BA}$ & $75-120$ & 10YR 6/4 & 0,12 & 1,2 & 9 & $-0,26$ \\
\hline
\end{tabular}




\begin{tabular}{cccccccc} 
N12 & Ap1 & $0-16$ & 9YR 3/2 & 0,36 & 5,2 & 9,2 & $-0,22$ \\
$\mathrm{~N} 12$ & Bw2 & $128-150$ & $6,5 Y R 3,5 / 4$ & 0,39 & 5,8 & 8,9 & 0,12 \\
\hline
\end{tabular}

Fonte: Adaptado de Madeira Netto (1993)

Os espectros obtidos por Madeira Netto (1993) foram reamostrados simulados para as bandas do sensor Landsat TM5 por meio do módulo spectral resampling do software ENVI 5.1.

Madeira Netto (1993) desenvolveu dois índice espectral, denominados de índice férrico (IFe (TM)) e índice hematita (IHm(TM)) com bandas simuladas do sensor Landsat TM5 para verificar a proporção relativa de os óxidos de ferro e hematita, respectivamente. Esses índices foram comparados com a relação hematita/ hematita + goethita e com o teor de hematita. O índice férrico utiliza as bandas simulada do vermelho (STM3) e verde (STM2) e o índice hematita utiliza as bandas do azul (STM1), verde (STM2) e vermelho (STM3). Todas as etapas descritas acima sobre os índices espectrais do Madeira Netto (1993) foram organizadas e sintetizadas na Figura 2.

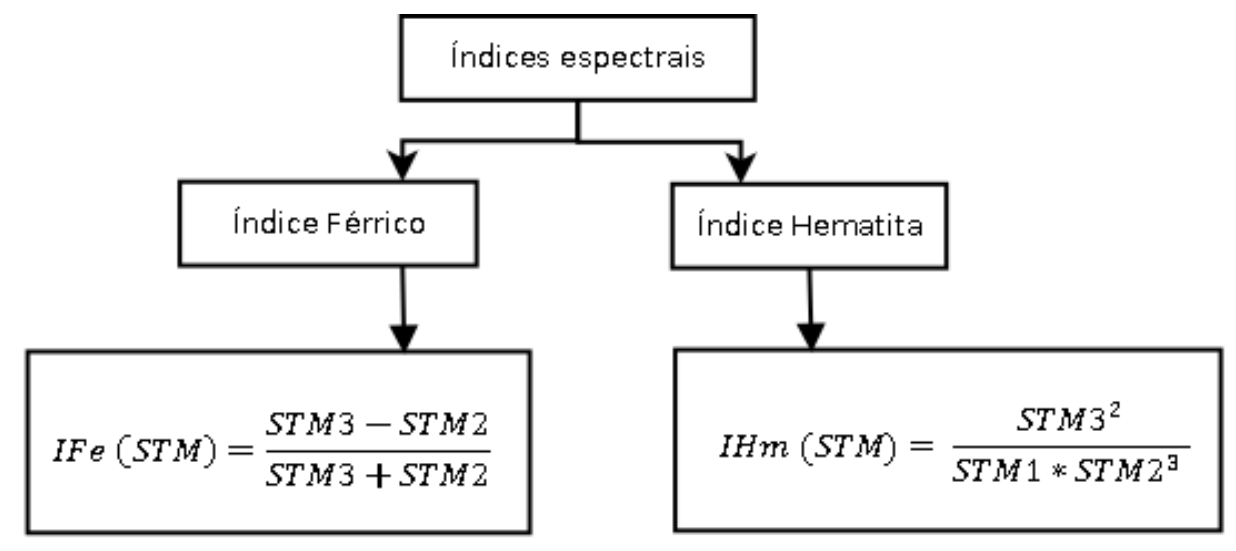

Figura 2: Fluxograma sobre os índices espectrais

Os espectros de reflectância difusa obtidos por Madeira Netto (1993) também foram reamostrados para as bandas do sensor WorldView II e seus índices também foram adaptados para o WorldView II, visando analisar sua potencialidade de detecção de parâmetros mineralógicos de solos, mais especificamente os minerais hematita e goethita. Esse sensor possui mais bandas na região do visível, se comparando ao sensor Landsat TM 5, e por isso foram testadas as novas bandas de acordo com seus comprimentos de onda.

O índice férrico (IFe(WVII)) foi testado utilizando duas combinações de bandas, sendo uma com a banda simulada do vermelho (SWV5) e a outra do verde (SWV3) e outra combinação 
utilizando as bandas amarelo (SWV4) e verde (SWV3). O resultado desse índice foi comparado estatisticamente com o mesmo índice utilizando os dados reamostrados para o Landsat TM 5 (IFe(TM)).

O índice hematita (IHm(WVII)) também foi adaptado utilizando duas combinações de bandas, uma com as bandas vermelho (SWV5), azul (SWV2) e verde (SWV3), e outra com amarelo (SWV4), azul (SWV2) e verde (SWV3). O resultado desse índice foi comparado estatisticamente com o mesmo índice utilizando os dados reamostrados para o Landsat TM 5 (IHm(TM)).

Todas as etapas descritas acima sobre a reamostragem para o sensor WorldView II dos índices espectrais do Madeira Netto (1993) foram organizadas e sintetizadas na Figura 3.

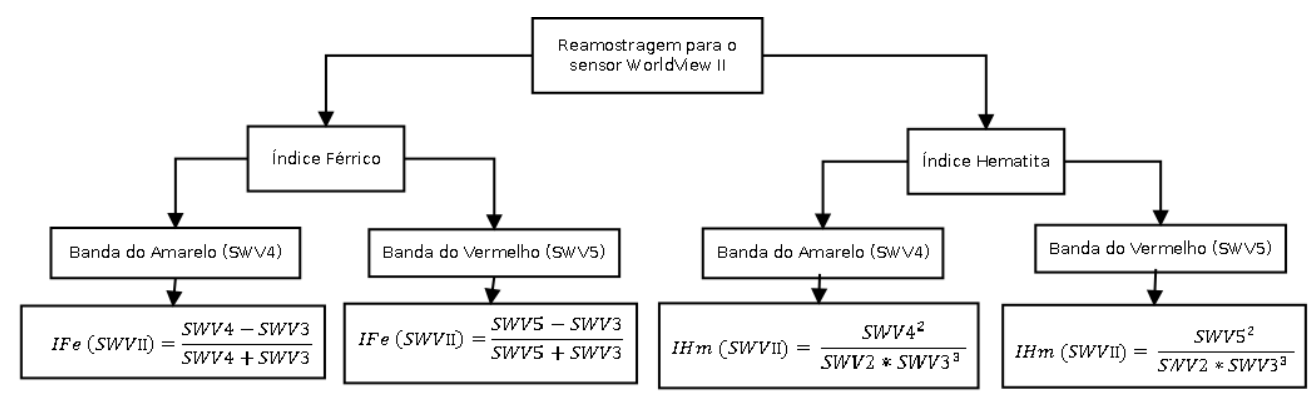

Figura 3: Fluxograma sobre a reamostragem dos índices espectrais

Nos dados reamostrados para as bandas do WorldView II, observa-se, quando da remoção do contínuo espectral (Figura 4b) que se evidenciam as feições espectrais da goethita e da hematita, o que não é possível com dados do Landsat TM5 (Figura 4a). Isso é possível devido à presença da banda 4 (amarelo). Salienta-se também que o procedimento de remoção do contínuo espectral gera valores de reflectância normalizados entre 0 a 1 para que seja possível a comparação de feições de absorção individuais dos minerais a partir de um valor de base comum (KOKALY e SKIDMORE, 2015). 


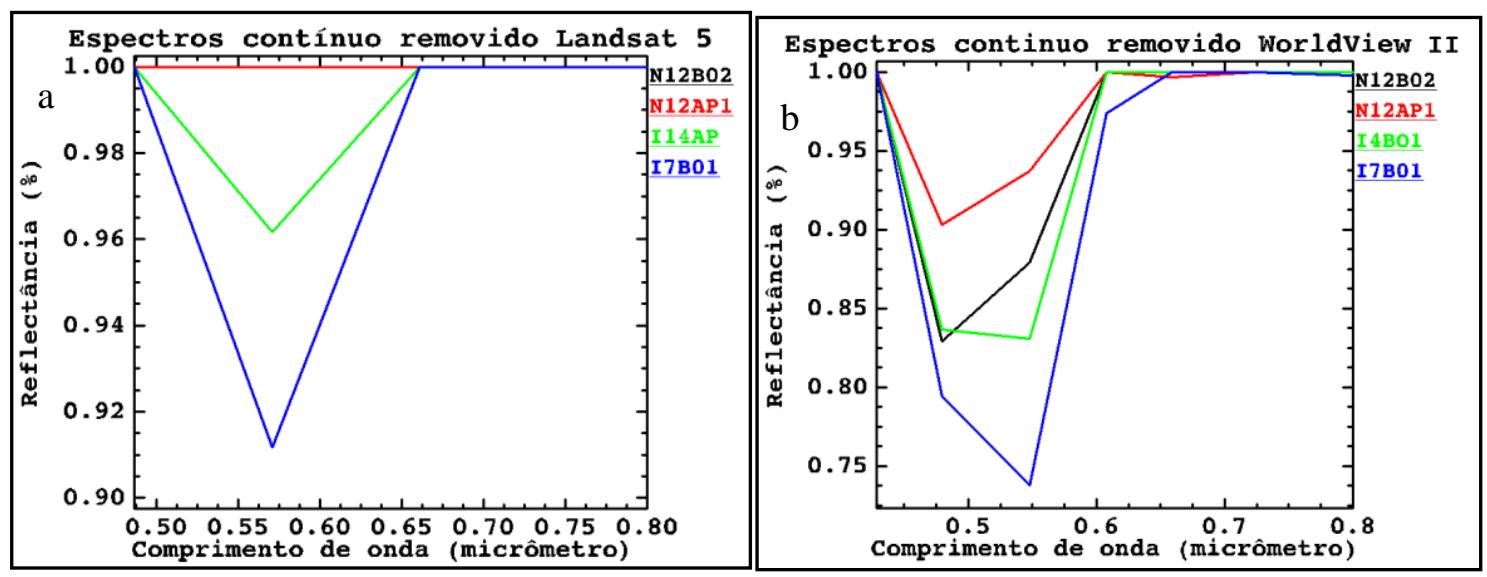

Figura 4: Espectros reamostrados e com o contínuo removido para o (a) Landsat TM 5 e para o (b) WorldView II.

Sabendo-se disso, foi proposto um índice espectral desenvolvido a partir da profundidade das feições espectrais e chamado RHGtPF, ou Relação Hematita/(Hematita+Goethita) por Profundidade de Feição, obtido em espectros com o contínuo espectral removido, testando as novas bandas do visível, se comparado com o Landsat TM5, que são a azul costal e a amarelo cujo desenvolvimento está detalhado na Figura 5. O índice RHGtPF foi comparado estatisticamente com a relação mineralógica $\mathrm{Hm} / \mathrm{Hm}+\mathrm{Gt}$ e com a relação RHGt de Munsell.

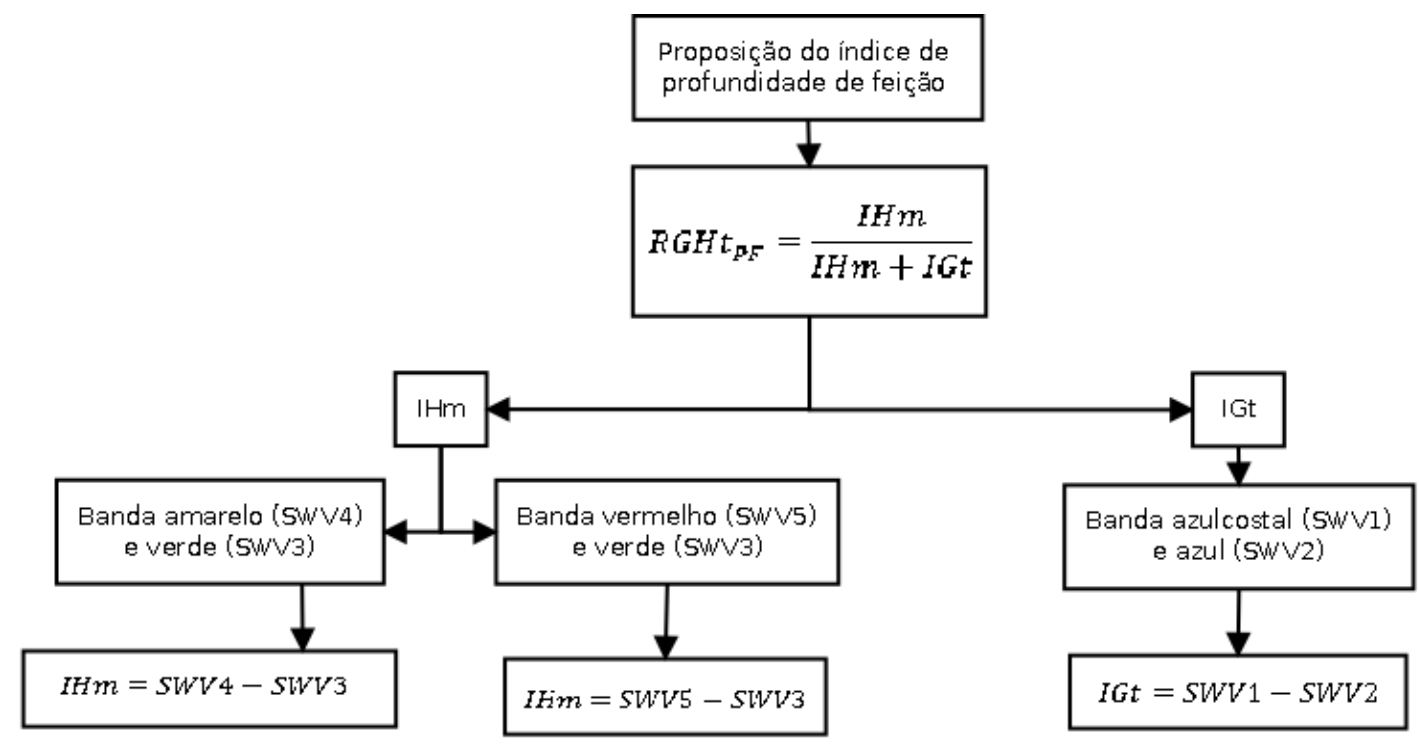

Figura 5: Fluxograma sobre a formulação do índice espectral RHGtPF. 
A Figura 6 apresenta o índice RHGtPF detalhando seus componentes.

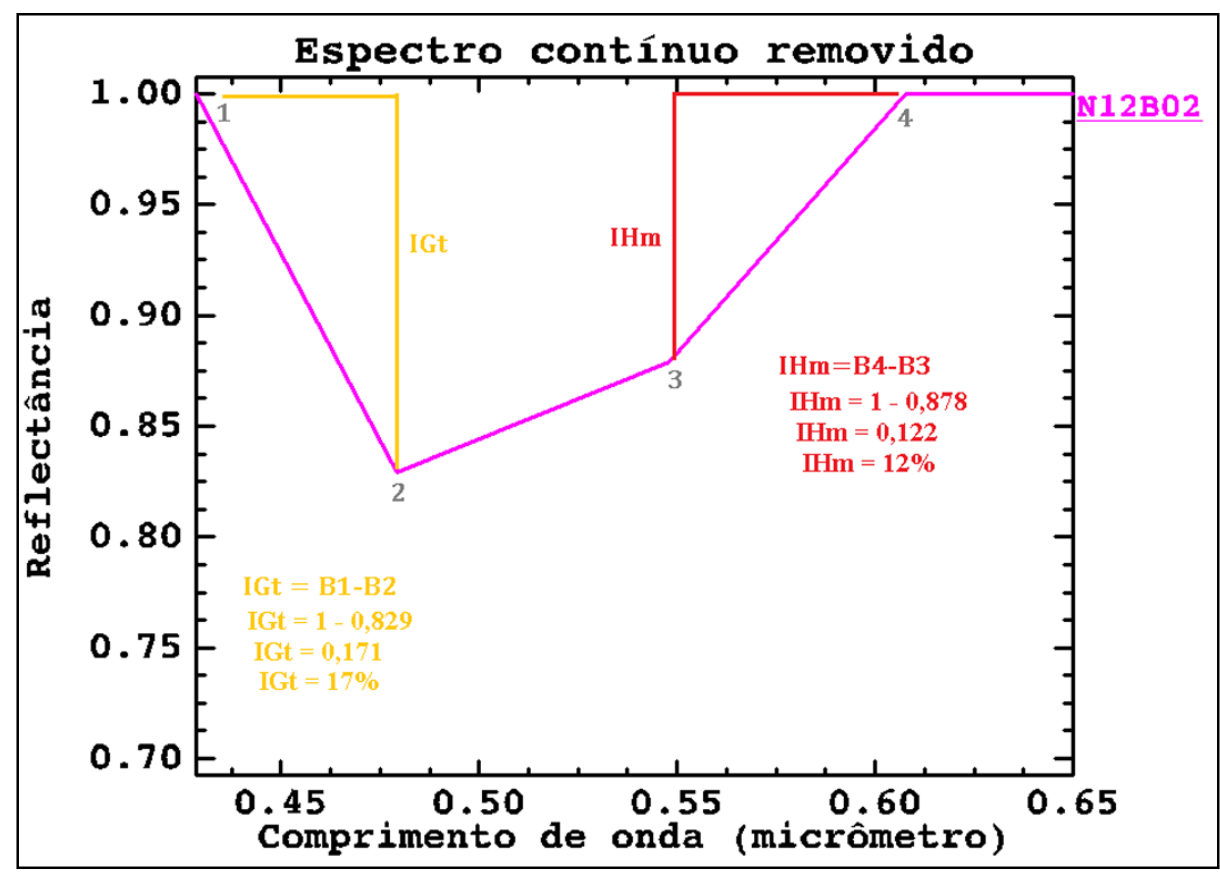

Figura 6: Índice RHGtPF

\section{RESULTADOS E DISCUSSÃO}

O índice simulado do Landsat TM 5 foi validado com dados mineralógicos e químicos por Madeira Netto (1993). Sabendo disso, comparou-se o mesmo índice, mas com outro sensor que possui mais bandas na região do visível, o sensor WorldView II, já que o índice utiliza esses determinados comprimentos de onda.

O índice IFe (TM5), já validado, foi comparado com o Ife (WVII) calculado com a banda do vermelho e com a do amarelo, para analisar qual delas tem a melhor resposta se comparando ao TM5. Observa-se que com a utilização da banda do amarelo no índice férrico degrada em $2 \%$. Mesmo assim, as duas expressões utilizadas com bandas do WorldView II são similares aos obtidos com o TM5, que, por sua vez apresentou elevada correlação com a análise química e mineralógica. O resultado da correlação de Pearson foi de uma correlação muito forte para as duas bandas, mas com a banda do vermelho $(r=0,99)$ foi mais alta se comparando com a banda do amarelo $(r=0,97)$.

O índice IHm (TM5), também foi comparado com o IHm (SWVII) calculado tanto com a banda do vermelho como com a do amarelo. O resultado da dispersão do índice hematita (IHm) utilizando o sensor TM5 e o sensor WVII com a banda do vermelho e também utilizando a banda 
na região do amarelo do sensor WorldView II também apresentou degradação, só que de $8 \%$. O resultado do coeficiente de correlação de Pearson também é elevado, mas a banda do vermelho apresentou resultado maior $(r=0,98)$, se comparando com a banda do amarelo $(r=0,90)$.

Com o resultado dos dois índices pode-se perceber que com a banda original, ou seja, a banda do vermelho, gera uma melhor resposta. Isso se deve ao fato de que na análise das relações mineralógicas avaliadas por meio de sistemas sensores, a proporcionalidade entre os teores está relacionada com as feições espectrais de absorção e não pela reflexão.

As feições espectrais que melhor separam esses minerais ocorrem, para a goethita em 0,48 $\mu \mathrm{m}$ (região do azul) e para a hematita, em $0,53 \mu \mathrm{m}$ (região do verde). A presença de uma banda que capta a reflexão na região do amarelo permite uma melhor visualização do matiz do solo, mas não mede a intensidade da feição e não melhora sua identificação.

Existem muitos estudos mineralógicos juntamente com vários sistemas sensores e com excelentes resultados estatísticos assim como foi observado nos índices propostos por Madeira Netto (1993). Demattê et al. (2004) também observaram a relação entre componentes do solo e as bandas do sensor Landsat TM 5 e o coeficiente de correlação entre os óxidos de ferro e as três primeiras bandas da região do visível foram -0,71, -0,69 e - 0,64 , apesar de os coeficientes serem menores que os obtidos nos resultados com os índices espectrais com dados simulados para o Landsat TM 5 e ajustados para as bandas do WorldView II.

O trabalho de Baptista et al. (2011) apresentou uma regressão entre os dados do sensor hiperespectral AVIRIS e os dados de análise termogravimétrica obtidos em laboratório para discretização da relação caulinita e gibbsita $(\mathrm{RCGb})$ com o $\mathrm{R}^{2}=0,75$. Mesmo sendo outros minerais, pôde-se observar a possibilidade de discretizar e quantificar as relações mineralógicas por meio de dados de sistemas sensores.

O índice RHGtPF baseado no contínuo removido e na profundidade de feição de espectros reamostrados para o sensor WorldView II, permite, devido às novas bandas do azul costal e do amarelo, diferenciar a hematita da goethita como feições distintas, diferente do Landsat TM5.

Comparou-se o índice RHGtPF com a análise química de Madeira Netto (1993) da relação hematita e goethita $(\mathrm{Hm} / \mathrm{Hm}+\mathrm{Gt})$ com a banda do amarelo e com a do vermelho. Como os dados não se ajustaram à normalidade pelo método de D'Agostino-Pearson, utilizaram-se testes não paramétricos. Pôde-se observar que o valor tau $(\tau)$ de Kendall foi de 0,54 para a banda do amarelo 
e de 0,56 com a banda do vermelho e o teste de Mann-Whitney mostrou que os dados são similares estatisticamente utilizando tanto uma banda quanto a outra. O coeficiente de determinação foi de 0,40 e 0,42 respectivamente.

Assim como na análise dos índices Ife e IHm, os resultados obtidos com RHGtPF o calculado com a banda do amarelo degrada em $2 \%$ se comparando com o obtido com a banda do vermelho. O resultado do teste de Mann-Whitney demonstra que índice RHGtPF é similar estatisticamente à relação mineralógica hematita/(hematita+goethita). Essa pequena degradação se deve ao fato da identificação e quantificação dos óxidos de ferro ser detectada pela feição espectral e não pelo pico de reflectância. A feição de absorção por transferência eletrônica da goethita, responsável por sua cor, ocorre à $0,48 \mu \mathrm{m}$, ou na região do azul e após a absorção o mineral começa a refletir na região do amarelo. Já a hematita que apresenta sua feição espectral centrada à $0,53 \mu \mathrm{m}$, ou no verde, apresenta sua reflexão ocorrendo na região do vermelho.

Comparando-se os resultados desse índice de profundidade de feição com estudos sobre discretização sobre minerais, pode-se observar que o coeficiente de determinação, apesar de ser satisfatório, é baixo em relação a alguns estudos. Chang et al. (2001), comparou o teor de ferro com o infravermelho e constataram o $\mathrm{R}^{2}=0,64$. Nanni e Demattê (2006), obtiveram uma equação de regressão múltipla com as bandas do Landsat TM 5 e $\mathrm{R}^{2}$ obtido foi de 0,88 . Isso porque, de acordo com Ahmad et al. (2015), os íons de $\mathrm{Fe}^{3+}$ podem ser encontrados entre 0,4 a 0,9 $\mu \mathrm{m}$. Segundo Dalmolin et al. (2005), os óxidos de ferro apresentam feições típicas na região do 0,9 $\mu \mathrm{m}$, que são mais intensas quanto mais teor de ferro existir. Visto isso, mesmo a região do visível sendo a mais importante devido a cor dos óxidos de ferro, pode-se dizer que, para quantificar os óxidos de ferro não depende apenas da região visível, mas também de outras feições de absorção características.

Não só se comparou o índice proposto com a relação $\mathrm{Hm} / \mathrm{Hm}+\mathrm{Gt}$, mas também com a relação de hematita e goethita da carta de Munsell, desenvolvido por Santana (1984), aqui denominado RHGt $_{54 \text { unsell }}$ com as bandas do amarelo e do vermelho. O valor do $\tau$ de Kendall foi de 0,55 para a banda do amarelo e de 0,53, para a do vermelho e o teste de Mann-Whitney mostrou que os dados não são similares estatisticamente tanto para uma banda como para a outra.

Observando os resultados das dispersões dos dois índices RHGtpF com a relação de Munsell (RHGt mumsell$_{\text {, }}$ pode-se verificar a mesma tendência observada com a relação hematita/(hematita+goethita), ou seja, com a banda do amarelo degradando em $2 \%$ se comparando 
com a banda do vermelho. Porém, a análise da correlação de Kendall mostra que o tau de Kendall do índice calculado com a banda do amarelo é maior que o calculado com a banda do vermelho, comportamento contrário ao observado com a relação RHGt, anteriormente analisada. Mas, como no caso anterior a variação não é significativa, pois também é de apenas $2 \%$. A análise do teste de Mann-Whitney, porém demonstra que índice e a relação mineralógica obtida por meio da carta de Munsell não são semelhantes estatisticamente. Sabendo-se disso, realizou-se outro teste de hipótese com a relação hematita e goethita $(\mathrm{Hm} /(\mathrm{Hm}+\mathrm{Gt}))$ e a $\mathrm{RHGt}_{55 \text { unsell }}$ e o resultado do teste U de Mann-Whitney demonstrou que os dados não são estatisticamente semelhantes. Isso quer dizer que os dados das relações comparadas são distintos, rejeitando a igualdade dos dados, como salientado no estudo de Vivaldi et al. (2013).

Com os resultados e a estatística descrita, pôde-se observar que a comparação com o novo índice e a relação $\mathrm{Hm} / \mathrm{Hm}+\mathrm{Gt}$ apresentou elevada similaridade, ou seja, correlacionáveis. Já a comparação com a relação de cor de Munsell não obteve similaridade entre os dados.

Almeida (2012) também não obteve bons resultados comparando o RHGtmunsell com o RHGt $_{\text {scale }}$ obtido a partir da utilização do algoritmo Spectral Feature Fitting sobre dados do sensor Hyperion, devido a oscilação que a relação mineralógica obtida por meio dos atributos da carta de Munsell apresentou, num transecto que saia de um ambiente predominantemente goethítico em direção a um hematítico.

Isso provavelmente deve estar relacionado a acurácia do observador na determinação dos componentes cromáticos de Munsell. Pode dizer que a quantificação da relação $\mathrm{Hm} / \mathrm{Hm}+\mathrm{Gt}$ está ligada a absorção dos minerais e a relação de cor de Munsell, com sua reflexão, ou seja, com a cor observada pelo olho humano.

Comparando os resultados com outros estudos sobre o sistema de Munsell observou coeficientes de determinação maiores do que os encontrados com o RHGtPF. Botelho et al. (2006), comparando as componentes da carta de Munsell, matiz, valor e croma, e o colorímetro encontraram o $\mathrm{R}^{2}$ de 0,93, 0,97 e 0,94, respectivamente para cada componente da carta de Munsell. A análise separada é importante devido a cada componente da carta de Munsell ter sua influência na cor.

Campos et al. (2003), analisaram o índice de avermelhamento com base no sistema de Munsell como teor de hematita e observaram $\mathrm{R}^{2}=0,76$ e esse mesmo índice, com base no sistema $\mathrm{L}^{*} \mathrm{a}$ b 
definido pelo CIE (Comissão Internacional de Iluminação) com o teor de hematita com $\mathrm{R}^{2}=0,96$. Isso porque o teor de hematita está ligado ao pigmento vermelho nos solos.

Fernandes et al. (2004) estudaram três relações entre o teor de hematita com o índice de vermelho descrito por Torrent et al. (1980), por Barrón e Torrent (1986) e o fator de vermelho descrito por Santana (1984), e observou um $\mathrm{R}^{2}$ de $0,79,0,86$ e de 0,86, respectivamente. Esses dois índices estão ligados ao teor de hematita, ou seja, apenas com a cor vermelha.

Quando o teste Mann-Whitney rejeita a hipótese de igualdade das medianas, indica que as amostras são distintas e que possuem medianas diferentes e gera o resultado dessas relações comparativas serem consideradas inadequadas (VIVALDI et al., 2013). Porém, é importante salientar que os dados de sensoriamento remoto têm a finalidade de gerar dados digitais semelhantes a realidade que o os olhos humanos capturam (VIVALDI et al., 2013). A relação RHGt $_{56 u n s e l l}$ é baseada nos componentes cromáticos do solo, contendo matizes, cromas e valores específicos. De acordo com Vivaldi et al. (2013) a análise visual tem predomínio sobre os resultados da análise estatística, pois a natureza não se prende apenas aos números.

\section{CONCLUSÕES}

1. A identificação e quantificação dos óxidos de ferro está ligada as feições de absorção da goethita e da hematita que estão localizadas nas bandas azul e verde do WorldView II, respectivamente. A utilização da banda do amarelo apresentou degradação de $2 \%$ em relação a com a banda do vermelha.

2. Com a remoção do contínuo espectral, observou que as bandas do azul costal e do amarelo ajudam na identificação dos minerais bem como na quantificação da relação mineralógica e isso viabilizou a proposição de um índice espectral baseado na profundidade de feição, RHGtPF, que permite, em comparação com o sensor Landsat TM 5, separar as feições de absorção dos dois minerais investigados na região do visível.

3. O índice RHGtPF apresentou similaridade espectral com a relação $\mathrm{Hm} / \mathrm{Hm}+\mathrm{Gt}$.

4. Já o RHGtPF e a relação $\mathrm{Hm} / \mathrm{Hm}+\mathrm{Gt}$ obtida por meio dos atributos cromáticos de Munsell não são estatisticamente similares. 


\section{REFERÊNCIAS BIBLIOGRÁFICAS}

AHMAD, L.; SHAH, M. T.; KHAN, S. D. Reflectance spectroscopy and remote sensing data for finding sulfide-bearing alteration zones and mapping geology in Gilgit-Baltistan, Pakistan. Earth Science Informatics, v.9, n.1, p.113-121, 2016. http://dx.doi.org/10.1007/s12145-015-0239-x.

ALMEIDA, C. D. S. Espacialização e quantificação de sesquióxidos de ferro (Goethita e Hematita) em solos tropicais por meio de sensoriamento remoto hiperespectral. Dissertação de Mestrado em Geociências Aplicadas. Universidade de Brasília, Brasília, 2012.

ALVES, M. R.; DEMATTÊ, J.A.M.; BARROS, P.P.S. Múltiplas Ferramentas Tecnológicas no Mapeamento Digital em Solos Tropicais. Revista Brasileira de Ciência do Solo, v.39, n.5, p.1261-1274, 2015. http://dx.doi.org/10.1590/01000683rbcs20140410

ALVES, M.E.; MASCARENHAS, Y.P.; VAZ, C.M.P. Comparação de procedimentos de quantificação de caulinita e gibbsita na fração argila desferrificada de latossolos. Revista Brasileira de Ciência do Solo, v.32, n.2, p.569-577. 2008. http://dx.doi.org/10.1590/S010006832008000200012

BAHIA, A. S. R. S.; MARQUES JÚNIOR, J.; SIQUEIRA, D, S. Procedures using diffuse reflectance spectroscopy for estimating hematite and goethite in Oxisols of São Paulo, Brazil. Geoderma Regional, v.5, p.150-156, 2015. http://dx.doi.org/10.1016/j.geodrs.2015.04.006

BALENA, S. P.; MESSERSCHMIDT, I.; TOMAZONI, J. C.; GUIMARÃES, E.; PEREIRA, B. F.; PONZONI, F. J.; BLUMD, W. E. H.; MANGRICH, A. S. Use of Fe ${ }^{3+}$ Ion Probe to Study Intensively Weathered Soils utilizing Electron Paramagnetic Resonance and Optical Spectroscopy. Journal of the Brazilian Chemical Society, v.22, n.9, p.1788-1794, 2011. http://dx.doi.org/10.1590/S0103-50532011000900023

BAPTISTA, G.M.M.; CORREA, R.S.; SANTOS, P.F.; MADEIRA NETTO, J.S.; MENESES, P.R. Use of Imaging Spectroscopy for Mapping and Quantifying the Weathering Degree of Tropical Soils in Central Brazil. Applied and Environmental Soil Science. Remote Sensing of Soil. Special Issue, 2011. p. 1-7.

BARBOSA, I.O.; LACERDA, M.P.C.; BILICH, M.R. Relações pedomorfogeológicas nas chapadas elevadas do Distrito Federal. Revista Brasileira de Ciência do Solo, v.33, n.5, p.13731383, 2009. http://dx.doi.org/10.1590/S0100-06832009000500029 
BOTELHO, M.R.; DALMOLIN, R.S.D.; PEDRON, F.A.; AZEVEDO, A.C.; RODRIGUES, R.B.; MIGUEL, P. Medida da cor em solos do Rio Grande do Sul com a carta de Munsell e por colorimetria. Ciência Rural, v.36, n.4, p. 1179-1185, 2006. http://dx.doi.org/10.1590/S010384782006000400021

CAMARGO, L. A.; JÚNIOR, J. M.; PEREIRA, G. T.; BAHIA, A. S. R. S. Clay mineralogy and magnetic susceptibility of Oxisols in geomorphic surfaces. Scientia Agricola, v.71, n.3, p.244256. 2014. http://dx.doi.org/10.1590/S0103-90162014000300010

CAMARGO, L.A.; MARQUES JÚNIOR.J.; PEREIRA, G.T.; HORVAT, R.A. Variabilidade espacial de atributos mineralógicos de um latossolo sob diferentes formas do relevo. I mineralogia da fração argila. Revista Brasileira de Ciência do Solo, v.32, n.6, p.2269-2277, 2008. http://dx.doi.org/10.1590/S0100-06832008000600006

CAMPOS, P.M.; LACERDA, M.P.C.; LOPES SILVA, C.; CAROLINO SÁ, M.A.; GOMES SOUSA, D.M. Drenagem interna como fator de diferenciação de Latossolos do Distrito Federal. Pesquisa Agropecuária Brasileira, v.45, n.3, p.306-314, 2010. http://dx.doi.org/10.1590/S0100204X2010000300011

CAMPOS, R.C; DEMATTÊ, J.A.M.; QUARTAROLI, C.F. Determinação indireta do teor de hematita no solo a partir de dados de colorimétrica e radiométrica. Pesquisa Agropecuária Brasileira, v.38, n.4, p.521-528, 2003. http://dx.doi.org/10.1590/S0100-204X2003000400011

CEZAR, E.; NANNI, M.R.; CHICATI, M.L.; SOUZA JÚNIOR, I.G.; COSTA, A.C.S. Uso de dados espectrais para estimar a relação entre óxidos de ferro e minerais 2:1 com suas respectivas reflectâncias. Semina: Ciências Agrárias, v. 34, n. 4, p. 1479-1492, 2013. http://dx.doi.org/10.5433/1679-0359.2013v34n4p1479

CHANG, C.W., LAIRD, D.A., MAUSBACH, M.J., MAURICE, J., HURBURGH, J.R. NearInfrared reflectance spectroscopy - principal components regression analyses of soil properties. Soil Science Society of America Journal, v.65, p.480-490, 2001.

CORREA, M.M.; KER, J.C.; BARRÓN, V.; FONTES, M.P.F.; TORRENT, J.; CURI, N. Caracterização de óxidos de ferro de solos do ambiente tabuleiros costeiros. Revista Brasileira de Ciência do Solo, v.32, n.1, p.1017-1031, 2008. http://dx.doi.org/10.1590/S010006832008000100028 
DALMOLIN, R.S.D.; KLAMT, C.N.G.E.; DICK, D.P. Relação entre os constituintes do solo e seu comportamento espectral. Ciência Rural, Santa Maria, v.35, n.2, p.481-489, 2005.

DEMATTÊ, J. A. M.; TOLEDO, A. M. A.; SIMÕES, M. S. Metodologia para reconhecimento de três solos por sensores: laboratorial e orbital. Revista Brasileira de Ciência do Solo, v.28, n.5, p.877-889, 2004. http://dx.doi.org/10.1590/S0100-06832004000500010

FERNANDES, R.B.A.; BARRÓN, V. TORRENT, J.; FONTES, M.P.F. Quantificação de óxidos de ferro de latossolos brasileiros por espectroscopia de refletância difusa. Revista Brasileira de Ciência do Solo, v.28, n.2, p.245-257, 2004. http://dx.doi.org/10.1590/S010006832004000200003

GENÚ, A. M.; DEMATTÊ, J. A. M. Prediction of soil chemical atributes using optical remote sensing. Acta Scientiarum. Agronomy, v.33, n.4, p. 723-727, 2011. http://dx.doi.org/10.4025/actasciagron.v33i4.7975

GERIGHAUSEN, H.; MENZ, G.; KAUFMANN, H. Spatially Explicit Estimation of Clay and Organic Carbon Content in Agricultural Soils Using Multi-Annual Imaging Spectroscopy Data. Applied and Environmental Soil Science. 2012. http://dx.doi.org/10.1155/2012/868090

INDA JUNIOR, A.V.; KÄMPF, N. Variabilidade de goethita e hematita via dissolução redutiva em solos de região tropical e subtropical. Revista Brasileira de Ciência do Solo, v.29, n.6, p.851866, 2005.http://dx.doi.org/10.1590/S0100-06832005000600003

JACOMINE, P.K.T. A Nova Classificação Brasileira De Solos. Anais da Academia Pernambucana de Ciência Agronômica, Recife, vols. 5 e 6, p.161-179. 2009.

KÄMPF, N. \& SCHWERTMANN, U. Goethite and hematite in a climosequence in Southern Brazil and their application in classification of kaolinitic Soils. Geoderma, v.29, n.1, p.27-39, 1982. . http://dx.doi.org/10.1016/0016-7061(83)90028-9

KOKALY, R. F.; SKIDMORE, A. K. Plant phenolics and absorption features in vegetation reflectance spectra near $1.66 \mu \mathrm{m}$. International Journal of Applied Earth Observation and Geoinformation, v. 43, p. 55-83, 2015. http://dx.doi.org/10.1016/j.jag.2015.01.010

LAGACHERIE, P.; BARET, F.; FERET, J. B.; MADEIRA NETTO, J. S.; ROBBEZ-MASSON, J. M. Estimation of soil clay and calcium carbonate using laboratory, field and airborne 
hyperspectral measurements. Remote Sensing of Environment, v.112, p. 825-835, 2008. http://dx.doi.org/10.1016/j.rse.2007.06.014

MADEIRA NETTO, J. S. Étude Quantitative des Relations Constituants Minéralogiques Réflectance Diffuse des Latosols Brésiliens: Application à l'utilisation pédologique des données satellitaires TM (Région de Brasilia). Éditions de l’ORSTOM, Paris, 1993, 236p.

NANNI, M.R.; DEMATTÊ, J.A.M. Comportamento da linha do solo obtida por espectrorradiometria laboratorial para diferentes classes de solo. Revista Brasileira de Ciência do Solo, v.30, n.6, p.1031-1038, 2006. http://dx.doi.org/10.1590/S0100-06832006000600012

REATTO, A.; BRUAND, A.; MARTINS, E.S.; MULLER, F.; DA SILVA, E.; CARVALHO JR, O.; BROSSARD, M. Variation of the kaolinite and gibbsite content at regional and local scale in Latosols of the Brazilian Central Plateau. Comptes Rendus. Géoscience, v.340, p. 741-748, 2008. http://dx.doi.org/10.1016/j.crte.2008.07.006

SANTANA, D.P. Soil formation in a toposequence of oxisols from Patos de Minas regions, Minas Gerais State, Brazil. West Lafayette: Purdue University, 129p. PhD Thesis.1984.

SCHAEFER, C. E. G. R.; FABRIS, J. D.; KER, J. C. Minerals in the clay fraction of Brazilian Latosols (Oxisols): a review. GeoScience World. Clay Minerals, v.43, n.1, p.137-154. 2008. http://dx.doi.org/10.1180/claymin.2008.043.1.11

SILVA JUNIOR, J.F.; MARQUES JÚNIOR, J.; CAMARGO, L.A.; TEIXEIRA, D.B.; PANOSS, A.R.; PEREIRA, G.T. Simulação geoestatística na caracterização espacial de óxidos de ferro em diferentes pedoformas. Revista Brasileira de Ciência do Solo, v.36, n.6, p.1690-1703, 2012. http://dx.doi.org/10.1590/S0100-06832012000600003

SOUSA JUNIOR, J.G.A.; DEMATTÊ, J.A.M.; GENÚ, A.M. Comportamento espectral dos solos na paisagem a partir de dados coletados por sensores terrestre e orbital. Revista Brasileira de Ciência do Solo, v.32, n.2, p.727-738, 2008. http://dx.doi.org/10.1590/S010006832008000200027.

SOUSA JUNIOR, J.G.A; DEMATTÊ, J.A.M.; ARAÚJO, S.R. Modelos espectrais terrestres e orbitais na determinação de teores de atributos dos solos: potencial e custos. Bragantia, v. 70, n. 3, p.610-621, 2011. http://dx.doi.org/10.1590/S0006-87052011000300017 
VENDRAME, P.R.S.; EBERHARDT, D.N.; BRITO, O.R.; MARCHÃO, R.L.; QUANTIN, C.; BECQUER, T. Formas de ferro e alumínio e suas relações com textura, mineralogia e carbono orgânico em Latossolos do Cerrado. Semina: Ciências Agrárias, v. 32, suplemento 1, p. 1657 1666, 2011. http://dx.doi.org/10.5433/1679-0359.2011v32Suplp1657

VIVALDI, D. D.; BAPTISTA, G. M. M.; MENESES, P. R. Avaliação dos processamentos de crosstalk e de correção atmosférica em dados ASTER para identificação da relação mineralógica caulinita/(caulinita + gibbsita) em solos no município de São João d'Aliança (GO). Revista Brasileira de Geociências, v. 43, p. 571-582, 2013. http://dx.doi.org/10.5327/Z2317$\underline{48892013000300011}$ 
CAPÍTULO 3: DISCRETIZAÇÃO ESPACIAL DOS ÓXIDOS DE FERRO, POR MEIO DE ALGORITMOS E ÍNDICE ESPECTRAL EM DADOS DO SENSOR WORLDVIEW II 


\section{RESUMO}

O objetivo desse estudo é a identificação dos óxidos de ferro no solo localizados na Universidade de Brasília (DF) usando a técnica Spectral Angle Mapper (SAM), Linear Spectral Unmixing (LSU) e índice espectral RHGtPF com dados do WorldView II. Os solos tropicais são ricos em óxidos de ferro que são a hematita e a goethita. O SAM é um método de classificação espectral que realiza o mapeamento entre o espetro obtido pela biblioteca espectral e o espectro do pixal da imagem pela similaridade entre eles. O Linear Spectral Unmixing é um método de classificação que determina a abundância relativa do endmembers na composição do pixel mistura. O índice RHGtPF foi analisado com base na relação $\mathrm{Hm} / \mathrm{Hm}+\mathrm{Gt}$ dos dados percentuais do LSU. O resultado do SAM foi satisfatório porque ele classificou corretamente os dois minerais. O resultado do LSU mostra que a correlação entre os dois minerais é inversa devido a diferença química e geomorfológica do meio ambiente. $\mathrm{O}$ índice RHGtPF quantifica e identifica os minerais óxidos de ferro.

Palavras chave: WorldView II, hematita, goethita, decomposição espectral linear, classificação por ângulo espectral.

\section{ABSTRACT}

The objective of this study is to identify iron oxides in the soil of University of Brasilia (DF), using the Spectral Angle Mapper (SAM), Linear Spectral Unmixing (LSU) and the RHGtPF spectral index with the WorldView II data. The tropical soils are rich in iron oxides, which are hematite and goethita. The SAM is a spectral grading method makes mapping between the spectral achieved by the spectral library and pixel by the similarity between them. The Linear Spectral Unmixing it is a grading method which determines the relative abundance of the endmembers in the composition of the pixel. The index RHGtPF was analyzed based in $\mathrm{Hm} / \mathrm{Hm}+\mathrm{Gt}$ relation of the overall percentage's LSU. The LSU's results shows that the correlation between both minerals it is reverse because of the chemical and geomorphological difference in the environment. The RHGtPF spectral index quantify and identify the iron oxides minerals.

Index terms: WorldView II, Hematite, Goethite, Linear Spectral Unmixing, Spectral Angle Mapper 


\section{INTRODUÇÃ̃O}

As regiões tropicais apresentam como características principais a alta temperatura e as oscilações de umidade que influenciam diretamente o meio ambiente. Cada compartimento ambiental busca atingir um equilíbrio com as condições ambientais vigentes. Dessa forma propriedades físicas, químicas e mineralógicas do solo, por exemplo, se alteram visando a harmonização do sistema (GUERRA e CUNHA, 1996).

A degradação química é mais acelerada nesses ambientes, devido à presença de água, podendo resultar em solos altamente intemperizados e em minerais secundários (GUERRA e CUNHA, 1996). Essas características de regiões tropicais interferem diretamente nas características do solo, como espessura, cor e mineralogia (DALMOLIN et al.,2005; GALVÃO et al., 2008).

Com isso, os solos brasileiros mais intemperizados são os Latossolos e sua característica é a presença de óxidos e hidróxidos de ferro na sua composição, ou seja, a hematita $\left(\mathrm{Fe}_{2} \mathrm{O}_{3}\right)$ e goethita (FeOOH) (MADEIRA NETTO et al., 1997; FERNANDES et al., 2004; BARBOSA et al., 2009). A identificação e a diferenciação desses óxidos e hidróxidos de ferro podem ser observadas por meio da cor dos solos que são expressas mediante a reflectância espectral dos solos que é obtida via sensoriamento remoto (CAMPOS et al., 2003).

Portanto, esses óxidos de ferro devem se diferenciar por suas assinaturas ou feições espectrais em comprimentos de ondas específicos de acordo com suas transições eletrônicas (BAPTISTA e MENESES, 2009).

No caso, a transição eletrônica de efeito cristalino da hematita e goethita ocorrem em 0,53 $\mu \mathrm{m}$ e $0,48 \mu \mathrm{m}$, respectivamente, ou seja, na faixa do visível que é responsável pelas cores desses minerais (SHERMAN e WAITE, 1985).

Para uma melhor visualização e diferenciação da cor dos óxidos de ferro, há a necessidade de uma imagem de satélite de um sistema sensor que discrimine particularmente cada comprimento de onda de forma separada, ou seja, a faixa espectral deve ser um pouco mais estreita e praticamente na região do visível e uma alta resolução espacial e espectral para obter maior detalhe e diferenciação. 
O presente estudo tem como objetivo identificar os óxidos de ferro dos solos tropicais no Distrito Federal por meio da técnica Spectral Angle Mapper (SAM), Linear Spectral Unmixing (LSU) e índice espectral RHGtpF (TEOBALDO e BAPTISTA, 2016) com os dados do sensor WorldView II. A escolha desse sistema sensor baseia-se na presença de uma banda no amarelo, o que provavelmente deve destacar bem a presença da goethita.

\section{MATERIAL E MÉTODOS}

\section{1. Área de estudo}

A área de estudo é na Universidade de Brasília no campus Darcy Ribeiro onde está sendo construído um novo prédio. Essa universidade se situa na Asa Norte. A Figura 1 apresenta a imagem escolhida que foi imageada no dia 8 de maio de 2010 pelo sensor WorldView II em uma composição colorida R5G4B3.

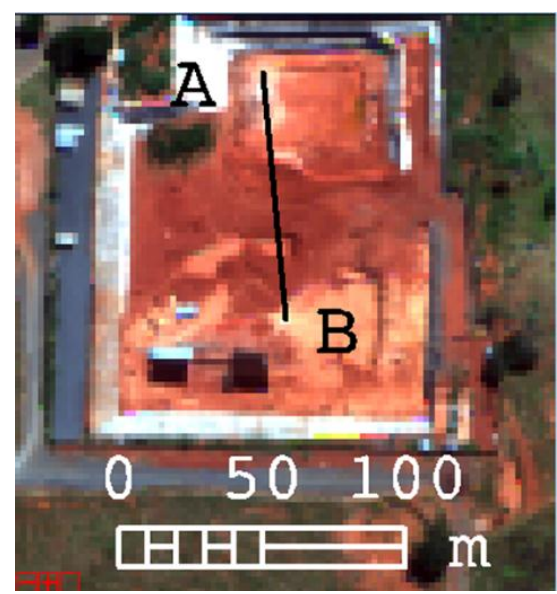

Fig.1: Composição colorida R5G3B2 nas cores reais da área estudada.

O clima do Distrito Federal, como um todo, apresenta uma sazonalidade em que o período do inverno manifesta-se com baixa umidade e precipitação e o período do verão com alta taxa de precipitação (BAPTISTA, 1998). Com esse clima, os solos costumam ser bem intemperizados e espessos em virtude da presença de chuva e calor. E a mineralogia desses solos são pobres em bases trocáveis e em sílica, as quais foram lixiviadas, e ricas em óxidos de ferro, como a goethita $(\mathrm{FeOOH})$ e hematita $\left(\mathrm{Fe}_{2} \mathrm{O}_{3}\right)$ (BAPTISTA e MENESES, 2009). 
A imagem da figura 1 apresenta gradações de solos mais avermelhados (hematíticos) e mais amarelados (goethíticos), no qual o solo está sendo preparado para uma construção de um novo prédio da universidade.

\subsection{Spectral Angle Mapper (SAM)}

O Spectral Angle Mapper (SAM) é um método de classificação espectral que realiza o mapeamento entre o espectro proveniente de uma biblioteca espectral e o espectro de um pixel da imagem por meio da similaridade entre eles (BAPTISTA, 2012). Essa comparação é feita por meio do ângulo entre o espectro de referência, ou seja da biblioteca (Figura 2), com cada pixel da imagem (VALÉRIO et al., 2009), e ângulos pequenos significa bons ajustes entre os dois espectros. Os espectros são tratados como vetores em um espaço "n” dimensional, no qual "n" é o número de bandas espectrais (BAPTISTA, 2012). Maior será a probabilidade da existência do material de referência no pixel da imagem, quanto melhor for o ajuste (DALLA NORA et al., 2010).

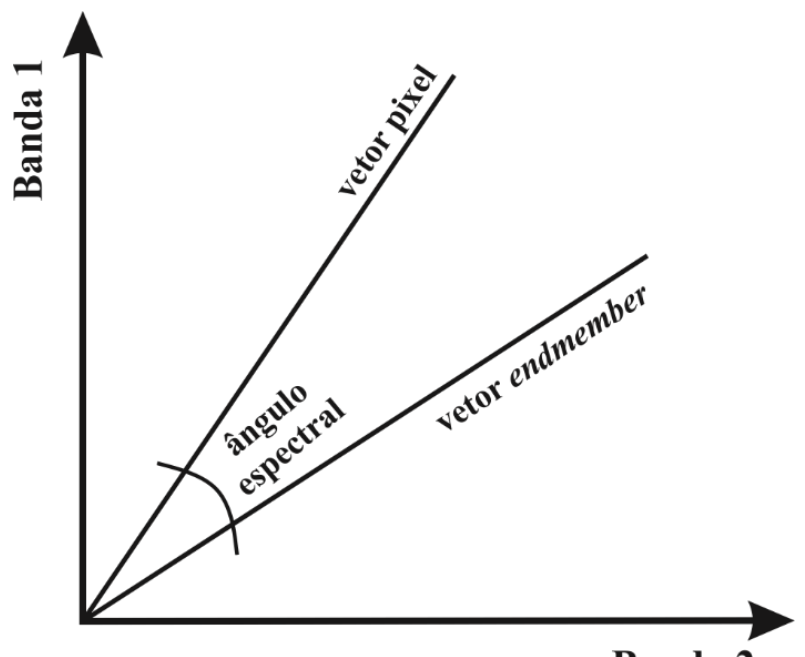

Banda 2

Fig. 2: Ângulo espectral entre curvas espectrais de dois materiais diferentes (A e B) medido pelo SAM.

Esse método tem como resultado uma imagem SAM, na qual a cor representa cada espectro de referência ou endmember, e as rule images, que apresentam o ajuste dos ângulos para cada espectro de referência escolhido (BAPTISTA, 2012), ou seja, ele identifica a existência ou não do espectro de referência (DALLA NORA et al., 2010). 


\subsection{Linear Spectral Unmixing (LSU)}

Os dados do espectrorradiômetro armazenam espectros que são chamados de quase puros e que podem ser utilizados para localizar membros finais (endmembers), ou seja, fazer uma separação espectral entre materiais (JENSEN, 2009). Essa etapa de processamento tem como objetivo buscar feições espectrais de absorção dos alvos e pixels que tem o comportamento espectral igual ou semelhante.

Dessa forma, Baptista e Meneses (2009) expressam que a reflectância de cada pixel é entendida como sendo uma combinação linear da reflectância, ou seja, endmembers. O Linear Spectral Unmixing é um método de classificação em que determina a abundância relativa dos endmembers na composição do pixel mistura (BAPTISTA, 2012).

Isto é, estimar a proporção dos componentes em cada pixel (MELLO et al., 2010). De acordo com Baptista e Meneses (2009), não se pode adotar um número de endmembers maior que o número de bandas do sensor. A decomposição espectral linear tende a separar os percentuais de cada material, ou seja, de cada endmember na composição do pixel, assim gerando um mapa de percentual de cada mineral presente.

\section{4. Índice RHGtPF}

Salienta-se que o procedimento de remoção do contínuo espectral gera valores de reflectância normalizados entre 0 a 1 para que seja possível a comparação de feições de absorção individuais dos minerais a partir de um valor de base comum (BREUNING, 2007).

Sabendo-se disso, aplicou-se o índice espectral RHGtPF (TEOBALDO E BAPTISTA, 2016) desenvolvido a partir da profundidade das feições espectrais obtido em espectros com o contínuo espectral removido, testando a nova banda do visível que é a banda da região do azul costal. Esse índice é descrito na equação 1:

$$
R G H t_{P F}=\frac{I H m}{I H m+I G t}
$$

Sendo que,

$$
I H m=S W V 5-S W V 3
$$

SWV5 = banda vermelho do WVII 
SWV3 = banda verde do WVII

$$
I G t=S W V 1-S W V 2
$$

SWV1 = banda azul costal do WVII

SWV2 = banda azul do WVII

A figura 3 mostra a explicação $\mathrm{e}$ o detalhe 0 índice RHGtpF.

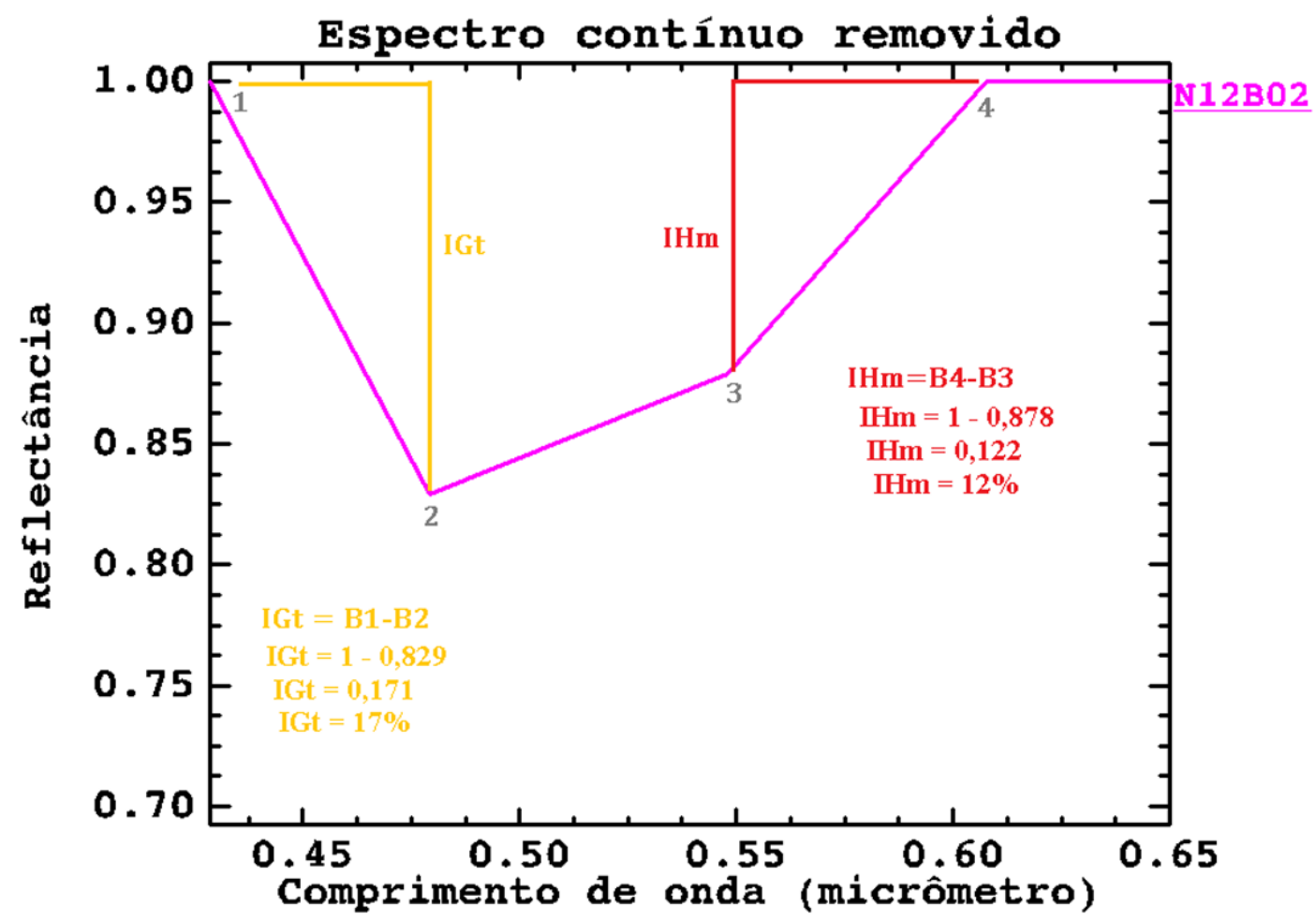

Fig.3: Índice RHGtPF (TEOBALDO e BAPTISTA, 2016)

\subsection{Processamento dos dados}

O software empregado para processar as imagens escolhidas foi o ENVI 4.8 e o sensor orbital utilizado foi WorldView II que possui oito bandas espectrais estreitas. Essas oito bandas estão divididas em: azul costal (Coastal), azul, verde, amarelo, vermelho, borda do vermelho (RedEdge), infravermelho próximo 1 (NIR-1) e infravermelho próximo 2 (NIR-2) (DIGITAL GLOBE, 2010; NOVACK et al., 2011). Ele possui $2 \mathrm{~m}$ de resolução espacial na faixa óptica e banda bem 
estreitas na faixa do visível e do infravermelho próximo tendo como objetivo melhor resolução espectral (KUMAR e ROY, 2013).

No pré-processamento, realizou a correção atmosférica pelo programa ATCOR 2/3 (Atmospheric and Topographic Correction for Satellite Imagery) que gera dados em reflectância de superfície. Esse programa é baseado no modelo MODTRAN 4 (Moderate Resolution Atmospheric Transmission) para realizar os cálculos de transmitância da atmosfera (SOARES et al., 2015).

Para realizar os métodos SAM e o LSU adotou-se como endmembers os espectros Goethite OH-2A e da Hematite O-1A do Jet Propulsion Laboratory (JPL), reamostrando-os para as funções de ganho dos detectores do sensor WorldView II.

Com o resultado do LSU, foram realizadas composições coloridas colocando a imagem da hematita no canal vermelho, o do erro médio quadrático (RMS) no verde e da goethita no azul. E os ângulos, em radianos, adotados no método SAM foi 0,25 para a hematita e 0,28 para a goethita.

O índice RHGtpF foi realizado na imagem, já com o contínuo removido, e comparou-se o resultado com os dados percentuais do Linear Spectral Unmixing. Os resultados dos percentuais de hematita e goethita foram usados para calcular a relação $\mathrm{Hm} / \mathrm{Hm}+\mathrm{Gt}$ com base nos resultados do LSU.

$\mathrm{Na}$ área selecionada da cena do WorldView II foi realizado um transecto que abrange áreas mais amareladas e mais avermelhadas, afim de analisar os valores de cada pixel pertencente a essa reta, com o intuito de entender qual é a correlação entre esses valores.

\section{RESULTADOS E DISCUSSÃO}

Os espectros de hematita e goethita da biblioteca do JPL, reamostrados para as bandas do sensor WorldView II são apresentados na figura 4. Quanto maior for a resolução espectral do sensor, melhor será a discretização do mineral, ou seja, tendo mais detalhes de qual comprimento de onda ocorre a absorção, mesmo se tratando de sensores multiespectrais. Comparando o espectro do JPL e o espectro reamostrado para o WorldView II, não perde a feição que diferencia os dois minerais estudados que se localiza na banda do amarelo. 


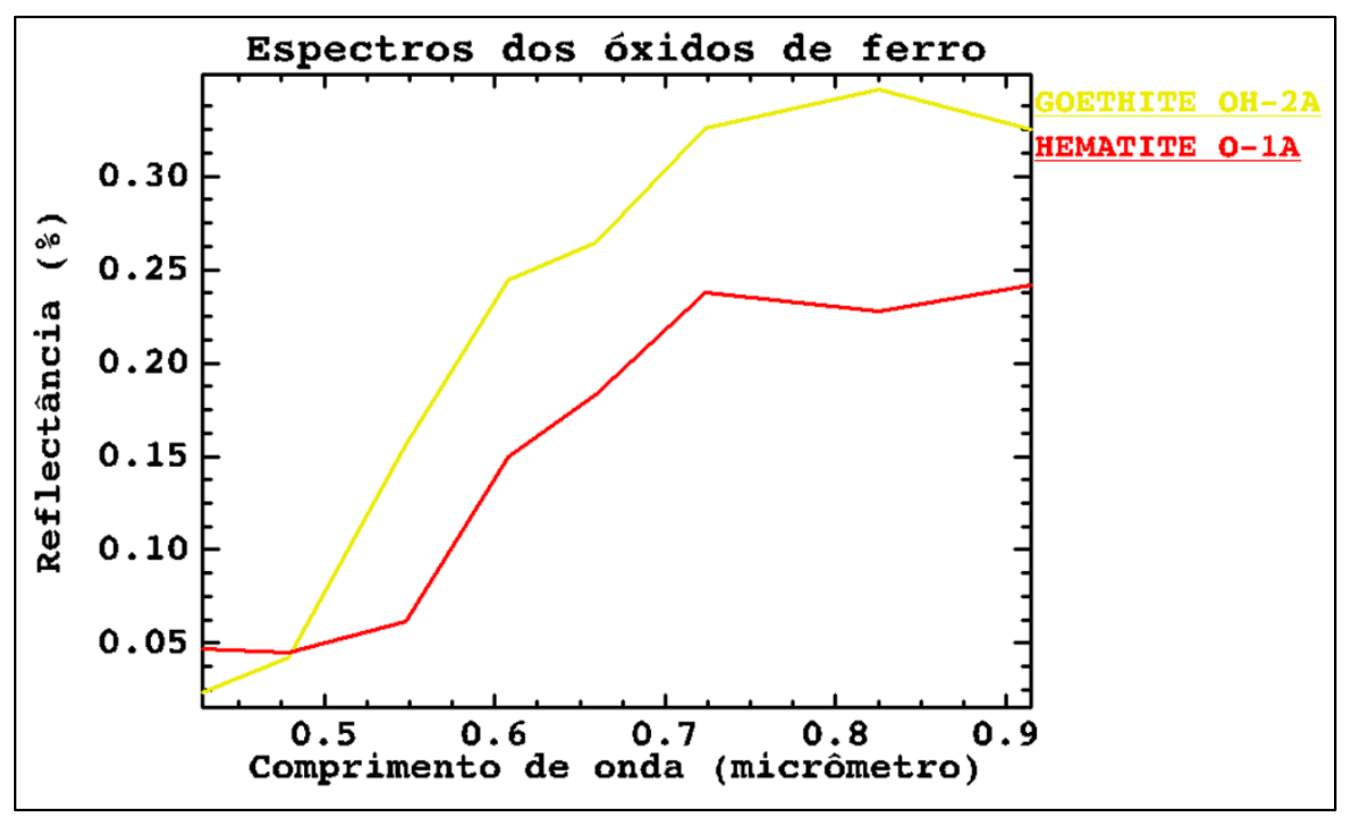

Fig. 34: Espectros de hematita e goethita reamostrados para o sensor WorldView II.

Para analisar cada método de classificação, foi realizado um transecto na área de estudo. O transecto realizado e os resultados do processamento do SAM são apresentados na Figura 5.
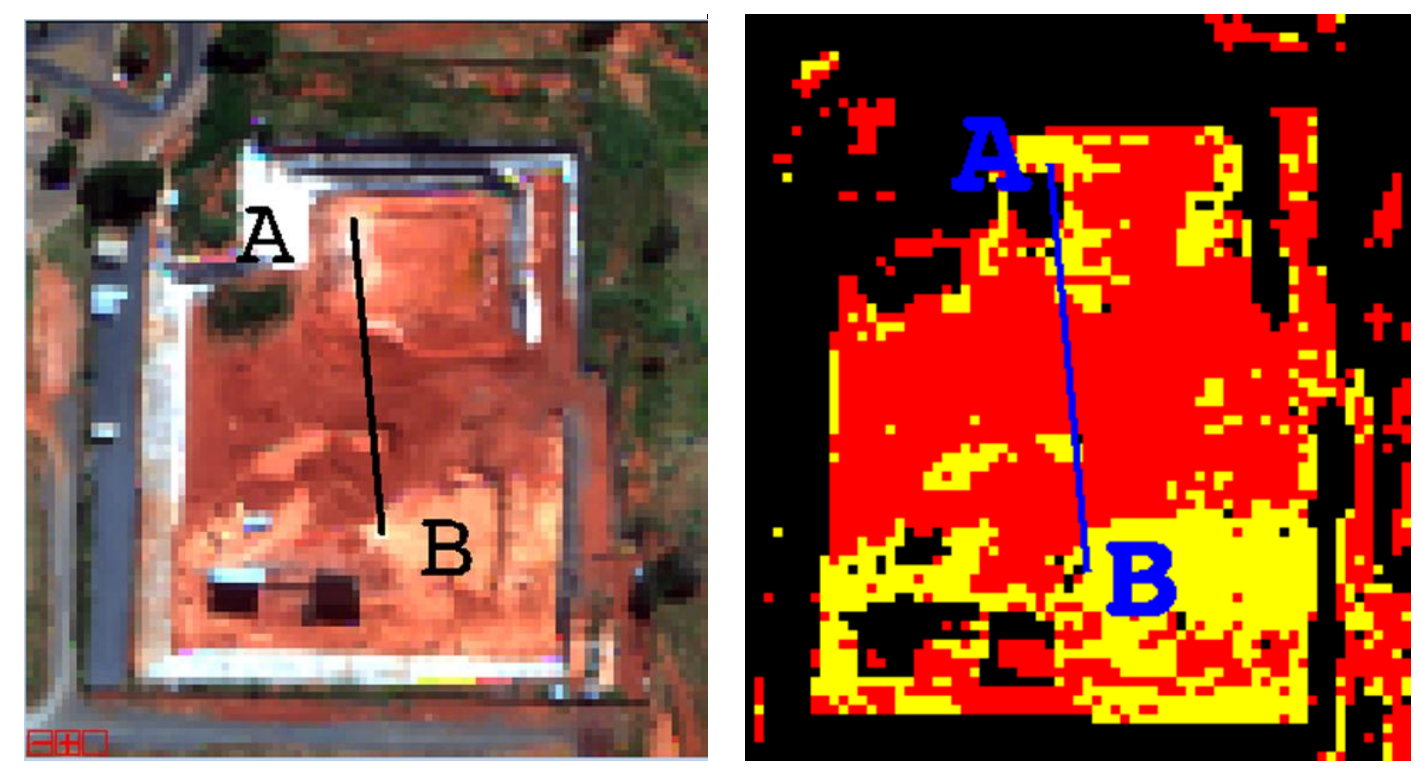

Fig. 45: Área estudada e método SAM, respectivamente.

Por meio dos resultados do processamento dos dados e do transecto, foi possível analisar qual a relação entre a goethita e a hematita no método de classificação SAM. O método SAM tem como objetivo observar o pixel e classificá-lo como um dos espectros escolhidos, nesse caso ele foi escolhido como goethita ou hematita de acordo com os espectros da biblioteca espectral de minerais do JPL. Com isso, esse algoritmo gera um mapa identificando os dois minerais 
analisados. Salienta-se que os pixels amarelos representam pixels com abundância de goethita e os vermelhos, de hematita.

Ele é bastante satisfatório pois comparando com a composição colorida, observa-se que a parte mais amarelada (clara) tem maior presença de goethita e onde é avermelhado (escura) tem maior presença de hematita. Isso confirma a teoria de que a presença dos óxidos de ferro está ligada a cor dos solos (CAMPOS et al., 2003; FERNANDES et al., 2004; DALMOLIN et al.,2005; BARBOSA et al., 2009). Com isso, o resultado do SAM segue a realidade observada na composição colorida, isto é, ele classifica e diferencia corretamente a goethita da hematita.

Para analisar a relação entre hematita e goethita no método LSU, foi realizado também um transecto na área de estudo para observar o coeficiente de correlação entre os dois minerais. O transecto analisado e os resultados do processamento do LSU são apresentados na Figura 6.
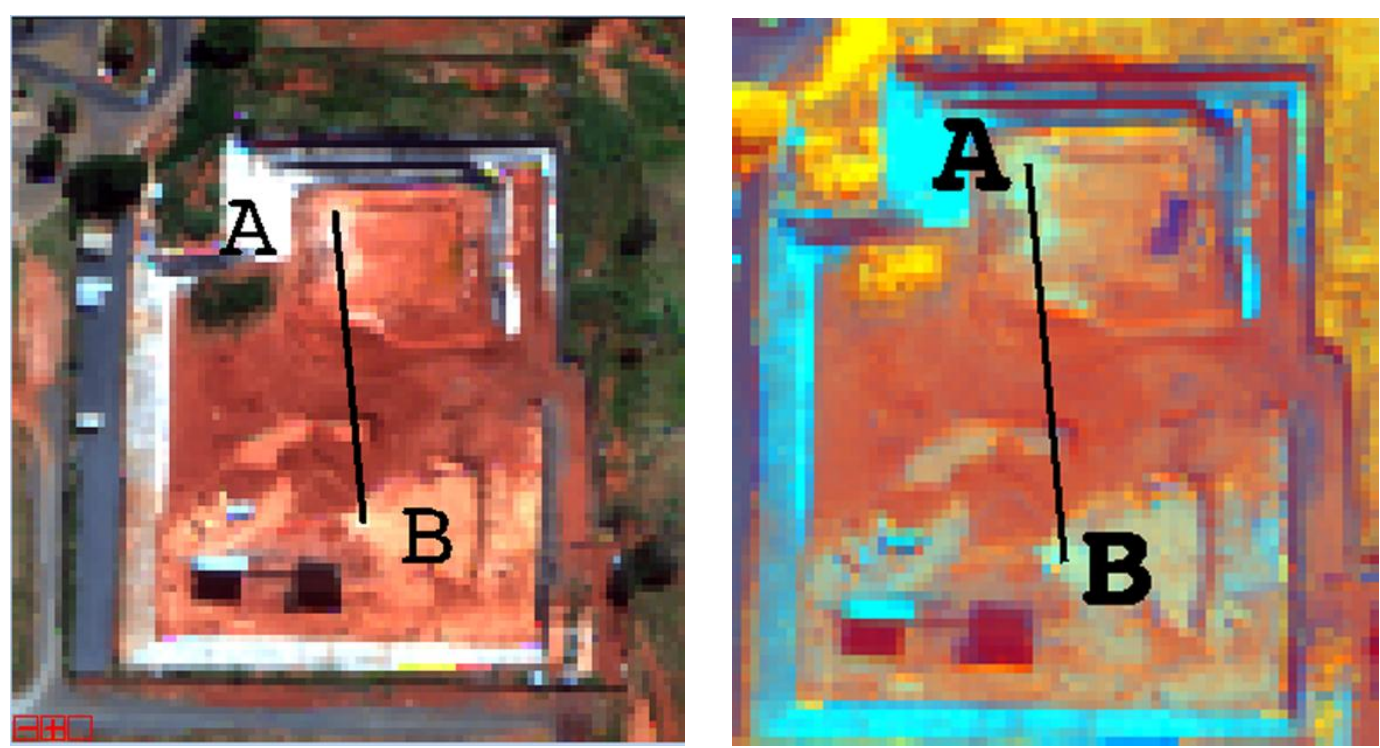

Fig. 6: Área estudada e método LSU, respectivamente. 


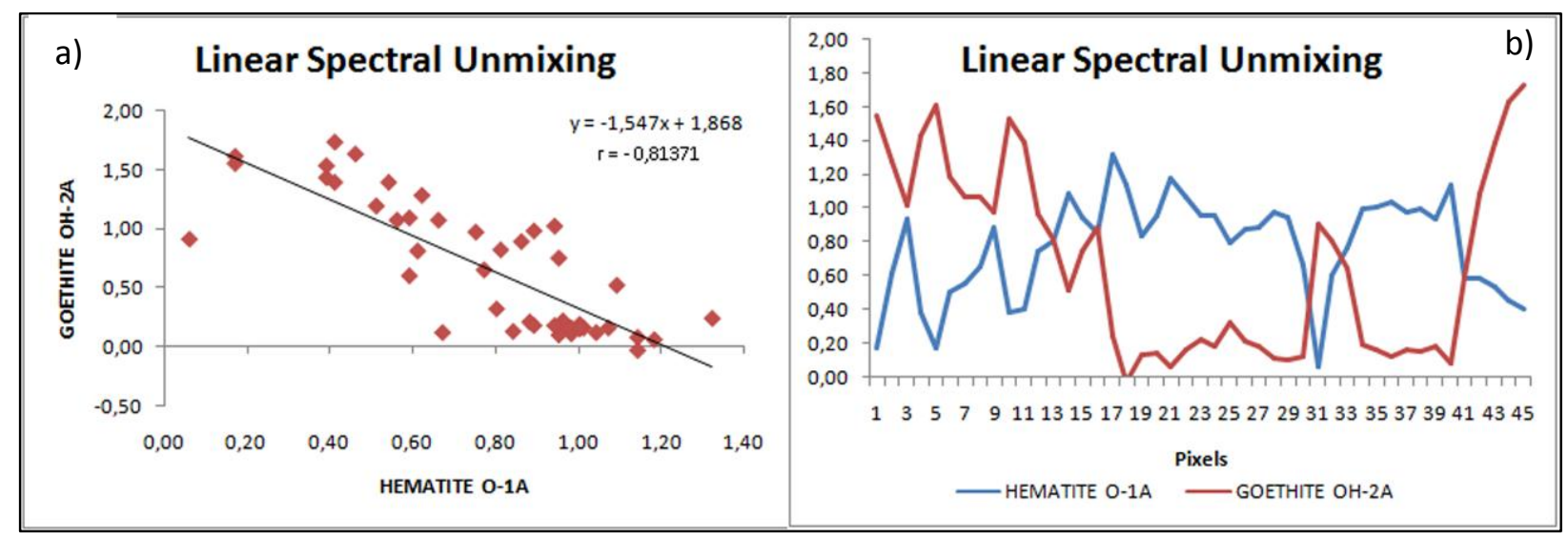

Fig.7: Regressão (a) e o gráfico (b) entre os valores da Goethita e Hematita obtida pelo método LSU.

O resultado da regressão do método de classificação Linear Spectral Unmixing foi considerado satisfatório (Figura 7a) pelo coeficiente de correlação de Pearson (r).

Visualizando a figura $7 \mathrm{~b}$, isso se deve ao fato de que a abundância do mineral deve ser expressa, por esse método, na forma de percentual, ou seja, variando de 0 a 1 . Se ocorre pixels com valores menores que 0 e maior que 1 , isso significa que o mineral não foi bem caracterizado ou os membros finais estão ausentes.

Estudos demonstram que os óxidos de ferro estão relacionados a cor do solo e ao regime pedohídrico da região (INDA JUNIOR e KÄMPF, 2005; CAMARGO et al., 2008; REATTO et al., 2008; BAPTISTA e MENESES, 2009; BARBOSA et al., 2009; CAMPOS et al., 2010; BAPTIST et al., 2011; SILVA JUNIOR et al., 2012).

Isso significa que há uma relação entre os óxidos de ferro com a geomorfologia, com o nível do lençol freático e com os diferentes estados químicos de oxirredução, ou seja, a presença da água no solo influencia na sua cor (REATTO et al., 2008).

Isso também é explicado por Melo et al. (2001) que estudaram a relação dos teores de hematita e a água e observou uma correlação inversa. Campos et al. (2010), estudando a topossequência de latossolos, observaram que os solos mais vermelhos estavam associados a locais mais oxidados, mais elevados e de melhor drenagem interna enquanto os solos mais amarelados estavam em ambientes oxi-redutores, mais úmidos e nas bordas de relevo. 
O gráfico obtido do método LSU é bem fiel a essa teoria, observa-se que quando a presença de hematita cresce, a presença de goethita decresce. Pode-se visualizar pelo coeficiente de correlação $\mathrm{r}$ que apresentou resultado negativo (inversamente proporcionais). Essa inversão acontece porque o ambiente hematítico é predominantemente oxidante e os goethíticos são oxiredutores.

Os resultados dos percentuais dos minerais goethita e hematita gerados pelo algoritmo LSU foram utilizados para calcular a relação $\mathrm{Hm} / \mathrm{Hm}+\mathrm{Gt}$ e com isso comparou-se essa relação com o índice RHGtpF no mesmo transecto.

A regressão entre a relação $\mathrm{Hm} / \mathrm{Hm}+\mathrm{Gt}$ utilizando os dados do LSU e o índice RHGtpF foi considerado forte positiva pela tabela de avaliação qualitativa da correlação de Pearson para o coeficiente de correlação (r) sendo aproximadamente 0,87. A Figura 8 mostra a regressão entre esses dados.

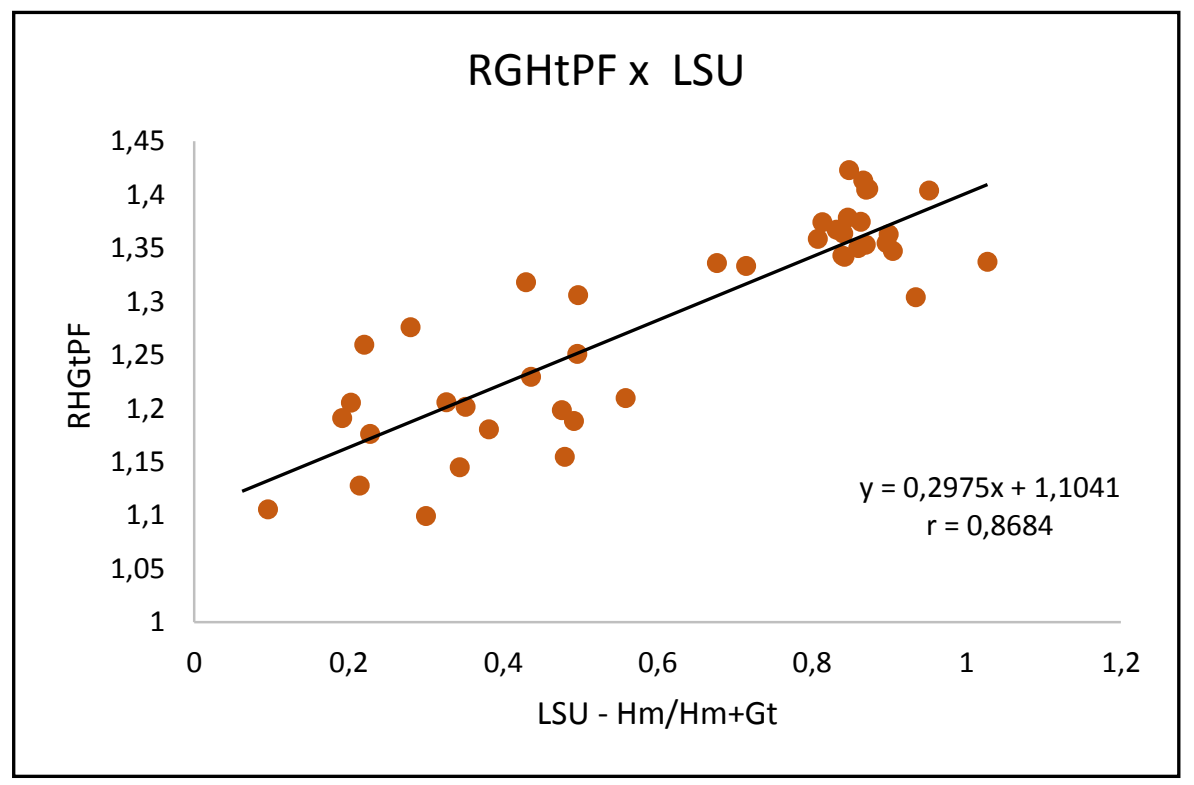

Fig. 58: Regressão entre a relação $\mathrm{Hm} / \mathrm{Hm}+\mathrm{Gt}$ utilizando os dados do LSU e o índice RHGtPF

Índices espectrais e razão de bandas são muito estudados para a classificação de imagens dependendo da curva espectral do objetivo em estudo. Mia e Fujimitsu (2012) utilizou a razão de bandas 3/1, 5/7 e 5/4 do sensor Landsat $7 \mathrm{ETM}^{+}$para descobrir óxidos de ferro, minerais contendo hidroxila e óxidos ferrosos, respectivamente e gerou uma composição colorida com essas razões de bandas. Deller (2006) também utilizou razão de bandas e composição colorida para mapear minerais e observou que a banda verde do Landsat TM, distingue melhor os óxidos de ferro devido a diferença de reflectância nessa região. 
Salienta-se que o índice RHGtpF pode quantificar a relação de $\mathrm{Hm} / \mathrm{Hm}+\mathrm{Gt}$ tendo em vista sua profundidade de feição localizada na região do visível. Para melhor visualização pode-se separar em intervalos os quais podem diferenciar a quantidade dos óxidos de ferro, como foi feito por Baptista et al. (2011).
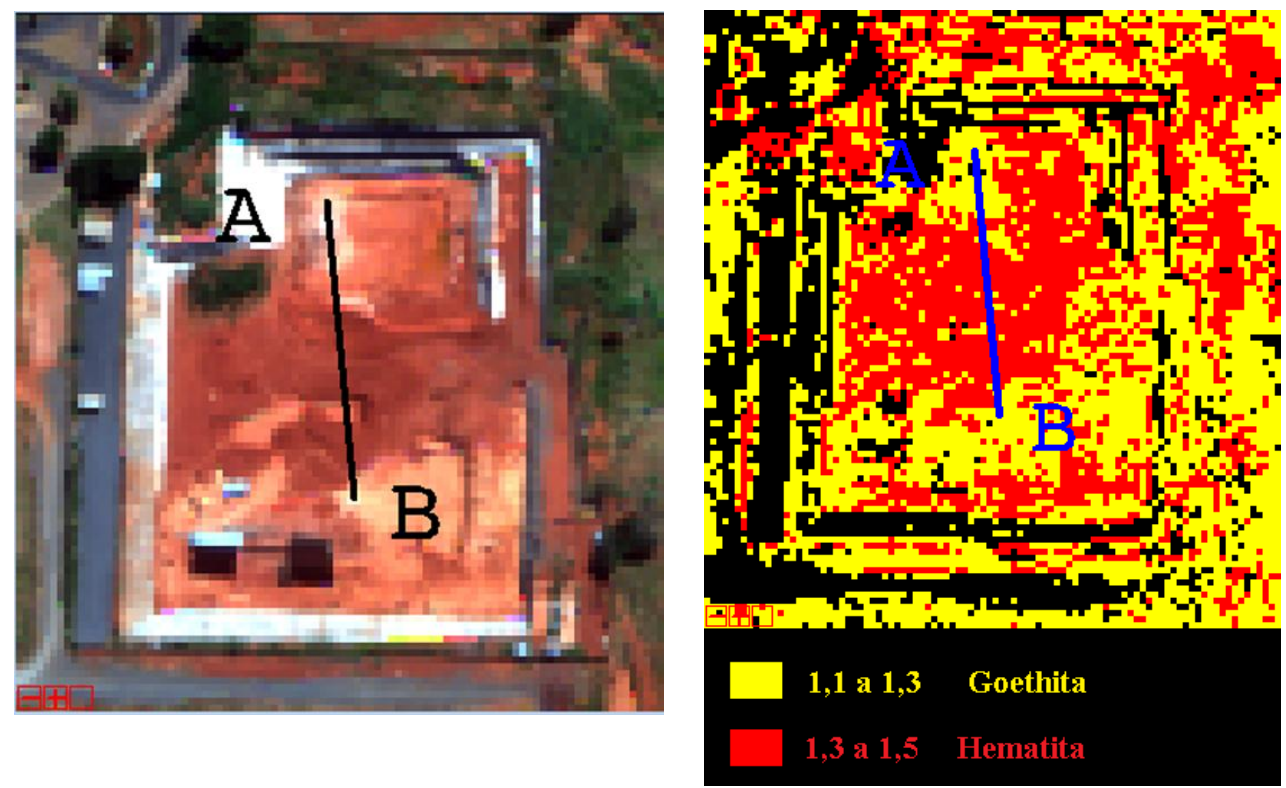

Fig. 9: Área estudada e aplicação do índice RHGtPF.

No resultado do índice RHGtPF foi aplicado a técnica density slice que permitiu dividir e demonstrar a presença dos dois óxidos de ferro separadamente. Para a identificação da goethita o intervalo utilizado varia de 1,1 a 1,3 e para a hematita de 1,3 a 1,5 como pode ser observado na Figura 9, que apresentou resultado bem semelhante ao obtido com o algoritmo SAM. Os valores mais altos do índice RHGtPF são ambientes hematíticos e os valores baixos são ambiente goethíticos (Figura 10). 


\section{RHGt $_{\mathrm{pF}}$}

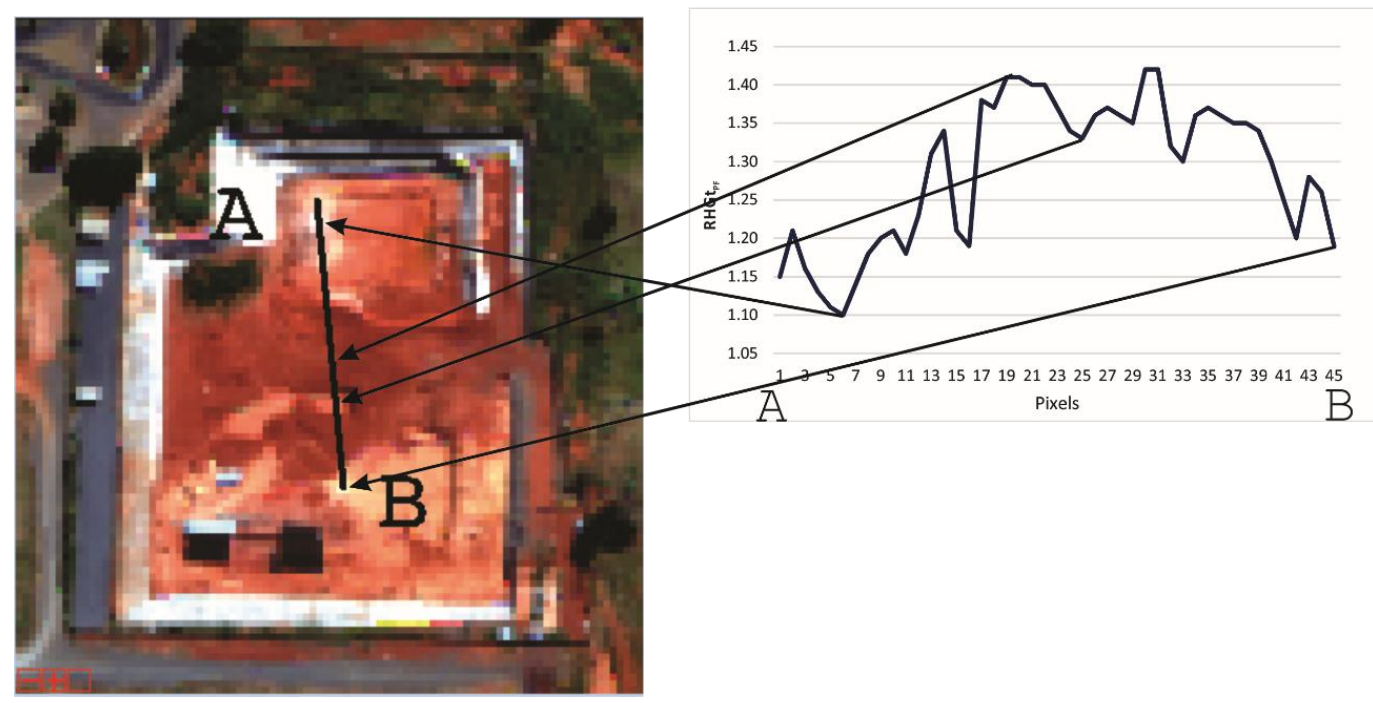

Fig. 610: Análise dos locais com hematita (mais altos no gráfico) e com goethita (mais baixos) no transecto e na imagem estudada.

$\mathrm{O}$ resultado pode ser comparado visualmente com a figura original da área estudada. E da mesma forma com a imagem do algoritmo spectral angle mapper. Isso certifica a teoria de que ambientes mais goethíticos possuem a cor amarela e ambientes mais hematíticos a cor vermelha (BOTELHO et al., 2006) como mostra a figura original comparando com o índice RHGtPF.

\section{CONCLUSÕES}

Por meio da classificação Spectral Angle Mapper, foi possível identificar a presença da hematita e da goethita na imagem analisada.

Com o algoritmo Linear Spectral Unmixing, pôde-se verificar a inversão de proporcionalidade entre a hematita e a goethita devido aos seus diferentes níveis de oxiredução e ao regime pedohídrico.

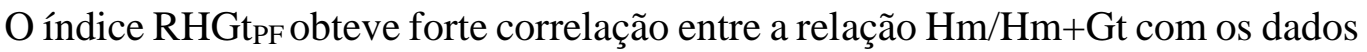
percentuais do LSU. Isso demonstra que ele é um bom índice para identificar e quantificar os minerais estudados.

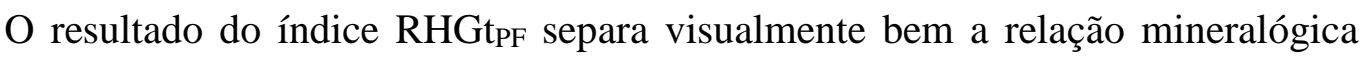
$\mathrm{Hm} / \mathrm{Hm}+\mathrm{Gt}$, sendo os valores mais elevados associados a ambientes hematíticos e os mais baixos, a ambientes goethíticos. 


\section{REFERÊNCIAS BIBLIOGRÁFICAS}

BAPTISTA, G.M.M. Caracterização climatológica do Distrito Federal. In: IEMA/SEMATEC/UnB, Inventário Hidrogeológico e dos Recursos Hídricos Superficiais do Distrito Federal. Brasília. Vol. 1, 187-208p. 1998.

BAPTISTA, G.M.M. Processamento de dados hiperespectrais. In: Meneses, P.R.; Almeida, T. Introdução ao processamento de imagens de sensoriamento remoto. Brasília. CNPQ. 2012.

BAPTISTA, G.M.M.; CORREAA, R.S.; SANTOS, P.F. MADEIRA NETTO, J.S.; MENESES, P.R. Use of Imaging Spectroscopy for Mapping and Quantifying the Weathering Degree of Tropical Soils in Central Brazil. DOI:10.1155/2011/641328. Applied and Environmental Soil Science. 2011.

BAPTISTA, G.M.M; MENESES, P.R. Identificação de sesquióxidos de ferro da fração argila de solos tropicais por meio de decomposição espectral linear dos dados do sensor AVNIR-2 do sistema ALOS. Anais XIV Simpósio Brasileiro de Sensoriamento Remoto, Natal, Brasil, INPE, p. 7655-7662. 2009.

BARBOSA, I.O.; LACERDA, M.P.C; BILICH, M.R. Relações pedomorfogeológicas nas chapadas elevadas do Distrito Federal. Revista Brasileira de Ciência do Solo, 33:13731383, 2009.

BOTELHO, M.R.; DALMOLIN, R.S.D.; PEDRO, F.A.; AZEVEDO, A.C.; RODRIGUES, R.B.; MIGUEL, P. Medida da cor em solos do Rio Grande do Sul com a carta de Munsell e por colorimetria. Ciência Rural, v.36, n.4, jul-ago, 2006.

BREUNIG, F. M.; CAMARGO, F. F.; ADAMI, M.; MANTELLI, L. R.; COSTA, M. C.; PONZONI, F. J.; FREITAS, J.G. Aplicação da técnica de remoção do contínuo para a discriminação espectral de diferentes dosagens de Nitrogênio aplicadas ao trigo (Triticum aestivum, L.- IAC-370). Anais XIII Simpósio Brasileiro de Sensoriamento Remoto, Florianópolis, Brasil, INPE, p. 91-98,21-26 abril 2007.

CAMARGO, L.A.; MARQUES JÚNIOR.J.; PEREIRA, G.T.; HORVAT, R.A. Variabilidade espacial de atributos mineralógicos de um latossolo sob diferentes formas 
do relevo. I - mineralogia da fração argila. Revista Brasileira de Ciências do Solo, 32:2269-2277, 2008.

CAMPOS, J.E.G. Hidrogeologia do Distrito Federal: Bases para a gestão dos recursos hídricos subterrâneos. Revista Brasileira de Geociências. 34(1):41-48, março de 2004.

CAMPOS, P.M.; LACERDA, M.P.C.; LOPES SILVA, C.; CAROLINO SÁ, M.A.; GOMES SOUSA, D.M. Drenagem interna como fator de diferenciação de Latossolos do Distrito Federal. Pesquisa agropecuária brasileira, Brasília, v.45, n.3, p.306-314, mar. 2010.

CAMPOS, R.C; DEMATTÊ, J.A.M.; QUARTAROLI, C.F. Determinação indireta do teor de hematita no solo a partir de dados de colorimétrica e radiométrica. Pesquisa Agropecuária Brasileira, Brasília, v. 38, n. 4, p. 521-528, abr. 2003.

DALLA NORA, E. Detecção e monitoramento da soja no Rio Grande do Sul: uma abordagem baseada na dinâmica espectral e fenológica da cultura. Perspectiva, Erechim. v.34, n.127, p. 63-71, setembro/2010.

DALMOLIN, R.S.D.; KLAMT, C.N.G.E; DICK, D.P. Relação entre os constituintes do solo e seu comportamento espectral. Ciência Rural, Santa Maria, v.35, n.2, p.481-489, mar-abr, 2005.

DELLER, M.E.A. Facies discrimination in laterites using Landsat Thematic Mapper, ASTER and ALI data - examples from Eritrea and Arabia. International Journal of Remote Sensing Vol. 27, No. 12, 2389-2409, 20 June 2006.

Digital GlOBE. White Paper: The Benefits of the 8 Spectral Bands of WorldView-2. Corporate (U.S.) 303.684.4561 or 800.496.1225. 2010.

FERNANDES, R.B.A.; BARRÓN, V. TORRENT, J.; FONTES, M.P.F. Quantificação de óxidos de ferro de latossolos brasileiros por espectroscopia de refletância difusa. Revista Brasileira de Ciência do Solo, 28:245-257, 2004.

GALVÃO, L.S.; FORMAGGIO, A.R.; COUTO, E.G.; ROBERTS, D.A. Relationships between the mineralogical and chemical composition of tropical soils and topography 
fioni hyperspectral remote sensing data. ISPRS Journal of Photogrammetry \& Remote Sensing 63 (2008) 259271. 2008.

GUERRA, A.J.T.; CUNHA, S.B. Geomorfologia e Meio Ambiente. Editora Bertrand, Brasil, 1996.

INDA JUNIOR, A.V.; KÄMPF, N. Variabilidade de goethita e hematita via dissolução redutiva em solos de região tropical e subtropical. Revista Brasileira de Ciências do Solo, 29:851-866, 2005

JENSEN, J.R. Sensoriamento Remoto do Ambiente: uma perspectiva em recursos terrestres. Editora Parêntese. 2009.

KUMAR, M.; ROY, P.S. Utilizing the potential of World View -2 for discriminating urban and vegetation features using object based classification techniques. Journal of the Indian Society of Remote Sensing 41(3):711-717 DOI 10.1007/s12524-012-0257-9. 2013.

MADEIRA NETTO, J.S.; BAPTISTA, G. M. M. Reflectância Espectral de Solos. 1. ed. Brasília: Embrapa, 2000. v. 200. 55p.

MADEIRA NETTO, J.S.; BEDIDI, A.; CERVELlE, B.; POUGET, M.; FLAY, N. Visible spectrometric indices of hematita $(\mathrm{Hm})$ and goethite $(\mathrm{Gt})$ content in lateritic soils: the aplication of Thematic Mapper (TM) image for soil-mapping in Brasília, Brazil.International Journal of Remote Sensing. London, v.18, p.2835-2852, 1997.

MELLO, M.P.; RUDORFF, B.F.T; VIEIRA, C.A.O.; AGUIAR, D.A. Classificação automática da colheita da cana-de-açúcar utilizando modelo linear de mistura espectral. Revista Brasileira de Cartografia No 62/02, 2010.

MELO, V. F.; FONTES, M. P. F.; NOVAIS, R. F.; SINGH, B.; SCHAEFER, C. E. G. R. Características dos óxidos de ferro e de alumínio de diferentes classes de solos. Revista Brasileira de Ciências do Solo, 25:19-32, 2001.

MIA, M. B.; FUJIMITSU, Y. Mapping hydrothermal altered mineral deposits using Landsat 7 ETM+ image in and around Kuju volcano, Kyushu, Japan. Indian Academy of Sciences. Journal of Earth System Science, 121, No., pp. 1049-1057. 2012. 
NOVACK, T.; RIBEIRO, B.M.G.; KUX, H.J.H. Análise dos dados do satélite WorldView-2 para a discriminação de alvos urbanos semelhantes com base em algoritmos de seleção de atributos. Anais XV Simpósio Brasileiro de Sensoriamento Remoto - SBSR, Curitiba, PR, Brasil, INPE p.7815. 2011.

REATTO, A.; BRUAND, A.; MARTINS, E.S.;MULLER, F.; MEDRADO DA SILVA,E.; CARVALHO JR,O.A.; BROSSARD, M. Variation of the kaolinite and gibbsite content at regional and local scale in Latosols of the Brazilian Central Plateau. Comptes Rendus Geoscience 340 (2008) 741-748. 2008.

SHERMAN, D.M.; WAITE, T.D. Electronic spectra of Fe3+ oxides and oxide hydroxides in the near IR to near UV. American Mineralogist. V.70, p.1262-1269, 1985.

SILVA JUNIOR, J.F.; MARQUES JÚNIOR, J.; CAMARGO, L.A.; TEIXEIRA, D.B.; PANOSS, A.R.; PEREIRA, G.T Simulação geoestatística na caracterização espacial de óxidos de ferro em diferentes pedoformas. Revista Brasileira de Ciência do Solo, 36:1690-1703. 2012.

SOARES, F. S.; KALAF DE ALMEIDA, R.; RUBIM, I. B.; BARROS, R. S.; CRUZ, C. B. M.; MELlO, G. V.; BAPTISTA NETO, J. A. Análise comparativa da correção atmosférica de imagem do Landsat 8: o uso do 6S e do ATCOR2. Anais XVII Simpósio Brasileiro de Sensoriamento Remoto - SBSR, INPE, João Pessoa-PB, Brasil, 25 a 29 de abril de 2015 .

TEOBALDO, D.; BAPTISTA, G.M.M. Potencialidade do sensor WorldView II para detecção de hematita e goethita em solos tropicais. Pesquisa Agropecuária Brasileira. 2016 (Submetido)

VALÉRIO, A.M.; KAMPEL, M.; STECH, J.L. Aplicação da técnica SAM (Spectral Angle Mapper) para dados hiperespectrais do corpo de água do reservatório de Manso, MT. Anais XIV Simpósio Brasileiro de Sensoriamento Remoto, Natal, Brasil, 25-30 abril 2009, INPE, p. 7933-7940. 


\section{CONCLUSÕES FINAIS}

Com a inovação e o lançamento de novos sistemas sensores tornou-se importante a verificação da sua potencialidade, bem como, para quantificação de minerais. O presente estudo permitiu verificar a potencialidade do sistema sensor WorldView II para identificação dos óxidos, hematita e goethita, de solos tropicais. Esse sensor possui novas bandas na região do visível onde esses dois minerais possuem uma das feições de absorções.

Percebe-se que as novas bandas do sensor foram estudadas e com elas discretizadas de forma mais eficaz a relação mineralógica da hematita e goethita. Com a remoção do contínuo espectral, observou que a banda do azul costal ajuda na quantificação e identificação dos minerais e com isso propôs um índice, tendo em vista que com a nova banda, em comparação com o sensor Landsat TM 5, separa-se as feições de absorção dos dois minerais na região do visível.

Isso possibilitou a geração de um novo índice RHGtPF, baseado na profundidade das feições espectrais tanto da goethita como da hematita, permitindo diferenciar os dois minerais, os quais tem feições de absorção muito próximas e que, ao se utilizar o sensor Landsat TM 5, não se poderia discretizar as feições individualmente, pois sua resoluçãoe espectral permite identificar somente uma feição integrada para os dois minerais.

De acordo com os testes estatísticos aplicados, observou que o RHGtpF e a relação Hm/Hm+Gt são similares entre si. Já o RHGtpFe a relação de Munsell não são apresentam similaridade estatística, porém sabe-se que a relação de Munsell é baseada em cores reais e que tem uma relação com as bandas visíveis do sistema sensor e que muitas vezes não se pode provar com métodos estatísticos.

O índice RHGt $t_{P F}$ obteve forte correlação entre a relação $\mathrm{Hm} / \mathrm{Hm}+\mathrm{Gt}$ obtida por meio dos dados percentuais do LSU, bem como apresentou coerência com o resultado obtido por meio do algoritmo SAM. Isso demonstra que ele é um bom índice para identificar e quantificar os minerais estudados.

Novos estudos devem ser incentivados no intuito de se explorar a potencialidade dos novos sistemas sensores na compreensão da cobertura pedológica em ambientes tropicais. 